FEDERAL RESERVE BANK OF SAN FRANCISCO

WORKING PAPER SERIES

\title{
Going Negative at the Zero Lower Bound: The Effects of Negative Nominal Interest Rates
}

\author{
Mauricio Ulate Campos \\ Federal Reserve Bank of San Francisco
}

September 2019

Working Paper 2019-21

https://www.frbsf.org/economic-research/publications/working-papers/2019/21/

\section{Suggested citation:}

Ulate Campos, Mauricio. "Going Negative at the Zero Lower Bound: The Effects of Negative Nominal Interest Rates," Federal Reserve Bank of San Francisco Working Paper 2019-21. https://doi.org/10.24148/wp2019-21

The views in this paper are solely the responsibility of the authors and should not be interpreted as reflecting the views of the Federal Reserve Bank of San Francisco or the Board of Governors of the Federal Reserve System. 


\title{
Going Negative at the Zero Lower Bound: The Effects of Negative Nominal Interest Rates
}

\author{
Mauricio Ulate Campos*
}

August 27, 2019

\begin{abstract}
After the Great Recession several central banks started setting negative nominal interest rates in an expansionary attempt, but the effectiveness of this measure remains unclear. Negative rates can stimulate the economy by lowering the rates that commercial banks charge on loans, but they can also erode bank profitability by squeezing deposit spreads. This paper studies the effects of negative rates in a new DSGE model where banks intermediate the transmission of monetary policy. I use bank-level data to calibrate the model and find that monetary policy in negative territory is between $60 \%$ and $90 \%$ as effective as in positive territory.
\end{abstract}

JEL codes: E32, E44, E52, E58, G21.

Keywords: Negative Interest Rates, ZLB, Monetary Policy, Bank Profitability.

\footnotetext{
*Website: www.mauricioulate.com. Email: mauricio.ulate@sf.frb.org. Affiliation: Federal Reserve Bank of San Francisco. The views in this paper do not necessarily reflect the views of the Federal Reserve Bank of San Francisco or the Federal Reserve System. I am grateful to my adviser Yuriy Gorodnichenko and to Andrés Rodríguez-Clare for their invaluable guidance and support. I also thank Pierre-Olivier Gourinchas, John Williams, Emi Nakamura, Jon Steinsson, Benjamin Faber, David Sraer, Benjamin Schoefer, Amir Kermani, Ludwig Straub, Tomasso Porzio, Michael Weber, David Baqaee, Ashley Lannquist, Jane Ryngaert, Walker Ray, Rupal Kamdar, Lidia Smitkova, Byoungchan Lee, Hassan Afrouzi, Nick Sander and Alessandra Fenizia for very helpful comments. I am also very grateful to the participants of the seminars in the University of Maryland, the University of Rochester, Texas A\&M, the Federal Reserve Board, the Federal Reserve Bank of Minneapolis, Claremont McKenna College, Banco de España, Banco Central de Chile, Universidad de Chile, ITAM, and BlackRock. All errors are my own.
} 


\section{Introduction}

A long tradition in macroeconomics has proposed the existence of a Zero Lower Bound (ZLB) on nominal interest rates. Intuitively, as cash offers a nominal return of zero percent, agents should not be willing to pay others to keep their money. However, recent experience from the aftermath of the Great Recession has shown that negative nominal interest rates (NNIR) are possible: the central banks of several advanced economies have used them as a policy tool. ${ }^{1}$ The Euro Area, Switzerland, Sweden, Denmark, and Japan all implemented NNIR at some point between 2014 and 2018 (Figure 1). Even if one abstracts from the Great Recession, the global, secular decline in interest rates increases the likelihood of recessionary episodes where nominal rates hit zero. ${ }^{2}$ In this environment, understanding whether negative rates can stimulate the economy is of great importance to academics and policy makers.

Two empirical regularities have been observed across countries setting NNIR: retail deposit rates have remained at zero (failing to follow the policy rate into negative territory), and lending rates have mostly declined. Given these facts, it appears that negative rates can partially stimulate the economy through the transmission mechanisms associated with the lending rate. However, commercial bank profitability could be eroded by a decline in the spread between lending and deposit rates. Bank profitability has therefore emerged as one of the most pressing concerns when adopting NNIR. ${ }^{3}$ For example, Benoit Cœuré, who serves on the Executive Board of the ECB, said in 2016: "A reduction in interest rates could harm interest margins, and this could be even more pronounced when rates enter negative territory, due to a potential Zero Lower Bound for retail deposit rates." This concern has been echoed in the business press. The Economist wrote in 2016: "If interest rates go deeper into negative territory, profit margins will be squeezed harder. And if banks are not profitable, they are less able to add to the capital buffers that let them operate safely."

In this paper, I study the effects of NNIR on the economy through the lens of a new DSGE model with New Keynesian features where banks intermediate the transmission of monetary policy. In the model, when the central bank sets negative nominal policy rates, deposit rates remain at zero. The lending rate is then affected by two forces. On the one

\footnotetext{
${ }^{1}$ Commercial banks hold substantial reserves that would be costly to keep in cash, and so they are willing to pay the central bank to store their money. However, there is a limit to how much they are willing to pay; this has been termed the physical lower bound (PLB; see, Cœuré, 2016). This paper will not have anything to say about the level of the PLB, and focuses instead on the effectiveness of setting rates below zero but above the PLB.

${ }^{2}$ See Kiley and Roberts (2017) and the references therein.

${ }^{3}$ Both central banks that implemented negative rates and those that did not have cited bank profitability as a concern; see, Bank of Japan (2016), Danmarks Nationalbank (2015), Bean (2013), and Jackson (2015).
} 


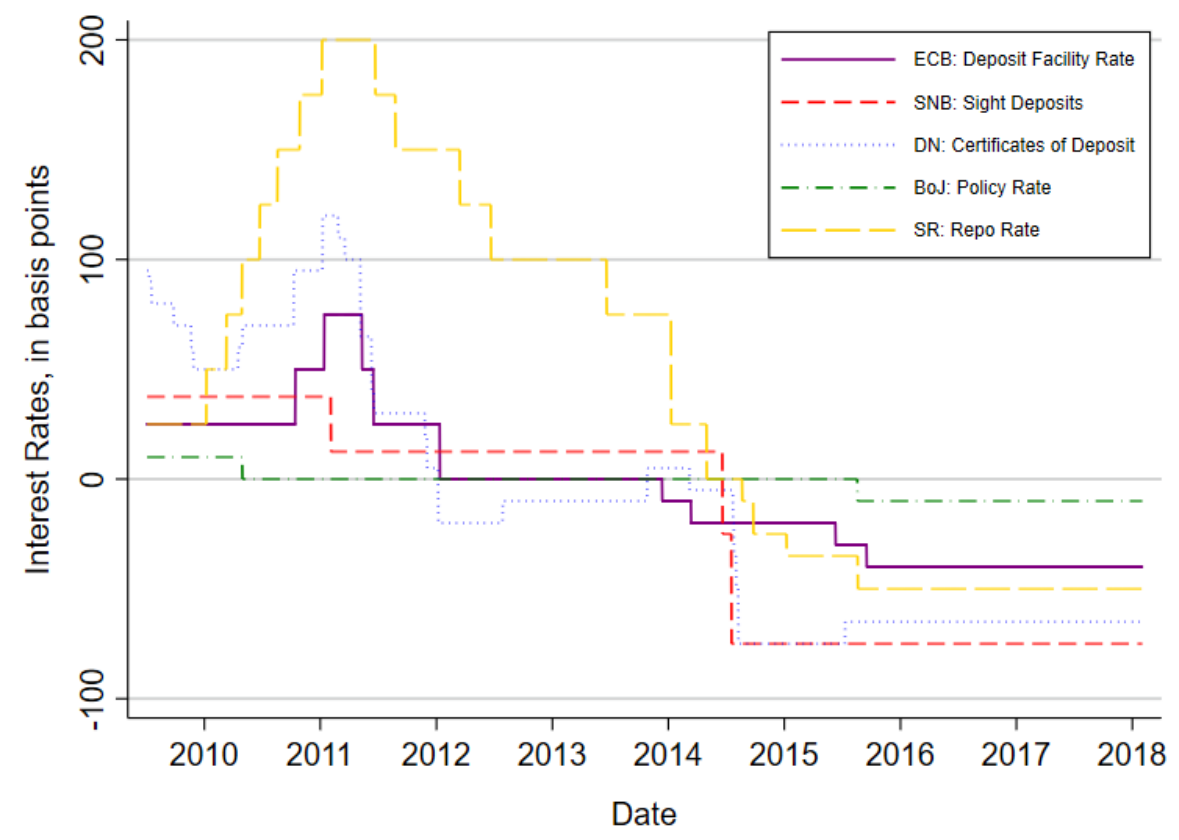

Figure 1: Negative rates experience

Notes: This figure shows the rates paid by the Central Bank of Denmark (DN), the ECB, the Central Bank of Sweden (SR), the Swiss National Bank (SNB), and the Bank of Japan (BoJ), in basis points, between 2010 and 2018. The concept of interest rate used for each region is described in the legend. The data was gathered directly from the central banks.

hand, the policy rate decline exerts downward pressure on the loan rate. This is the bank lending channel of monetary policy, which tends to stimulate the economy. On the other hand, the erosion of bank profitability brought about by the decline in the deposit spread will, over time, be transmitted to a decline in bank equity. This leads to upward pressure on the lending rate. I will refer to this as the net-worth channel of monetary policy, which has a contractionary effect. The equilibrium behavior of the lending rate depends on the relative importance of the two channels.

The model features three main frictions affecting the banking sector. First, banks have some monopoly power in lending and managing deposits. As a result, the deposit rate that financial intermediaries pay households is different from the policy rate that the central bank pays on reserves. The policy rate also differs from the rate that borrowers pay commercial banks for loans. This friction is essential for the bank lending channel, since banks are only able to lower their lending rate (despite the fact that their funding costs are constant, i.e., stuck at the ZLB) because of the existence of a profit margin. The second friction is that, after a shock, banks cannot immediately regain their optimal level of equity. Instead, they accumulate capital slowly, through retained earnings. The third friction is that 
bank equity matters for lending. In particular, banks care about their level of leverage, and they are reluctant to lend when this variable is too high. Frictions two and three lead to the existence of a relevant bank net-worth channel. The combination of the stimulative bank lending channel and the contractionary bank net-worth channel implies that setting NNIR has both beneficial and detrimental effects, the relative importance of which determines the overall usefulness of setting a negative policy rate.

I start by developing a static model of the banking sector that contains only the first friction (bank monopolistic competition). In this model there is a continuum of commercial banks. Each individual bank receives an exogenous level of equity and obtains deposits from consumers. With the resources available after combining their equity and deposits, commercial banks can either provide loans to firms or keep reserves at the central bank. Banks face an upward-sloping deposit supply curve and a downward-sloping loan demand curve. Deposit supply and loan demand for each individual bank arise from the fact that depositors and borrowers have CES preferences across banks. The aggregate amounts of deposits supplied and loans demanded are taken as given for now, as this is a partial equilibrium exercise. Additionally, the model assumes that if a bank sets a negative deposit rate then it obtains no deposits, as consumers could simply save in cash.

In this context, there exists a positive, but small, threshold for the policy rate, denoted by $\tilde{\iota}$, at which the behavior of banks changes. I will refer to the case where the policy rate is above $\tilde{\iota}$ as "Regime 1." In this regime, because of the monopolistic competition setup, each bank sets its loan rate as a mark-up on the policy rate and its deposit rate as a markdown on it. Consequently, changes in the policy rate are fully passed through to the loan and deposit rates. It will be useful to define the loan spread as the difference between the loan and the policy rate, and the deposit spread as the difference between the policy and the deposit rate. Bank return on equity (ROE) can then be expressed as the sum of three terms: the policy rate, the loan spread times the loan-to-equity ratio, and the deposit spread times the deposit-to-equity ratio. In Regime 1 the spreads do not change with the policy rate, and so ROE moves one-for-one with the policy rate.

When the policy rate is below $\tilde{\iota}$, denoted "Regime 2," banks would like to set a negative deposit rate to earn their usual deposit spread. However, if they do so they lose all deposits, and so they set a zero deposit rate instead. ${ }^{4}$ The loan rate is still set as a markup on the policy rate, since holding reserves is the marginal use of bank funds. Therefore, a decline in the policy rate is still fully transmitted into the lending rate, giving rise to the

\footnotetext{
${ }^{4}$ There exists a second threshold $\underline{i}<0$ below which it becomes too costly for banks to accept deposits that earn a negative spread; in that region some banks stop receiving deposits. I postpone this discussion to Section 2.
} 
stimulative bank lending channel of NNIR mentioned above. In this regime, the loan spread remains constant, but the deposit spread falls with the policy rate. Consequently, ROE falls more than one-for-one with the policy rate. In this static model, the steep decline in ROE that occurs in Regime 2 after a cut in the policy rate has no perverse effects on the lending rate, due to the lack of dynamics and the absence of additional frictions; the contractionary bank net-worth channel is not operational yet.

The static model has four testable predictions. First, in Regime 2 the deposit rate stops reacting to the policy rate. Second, the lending rate continues to fall with the policy rate even in Regime 2. Third, bank ROE is affected by a cut in the policy rate more in Regime 2 than in Regime 1. Fourth, the higher sensitivity of bank return on equity to the policy rate in Regime 2 is more pronounced for banks that rely heavily on retail deposits for funding. I use bank-level data from more than five thousand banks in 10 advanced regions (i.e., the five advanced regions that have set negative rates and five other comparable advanced regions, including the United States, that have set very low rates) to test these predictions. The first step is to estimate the threshold level $\tilde{\iota}$. A variety of tests confirm the existence of a change in the slope of the response of both the deposit rate and ROE to the policy rate when the policy rate is around 50 basis points. Consequently, I set $\tilde{\iota}=0.5 \%$. I then test the four predictions and find strong support for them in the data. The prediction that the loan rate continues to fall with the policy rate in Regime 2 is especially useful for differentiating between my model and alternative ones that propose that negative rates cannot be expansionary.

I then extend the static bank model to a dynamic setup, introduce frictions two and three (i.e. slow-moving bank capital and the importance of bank equity for lending), and embed this in a DSGE model. In this context, I can study both the beneficial effects of negative rates (expressed through the bank lending channel), as well as the detrimental ones (expressed through the bank net-worth channel). The bank net-worth channel works as follows. First, negative policy rates and the Zero Lower Bound on deposit rates generate a decline in the deposit spread. Second, the decline in the deposit spread translates to a decline in bank ROE that is significantly bigger than the one that would occur after a cut in the policy rate above $\tilde{\iota}$. Third, over time the decline in ROE accumulates to a decline in bank equity, since banks cannot replenish their equity frictionlessly. Finally, the decline in bank equity leads to upward pressure on the loan rate, as banks with less equity require a higher loan rate to be willing to lend.

I calibrate the full model to obtain estimates of the relative efficiency, in welfare terms, of cutting the policy rate below $\tilde{\iota}$ compared to doing so above $\tilde{\iota}$. In the banking sector, the elasticity of loan demand and the importance of bank equity for lending (modeled as the cost of deviating from a target level of leverage) are the most important parameters. I 
use information on the cross-section of banks in each region to structurally estimate these parameters, leveraging the distribution of loan rates and loan amounts across banks with different levels of equity. The calibrated model indicates that the relative efficiency of a cut in the policy rate below $\tilde{\iota}$ (compared to one above $\tilde{\iota}$ ) is between $60 \%$ and $90 \%$. This estimated relative efficiency is fairly high, and indicates that the harmful implications of negative rates on bank profitability seem to be less serious than previously thought. There are two reasons why the relative efficiency is high despite the existence of the contractionary bank net-worth channel. First, the estimates of the importance of bank equity for lending are small. This is consistent with the fact that in the data, after controlling for bank fixed effects, a decline in the equity of a particular bank does not have a big effect on that bank's lending amount or its loan rate. Second, in the full model, when the policy rate and the loan rate fall, aggregate loan demand increases and banks can switch reserves for loans, decreasing the impact of negative rates on their ROE (this mechanism is not operational in the static model).

There are few academic papers dealing with the topic of NNIR from a theoretical perspective. Rognlie (2015) focuses on money demand while sidestepping the issue of bank profitability. Brunnermeier and Koby (2017) study the "reversal rate," i.e., the level of the interest rate where decreasing the policy rate further becomes contractionary for lending. However, they do so in a partial equilibrium framework without nominal rigidities, and so they cannot analyze whether setting NNIR is optimal. Amador et al. (2017) investigate how setting negative rates can help a small economy that is experiencing capital inflows, but they do not discuss concerns related to bank profitability. Similarly to my paper, Eggertsson, Juelsrud, and Wold (2017) study NNIR in a monetary DSGE model with banks, but both their assumptions and their conclusions are very different from mine. Their model does not incorporate bank monopoly power and, as a result, NNIR policies are never expansionary, regardless of parameter values. ${ }^{5}$ By contrast, in my model NNIR can be expansionary or contractionary, as well as welfare-improving or welfare-reducing, depending on parameter values. The Eggertsson et al. (2017) model implies that declines in the policy rate in negative territory are not transmitted to the lending rate, while my model predicts that they are. ${ }^{6} \mathrm{I}$ provide evidence that the behavior of the lending rate is consistent with my model.

The theoretical framework that I implement is related to papers that study the relation between households and banks, like Kiyotaki and Moore (2012) and Curdia and Wood-

\footnotetext{
${ }^{5}$ The intuition for why interest rate cuts are not expansionary in their model is that if the deposit rate is stuck at zero then banks' funding costs (via deposits) are no longer responsive to the policy rate, and therefore banks (since they do not have monopoly power) are not able to decrease the lending rate.

${ }^{6}$ While in my model the bank net-worth channel can lead to upward pressure on the lending rate, this only occurs over time, since the decline in bank profitability is only transmitted to a decline in bank equity after some periods.
} 
ford (2015). More specifically, it relates to papers that stress the agency problem between households and banks, like Gertler and Karadi (2011, henceforth GK), Gertler and Kiyotaki (2010), and Gerali, Neri, Sessa, and Signoretti (2010, henceforth GNSS). Relative to this literature, the contribution of this paper is to provide a model that combines all the frictions in the financial sector required to allow the study of NNIR with both beneficial and detrimental aspects. In my model, deposits and loans have the same duration, a feature that sidesteps maturity transformation as an aspect of banking. This setup is used for tractability, but it is also motivated by Drechsler et al. (2018).

There is a growing empirical literature that studies the effects of NNIR on commercial banks. Ampudia and Van den Heuvel (2017) study the effect of negative rates on banks' stock prices. They try to get at causal identification by using high-frequency techniques, and find that an unexpected decrease in the policy rate has particularly negative effects on banks' stock prices during the negative rate period. Borio et al. (2017) discuss the influence of monetary policy on bank profitability, in the context of very low (but not yet negative) rates. They find that low rates and an unusually flat term structure erode bank profitability. Claessens et al. (2017) find that a one percentage point interest rate decline implies an 8 basis points lower net interest margin in normal times, but this effect increases to 20 basis points at low rates. More recent papers, like Basten and Mariathasan (2018), Demiralp et al. (2017), Eisenschmidt and Smets (2018), and Lopez et al. (2018), study the effects of NNIR in Europe and Japan. They generally find that lending volumes have increased, lending

rates have fallen, and banks have modified their behavior to reduce the impact of negative rates on their profitability. In contrast to my paper, this literature is atheoretical, and hence cannot interpret these findings in the context of a model that allows for the quantification of the effects of NNIR on the broader economy.

The rest of the paper is organized as follows. Section 2 introduces the static banking model and discusses the interest rate spreads that emerge and how banks are hurt disproportionately when the policy rate falls below $\tilde{\iota}$. Section 3 uses bank-level data to test the four predictions of the static model. Section 4 extends the static model to a fully-fledged DSGE model. Section 5 outlines how I use the data to inform the calibration of the full model. Section 6 discusses the response of the model economy to a large recessionary shock. Section 7 studies the relative efficiency, in welfare terms, of a cut in the policy rate in Regime 2 compared to Regime 1 . Section 8 concludes.

\section{The Static Banking Model}

This section contains a static and partial equilibrium model of the banking sector that illustrates how a decline in the policy rate, even in negative territory, can be transmitted to 
a decline in the lending rate. The model also illustrates how negative rates can undermine bank profitability in the presence of a lower bound on the deposit rate. The objects of interest in this section are the (exogenous) policy rate, as well as the (endogenous) deposit and lending rates, and the return on bank equity. The amount lent and the amount of deposits received by each bank are endogenous, but the aggregate amounts are exogenous, due to the partial equilibrium nature of the exercise.

There is a continuum of banks, indexed by $j$, between zero and one. Each bank is given a certain level of equity as an endowment at the beginning of the period. On the liability side a bank combines equity, denoted by $F_{j}$, and deposits, denoted by $D_{j}$. Meanwhile, on the asset side, it issues loans $L_{j}$ and holds reserves $H_{j}$. The objective of banks is to maximize their resources at the end of the period, when loans and deposits are repaid. Each bank has some monopoly power that will be modeled using a CES framework. Specifically, each bank faces a downward-sloping loan demand and an upward-sloping deposit supply (even though aggregate loan demand and deposit supply are constant). In this simple setup, due to the presence of curvature in loan demand and deposit supply, there is no need to impose a leverage constraint on banks.

Banks choose the interest rate they charge on loans $i_{j}^{l}$, the amount they lend, the interest rate they pay on deposits $i_{j}^{d}$, the amount of deposits they take, and the amount of reserves they hold in the central bank, which earns the policy rate $i$, subject to several constraints. The maximization problem that the individual bank $j$ faces is therefore the following:

$$
\begin{aligned}
\max _{i_{j}^{l}, L_{j}, i_{j}^{d}, D_{j}, H_{j}} & \left(1+i_{j}^{l}\right) L_{j}+(1+i) H_{j}-\left(1+i_{j}^{d}\right) D_{j} \\
\text { s.t. } & \\
L_{j}= & \left(\frac{1+i_{j}^{l}}{1+i^{l}}\right)^{-\varepsilon^{l}} \mathbf{L} \\
D_{j}= & \begin{cases}\left(\frac{1+i_{j}^{d}}{1+i^{d}}\right)^{-\varepsilon^{d}} \mathbf{D} & \text { if } i_{j}^{d} \geq 0 \\
0 & \text { if } i_{j}^{d}<0\end{cases} \\
L_{j}+H_{j}=F_{j}+D_{j} & \\
H_{j} \geq 0 . &
\end{aligned}
$$

The functional forms of loan demand (equation 1), and deposit supply (equation 2), are microfounded in Appendix A. ${ }^{7}$ Equation (2) indicates that a bank obtains no deposits if

\footnotetext{
${ }^{7}$ Specifically, Appendices A.1-A.2 describe how to obtain equations (1) and (2) using the CES framework.
} 
it sets negative nominal deposit rates, since in that case households could save simply by using cash. The aggregate amounts of loans demanded by firms and deposits supplied by households are $\mathbf{L}$ and $\mathbf{D}$ respectively. As mentioned above, these aggregate quantities are not affected by any rates. Equation (3) is the balance sheet constraint, which indicates that total assets (loans plus reserves) have to be equal to liabilities plus equity. Equation (4) states that reserves at the central bank must be nonnegative. ${ }^{8}$

I assume that $\varepsilon^{l}>1$ and $\varepsilon^{d}<-1$, that all banks have the same amount of initial equity $F_{j}=\mathbf{F}$, and that $\mathbf{D}>\mathbf{L}>\mathbf{F} .{ }^{9}$ The formal solution to the bank problem is described in Proposition 1, which is given in Appendix A.4 together with its proof. Here I describe the results intuitively. The solution consists of regimes that apply depending on the level of the policy rate. Regime 1 applies when $i \geq \tilde{\iota}$, Regime 2 does when $\underline{i} \leq i<\tilde{\iota}$, and Regime 3 does when $i<\underline{i}$. The thresholds are described below.

In Regime 1, when the policy rate is in "normal" territory (i.e., above $\tilde{\iota}$ ), all banks set the same (gross) loan and deposit rates, which are given as a mark-up and a mark-down on the gross policy rate:

$$
1+i_{j}^{l}=\frac{\varepsilon^{l}}{\varepsilon^{l}-1}(1+i), \quad 1+i_{j}^{d}=\frac{\varepsilon^{d}}{\varepsilon^{d}-1}(1+i) .
$$

This is reminiscent of the solution to the pricing problem of a monopolistically competitive goods producer. ${ }^{10}$ The loan spread is given by $i_{j}^{l}-i=(1+i) /\left(\varepsilon^{l}-1\right)$ and the deposit spread by $i-i_{j}^{d}=(1+i) /\left(1-\varepsilon^{d}\right)$, both of these are positive. Even though the spreads technically vary with the policy rate, their slopes with respect to the policy rate (given by $\left(\varepsilon^{l}-1\right)^{-1}$ and $\left.\left(1-\varepsilon^{d}\right)^{-1}\right)$ are very small. ${ }^{11}$ This justifies the claim in the Introduction that in Regime 1 the spreads are (approximately) invariant to the policy rate. In this regime, all banks obtain an amount of deposits equal to the aggregate supply of deposits (D), give an amount of loans equal to the aggregate demand of loans $(\mathbf{L})$, and hold a positive amount of reserves at the central bank $\left(H_{j}=\mathbf{F}+\mathbf{D}-\mathbf{L}\right)$. Banks hold reserves not because they are forced to do so

\footnotetext{
Appendix A.3 shows that the CES formulation can be microfounded through a heterogeneous setup where each agent interacts with a single bank but has stochastic utility across banks (perhaps because of proximity or switching costs).

${ }^{8}$ Banks can borrow from the central bank using the discount window, but this usually carries a high cost and the stigma of being in financial trouble. Hence, I ignore the possibility of borrowing from the central bank. ${ }^{9}$ Since $\varepsilon^{l}>1$, a higher loan rate decreases loan demand. Deposits work differently, as costumers are looking for high rates (bank customers supply deposits instead of demanding them). $\varepsilon^{d}<-1$ indicates that banks that pay a higher rate obtain more deposits.

${ }^{10}$ As an illustrative example consider $i=3 \%, \varepsilon^{l}=34$, and $\varepsilon^{d}=-199$; in this case $i^{l} \approx 6 \%$ and $i^{d} \approx 2.5 \%$, for a loan spread of $3 \%$ and a deposit spread of 50 basis points. This is similar to the levels observed in the data for advanced countries if one takes long-run averages.

${ }^{11}$ This follows from the fact that the absolute values of $\varepsilon^{l}$ and $\varepsilon^{d}$ are likely to be very high, see footnote 10.
} 
(there is no reserve requirement), but because it is optimal for them to restrict the amount of loans that they provide when they are facing a downward sloping loan demand curve. Consequently, they keep their "unused" funds as reserves in the central bank.

The prescription that $1+i_{j}^{d}=\frac{\varepsilon^{d}}{\varepsilon^{d}-1}(1+i)$ implies that $i_{j}^{d}$ would become negative when the policy rate falls below the threshold $\tilde{\iota} \equiv-\frac{1}{\varepsilon^{d}}>0$. Once the policy rate crosses $\tilde{\iota}$, commercial banks would like to set negative nominal deposit rates in order to obtain their usual spread on deposits; however, if they did so, they would end up losing all their deposits, and so they set a zero deposit rate instead. This is Regime 2 , where all banks set $i_{j}^{d}=0$, receive an amount of deposits $\mathbf{D}$, give an amount of loans $\mathbf{L}$, and still hold a positive amount of reserves at the central bank. In this regime the loan rate setting behavior of banks is the same as in Regime 1, since the marginal use of commercial banks' resources is still as reserves at the central bank, and the loan rate is set as a mark-up on that opportunity cost (i.e., $\left.1+i_{j}^{l}=\frac{\varepsilon^{l}}{\varepsilon^{l}-1}(1+i)\right)$. This is the sense in which the bank lending channel remains operational below $\tilde{\iota}$; declines in the policy rate are still transmitted to the loan rate as they are above $\tilde{\iota}$.

Notice that when the deposit rate reaches zero banks cannot start turning away the marginal depositor. They either maintain a zero deposit rate and accept all the money that households wish to deposit, or they set a negative deposit rate and lose all deposits. Intuitively, this means that Regime 2 exists because there is a range of low and negative policy rates where banks prefer to receive deposits even if they make a low or negative spread on them, because it allows them to maintain their leverage and earn more on their loan franchise. Regime 2 stops applying when the policy rate crosses the threshold $\underline{i}<0$, where offering deposits at a zero rate is so costly that at least one commercial bank has incentives to deviate.

Regime 3, which applies when $i<\underline{i}$, is no longer a symmetric equilibrium, since a fraction of the banks still obtains deposits, while the remaining fraction stops doing so. This regime is described in detail in Appendix A.4. For the purposes of this section, the important feature of Regime 3 is that the aggregate loan rate $i^{l}$ is weakly decreasing in $i$. Intuitively, a decline in $i$ creates a disincentive to receive deposits, since some reserves would have to be kept at the central bank, earning a negative $i$. This (weakly) decreases the fraction of banks that takes deposits, allowing all banks to (weakly) increase their loan rate. This effect is reminiscent of the "reversal rate" of Brunnermeier and Koby (2017). Eventually, as the policy rate keeps decreasing, the fraction of banks that does not take deposits becomes independent of the policy rate, and so do all other bank variables, since every bank stops keeping reserves at the central bank.

In order to clarify the channels through which banks earn money, denote end of period 
equity by $F_{j}^{\prime}$. Using equation (3) this can be expressed as

$$
F_{j}^{\prime}=(1+i) F_{j}+\left(i_{j}^{l}-i\right) L_{j}+\left(i-i_{j}^{d}\right) D_{j}
$$

This expression highlights the fact that banks generate profits via three distinct channels:

1. They can keep their equity as reserves in the central bank, obtaining a gross return of $(1+i)$.

2. They obtain a loan spread of $i_{j}^{l}-i$ on each dollar lent.

3. They also obtain a deposit spread of $i-i_{j}^{d}$ on each dollar of deposits received. This is the term that gets "squeezed" when the policy rate is too low, i.e., when $i<\tilde{\iota}$.

The "additional" profits mentioned in items 2 and 3 are due to the existence of monopoly power in the banking sector, which is well documented empirically. ${ }^{12}$ Bank (gross) return on equity ( $\mathrm{ROE})$ is given by

$$
\frac{F_{j}^{\prime}}{F_{j}}= \begin{cases}(1+i)\left(1+\frac{1}{\varepsilon^{l}-1} \frac{\mathbf{L}}{\mathbf{F}}+\frac{1}{1-\varepsilon^{d}} \frac{\mathbf{D}}{\mathbf{F}}\right) & \text { if } \tilde{\iota} \leq i \\ 1+\frac{1}{\varepsilon^{l}-1} \frac{\mathbf{L}}{\mathbf{F}}+i\left(1+\frac{1}{\varepsilon^{l}-1} \frac{\mathbf{L}}{\mathbf{F}}+\frac{\mathbf{D}}{\mathbf{F}}\right) & \text { if } \underline{i} \leq i<\tilde{\iota} \\ {\left[(\mathbf{L} / \mathbf{F})^{\frac{\varepsilon^{l}-1}{\varepsilon^{l}}}-\mu(i)\right]^{\frac{1}{\varepsilon^{l}-1}}(1-\mu(i))^{\frac{1}{1-\varepsilon^{l}}} \frac{\varepsilon^{l}}{\varepsilon^{l}-1}(1+i)} & \text { if } i<\underline{i} .\end{cases}
$$

This is a continuous function, depicted in Figure $2 .{ }^{13}$ If one takes $\frac{1}{\varepsilon^{l}-1}$ and $\frac{1}{1-\varepsilon^{d}}$ to be small (which will be the case in my calibration), then the derivative of ROE with respect to the policy rate is roughly one when $i>\tilde{\iota}$, but approximately $(1+\mathbf{D} / \mathbf{F})$ when $\underline{i} \leq i<\tilde{\iota}$ (i.e., in Regime 2). Since the deposit-to-equity ratio is high in the data (generally between 4 and 9), the effect of the policy rate on ROE will be substantially higher in Regime 2. The intuition for ROE increasing with the policy rate in normal territory (i.e., above $\tilde{\iota}$ ) is that bank funds can be loaned out or kept as reserves in the central bank; if the rate on reserves increases, then it pushes up the outside option of each individual bank and leads to an increase in the loan rate and ROE. Figure 2 is important because the relationship between bank return on equity and the policy rate is a crucial mechanism in the full model I develop in Section 4. Recall that in this static model the aggregate amounts of deposits and loans $(\mathbf{L}$ and $\mathbf{D})$ are taken as given, and are independent of the policy rate. Even though later, in the full model, the aggregate amounts of loans and deposits will be affected by the policy rate, the intuition behind Figure 2 will remain valid.

The interest rate $\tilde{\iota}$ represents the threshold where further cuts in the policy rate would

\footnotetext{
${ }^{12}$ See Berger et al. (2004), Degryse and Ongena (2008), Drechsler et al. (2017), and Drechsler et al. (2018).

${ }^{13}$ The expression for $\mu(i)$ is given in Appendix A.4.
} 


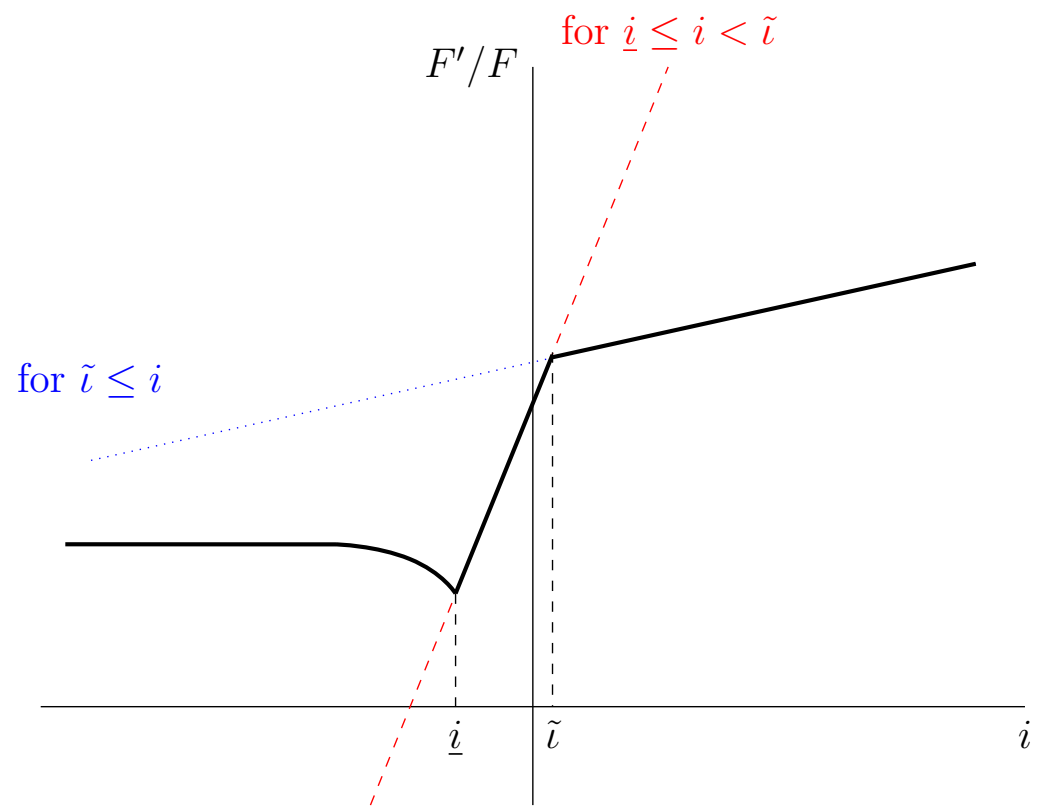

Figure 2: Model implied relationship between ROE and $i$

Notes: This figures describes the model-implied relationship between bank (gross) return on equity $\left(F^{\prime} / F\right.$, denoted $\left.\mathrm{ROE}\right)$, on the $y$ axis, and the policy rate $(i)$, on the $x$ axis. The levels $\tilde{\iota}$ and $\underline{i}$ represent thresholds where commercial banks start reacting differently to the policy rate; their expressions are given in the text.

turn deposit rates negative in the absence of the deposit ZLB. However, since deposit rates are constrained by zero, $\tilde{\iota}$ instead represents the point where further lowering the policy rate starts affecting banks disproportionately, because they cannot charge their usual spread on deposits. Even though cuts in the policy rate above $\tilde{\iota}$ have a negative effect on bank ROE, they have a much more negative effect below $\tilde{\iota}$. The switch between Regimes 1 and 2 occurs before policy rates hit zero (since $\tilde{\iota}>0) .{ }^{14}$

The threshold $\underline{i}$ represents the point at which fears of "disintermediation" start becoming relevant, since at this point some banks prefer to stop offering certain services (like taking deposits) because they are too unprofitable. The expression for $\underline{i}$ contains the elasticity $\varepsilon^{l}$ (not $\varepsilon^{d}$ ), which indicates that this threshold is related to monopoly power in the lending market rather than to monopoly power in the deposit market. Intuitively, even if banks are making low or negative profits while receiving deposits, they can use these funds to make loans and earn the spread between the policy rate and the lending rate, which is governed by $\varepsilon^{l}$. Notice that the threshold for disintermediation is strictly smaller than zero

\footnotetext{
${ }^{14}$ How far above zero this happens is governed by $\varepsilon^{d}$ in the static model, but will depend on additional parameters in the full model described in Section 4 and Appendix A.5.
} 
(i.e., $\underline{i}<0$ ), and hence there is some room for policy rates to become negative without raising fears of disintermediation.

Below $\underline{i}$ there is an interval where ROE increases as the policy rate decreases. As mentioned above, in that range a decline in $i$ creates a disincentive to receive deposits, since some reserves would have to be kept at the central bank, where they would earn a negative $i$. Therefore, the fraction of banks that takes deposits decreases, lowering the "threat" that the abundant funds of these banks represents for the aggregate supply of loans. This gives all banks more room to exercise their monopoly power, allowing them to increase their loan rate and consequently their ROE. As the policy rate continues to decline, this perverse effect on ROE disappears, since all banks stop holding reserves at the central bank. For the baseline calibration I describe in Section $5, \underline{i}$ will be around $-2.2 \%{ }^{15}$ Because this threshold is so low, in the following sections I will ignore the region below $\underline{i}$. Indeed, the lowest level of rates ever set in any country was -75 basis points, far above my estimates of $\underline{i}$. In the full model presented in Section 4 I also ignore this region, and confine the analysis to situations where the policy rate is not too far below $-2 \%$.

In summary, the model in this section illustrates that there is a range of low and negative rates, between $\tilde{\iota}$ and $\underline{i}$ (roughly between 50 and -200 basis points), where declines in the policy rate are still transmitted to the loan rate due to the presence of bank monopoly power. This implies that rate cuts in this range can be stimulative through the bank lending channel, even in the presence of a ZLB for deposit rates. A decline in the policy rate in the $[\underline{i}, \tilde{\imath}]$ range also leads to a decline in bank ROE which is bigger than the one that would occur if the rate cut happened above $\tilde{\iota}$. In this static model such a decline in ROE does not affect the loan rate (implying that negative rates would only have beneficial effects), but in the full model the decline in ROE can lead to upward pressure in the loan rate, making cuts in the policy rate less effective at stimulating the economy.

\section{Empirical Analysis}

\subsection{Data Description and Summary Statistics}

To test the predictions of the static model, and to later identify some of the parameters of the full model, I compiled a sample of yearly data for individual commercial banks obtained from Fitch Solutions (the same underlying data behind the phased-out Bankscope dataset).

\footnotetext{
${ }^{15}$ Since the Physical Lower Bound (PLB) mentioned in footnote 1 is probably between -100 and -200 basis points, the PLB may be above $\underline{i}$ or vice versa. Regardless of which one is closer to zero, it would probably be a stretch for central banks to set rates on reserves below -200 basis points.
} 
Table 1: Summary statistics for banking variables between 1990 and 2017

\begin{tabular}{lccccc}
\hline \hline \multicolumn{1}{c}{ Variable } & Mean & Std. Dev. & Min. & Max. & N \\
\hline Rate on Av. Earning Assets & 4.57 & 1.99 & 0.60 & 10.50 & 80086 \\
Deposit Rate & 1.02 & 1.18 & 0.00 & 6.62 & 31615 \\
Net Interest Margin & 2.46 & 0.99 & 0.01 & 6.12 & 80441 \\
ROAA & 0.48 & 0.66 & -2.76 & 3.50 & 80545 \\
ROAE & 5.78 & 7.91 & -43.60 & 33.07 & 80202 \\
Log of Net Loans & 6.60 & 1.78 & 2.84 & 13.09 & 84721 \\
Log of Total Customer Deposits & 6.71 & 1.74 & 2.13 & 13.14 & 83532 \\
Log of Equity & 4.48 & 1.76 & 1.04 & 10.88 & 85240 \\
Log of Total Assets & 7.13 & 1.75 & 4.17 & 13.91 & 85311 \\
Customer Deposits to Assets ratio & 0.72 & 0.18 & 0.01 & 0.96 & 83599 \\
Net Loans to Assets ratio & 0.62 & 0.17 & 0.03 & 0.97 & 84823 \\
\hline \hline
\end{tabular}

Notes: This table contains summary statistics for banking variables between the years 1990 and 2017. ROAA stands for return on average assets and ROAE for return on average equity. "N" denotes to the total number of observations across all countries and years.

The sample spans 28 years (1990-2017) and 19 countries in 10 advanced regions (i.e., the five regions that have set negative nominal rates: the Euro area, Sweden, Switzerland, Denmark, and Japan, and five comparable regions that have set very low rates: U.S., U.K., Canada, Norway and Australia). The data on the policy rates in these countries was obtained directly from their respective central banks.

To reduce the adverse effects of outliers, I excluded banks that: have less than 50 million dollars in total assets, have less than 5 yearly observations, or have extreme values in the quantities of interest. ${ }^{16}$ The selected sample includes 5,405 banks. ${ }^{17}$ The total number of observations is approximately 85,000. Variables are winsorized at the $0.5 \%$ level on each side to further minimize the adverse effects of outliers. Table 1 contains some summary statistics of the variables of interest, like the rate paid on average earning assets, which will be used as a measure of the loan rate, the rate paid on customer deposits, the net interest margin, the return on average assets (ROAA), and the return on average equity (ROAE). It also contains other important quantities.

\footnotetext{
${ }^{16}$ I exclude banks that in any year have higher than $15 \%$ deposit rate, loan rate, net interest margin, or ROAA, higher than $150 \%$ ROAE, or a ratio of a specific asset category to total assets that is greater than one. This removes less than $9 \%$ of the observations and has a very small effect on the results, but helps with precision.

${ }^{17}$ The breakdown across countries is: 65 in Canada, 83 in Australia, 132 in Norway, 131 in the U.K., 1,235 in the U.S., 75 in Sweden, 64 in Denmark, 306 in Switzerland, 605 in Japan, and 2,709 in the Euro Area. Appendix Figures 15 and 16 contain graphs of the policy rate in the 10 regions in the sample across years.
} 


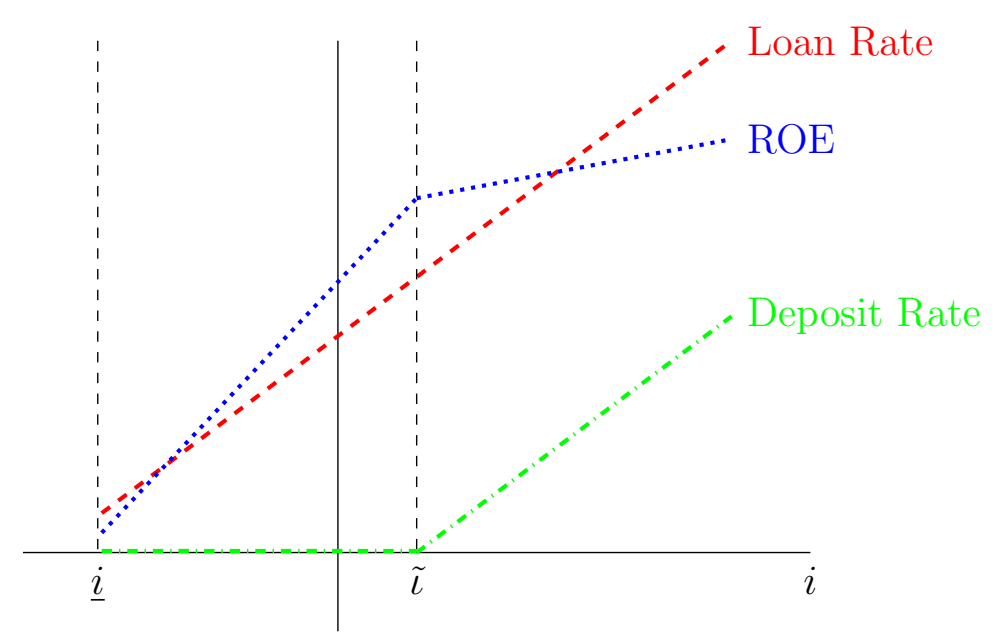

Figure 3: Relationship between important variables and $i$

Notes: This figure describes the relationship, implied by the static model, between the loan rate, the deposit rate, and return on equity (ROE), on one hand, and the policy rate in the other hand. The thresholds $\tilde{\iota}$ and $\underline{i}$ are described in Section 2 .

\subsection{Threshold Effects}

The model presented in Section 2 has stark predictions regarding the behavior of the variables of interest around the threshold $\tilde{\iota}$ that are summarized in Figure 3. The figure shows that above $\tilde{\iota}$ both the deposit rate and the loan rate increase with the policy rate, and that ROE increases as well, but at a relatively slow pace. Below $\tilde{\iota}$ the deposit rate is already at zero and stops responding to declines in the policy rate, the loan rate continues to decrease, and return on equity reacts strongly to the policy rate. ${ }^{18,19}$

There are several ways to allow for potentially nonlinear effects. ${ }^{20}$ One option is to run a locally weighted regression of the dependent variable at the bank level on the policy rate after residualizing out bank fixed effects and time fixed effects. This is done in Appendix B.3, and it supports the predictions of the model, but it does not allow for identification of the threshold value $\tilde{\iota}$. An alternative option is to run regressions of the following type:

$$
y_{b, t}=\alpha_{b}+\delta_{t}+\beta_{1} i_{c(b), t}+\beta_{2}\left(i_{c(b), t}-\tilde{\iota}\right) D_{c(b), t}+\varepsilon_{b, t}
$$

\footnotetext{
${ }^{18}$ The range of the policy rate presented in Figure 3 is entirely above the threshold $\underline{i}$. I ignore the region below $\underline{i}$ because I do not expect to learn anything about this region from the available data, since the negative rates set in advanced countries have never gone below negative 75 basis points while $\underline{i}$ is $\approx-2 \%$ in my calibration.

${ }^{19}$ The levels of the rates and ROE in Figure 3 do not have any particular significance, the important concept being highlighted is their reaction to the policy rate.

${ }^{20}$ For comparison, the linear results are reported in Appendix B.2.
} 
where $y_{b, t}$ is some outcome variable (the deposit rate, the loan rate, or ROAE) for bank $b$, in country $c(b)$ and year $t$, and $i_{c(b), t}$ is the policy rate in that country and year. The regressions include a bank fixed effect $\left(\alpha_{b}\right)$ and a year fixed effect $\left(\delta_{t}\right)$. The dummy $D_{c(b), t} \equiv \mathbb{1}\left(i_{c(b), t}>\tilde{\iota}\right)$ is an indicator of whether the policy rate is above $\tilde{\iota}$; the effect of the policy rate on the dependent variable is allowed to have a different magnitude above and below $\tilde{\iota}$. These regressions require knowing the level of the threshold; I start by setting $\tilde{\iota}=0.5 \%$ and then justify this choice in Section 3.3.

Table 2 contains the results of the regressions in equation (6). The coefficient on the policy rate, denoted $\beta_{1}$, measures the slope below the threshold. The coefficient on $\left(i_{c(b), t}-\tilde{\imath}\right) D_{c(b), t}$, denoted $\beta_{2}$, measures the difference in slope between the portion below the threshold and the portion above the threshold. Therefore, the sum of the two coefficients $\left(\beta_{1}+\beta_{2}\right)$ measures the slope above the threshold. The results conform well to the predictions of the model. The loan rate reacts strongly and significantly to the policy rate below the threshold, and it reacts similarly above the threshold (the significance level increases). The deposit rate does not react to the policy rate below the threshold, but does react strongly and significantly above it. ROAE reacts very strongly to the policy rate below the threshold and mildly above it. Appendix B.4 documents the robustness of these results to a number of modifications of the baseline specification, such as including a lag of the dependent variable, including the threshold level as an independent variable in the regression, controlling for the time-varying bank-specific level of equity and assets, or controlling for different indicators of financial or banking crises.

Notice that I do not have exogenous variation in policy rates, and hence these results are simply correlations that hold in the data and have the interpretation of general equilibrium relationships that would hold in a model. Nevertheless, they can be informative of which mechanisms are operational in the real world. For example, the fact that the loan rate declines with the policy rate below $\tilde{\iota}$ can be used to distinguish between my paper and Eggertsson et al. (2017). In their model the loan rate stops declining once the deposit rate is at zero, while in my model the loan rate continues to decrease due to the presence of bank monopoly power. ${ }^{21}$ The evidence in Table 2 is consistent with my model.

\footnotetext{
${ }^{21}$ In theory the results in Eggertsson et al. (2017) apply for $\tilde{\iota}=0$ and not for some other level, like 50 basis points. The results of the regressions described in equation (6) in the case where $\tilde{\iota}=0$ are given in appendix Table 16. The results are similar to the ones reported above, although the significance of $\beta_{1}$ is diminished due to the presence of less observations to identify it.
} 
Table 2: Regressions for main variables of interest

\begin{tabular}{lccc}
\hline \hline & $(1)$ & $(2)$ & $(3)$ \\
& Loan Rate & Deposit Rate & ROAE \\
\hline Policy Rate & $0.578^{* * *}$ & -0.035 & $5.004^{* * *}$ \\
& $(0.145)$ & $(0.139)$ & $(1.063)$ \\
$(i-\tilde{\iota}) * \mathbb{1}(i \geq \tilde{\iota})$ & -0.155 & $0.479^{* * *}$ & $-4.194^{* * *}$ \\
& $(0.141)$ & $(0.142)$ & $(1.024)$ \\
\hline$\beta_{1}+\beta_{2}$ & $0.423^{* * *}$ & $0.444^{* * *}$ & $0.810^{* * *}$ \\
s.e. $\left(\beta_{1}+\beta_{2}\right)$ & 0.026 & 0.035 & 0.203 \\
$\mathrm{~N}$ & 80078 & 31554 & 80199 \\
$\mathrm{R}$ squared & 0.93 & 0.85 & 0.41 \\
Mean dep. var. & 4.58 & 1.01 & 5.78 \\
\hline \hline
\end{tabular}

Notes: This table contains the results of regressing the three variables of interest (loan rate, deposit rate, and return on average equity), on bank fixed effects, time fixed effects, the policy rate, and an interaction between the policy rate and an indicator of whether the policy rate is above the threshold $\tilde{\iota}$ (taken to be 50 basis points in this table). S.E. are in parentheses. Clustering is done at the country-year level. Stars: * for $\mathrm{p}<.10,{ }^{* *}$ for $\mathrm{p}<.05,{ }^{* * *}$ for $\mathrm{p}<.01$.

\subsection{Identifying the Threshold}

The previous regressions require knowledge of the threshold level $\tilde{\iota}$. The full model presented in Section 4 implies that $\tilde{\iota}$ is very well approximated by the steady state difference between the policy rate and the deposit rate. In the data, the average difference between the policy rate and the deposit rate is around 50 basis points, both measured through the IMF IFS and in my sample (once I collapse it to the country-year level and then take a simple mean), thus motivating my initial choice of the threshold. ${ }^{22}$ It is nevertheless desirable to check whether atheoretical empirical tests on the level of the threshold support this choice.

One simple way to identify $\tilde{\iota}$ is to estimate the regressions in equation (6) for different possible threshold levels and then choose the one that minimizes the root mean squared error. This quantity (the RMSE) is shown in Appendix Figure 11 for different possible break levels between a $0 \%$ and a $1 \%$ annual level of the policy rate for the deposit rate and ROAE. The root mean squared error is minimized between 45 and 65 basis points for both variables. At those levels the t-stat for the interaction coefficient is greater than 2, and hence the null hypothesis of equal slope coefficients above and below the threshold is rejected. Notice that

\footnotetext{
${ }^{22}$ This 50 basis points difference is obtained both when taking a simple average for all the banks within a country and when using the model implied appropriate CES weighting (using an annual $\varepsilon^{d}$ of -199).
} 
even though the estimated thresholds for the deposit rate and ROAE are not exactly the same (the threshold is identified at 46 basis points for the deposit rate and 62 basis points for ROAE), they are very close. ${ }^{23,24}$

As pointed out by Hansen (1999), inference in the presence of an unknown threshold is complicated by the presence of a nuisance parameter, because the break point is not present under the null hypothesis. In Appendix B.5 I perform a test to identify the threshold based on Hansen's methodology. I also apply a test developed by Chay and Munshi (2015) that uses more information present on the deposit rate data in order to identify the threshold. Both methodologies find a threshold level remarkably close to 50 basis points. Since the model (together with the aggregate data) and the empirical tests all point to a value of $\tilde{\iota}$ that is close to 50 basis points, I will use that as my preferred estimate for $\tilde{\iota}$.

\subsection{Deposit Channel Evidence}

According to the model in Section 2, the reason banks are hurt more by a decline in the policy rate below $\tilde{\iota}$ is that they cannot pass it through to their depositors. In the static model all banks have the same amount of customer deposits (since all banks are identical), but in the data banks differ significantly along this dimension. Some banks finance themselves more through equity, bank deposits, or derivatives than through customer deposits. Hence, in the data, banks have different customer-deposits-to-assets (CDA) ratios, and it is possible to analyze how banks are affected by policy rates above and below $\tilde{\iota}$ according to their CDA ratio. My model predicts that banks with a high CDA ratio will be affected more by a decline in the policy rate below $\tilde{\iota}$ than banks with a low CDA ratio, but that both types of banks will be affected similarly above the threshold. To test this I split banks into quintiles according to their CDA ratio the first time I observe them in the panel. ${ }^{25}$ Then I run the

${ }^{23}$ Appendix Figure 12 shows the equivalent to Appendix Figure 11 once a lag of the dependent variable is included. In this case the threshold is found at exactly the same level of 48 basis points for both the deposit rate and ROAE. While this coincidence is predicted by the model, it is reassuring to find that it holds in the data.

${ }^{24}$ Even though this procedure is predicated on minimizing the RMSE, it will not always find a break point once it is combined with the analysis of the t-statistic for the interaction coefficient. One way to illustrate this is by running the same procedure for the loan rate, which the model predicts should not have a break around the threshold $\tilde{\iota}$. Appendix Figure 13 displays the results of this test. The RMSE is minimized at 1, but throughout all possible threshold candidates the t-stat for the interaction coefficient is always below 2 .

${ }^{25}$ Since the panel is not balanced, simply taking the CDA ratio in 1990 would include very few banks in the sample. One alternative is to obtain a balanced panel between 1995 or 2000 and 2016 and take the CDA ratio in the first year of that panel. Another alternative is to take the average CDA ratio of each bank across years. Both of these options yield similar results. A description of the CDA ratio variable is given in Appendix Table 17. 
following regression:

$$
R O A E_{b, t}=\alpha_{b}+\sum_{j=1}^{5}\left(\delta_{t}^{j}+\beta_{1}^{j} i_{c(b), t}+\beta_{2}^{j}\left(i_{c(b), t}-\tilde{\iota}\right) D_{c(b), t}\right) I_{b}^{j}+\varepsilon_{b, t}
$$

where $I_{b}^{j} \equiv \mathbb{1}\left(C D A_{b} \in Q_{j}\right)$ is an indicator that takes the value of one when bank $b$ belongs to quintile $j$ and zero otherwise. In this notation $Q_{j}$ is the interval that includes all values of the $C D A$ ratio that belong in quintile $j$. Notice that in this regression the value of the year fixed effect is allowed to vary across quintiles of the CDA ratio (so that there are five sets of time fixed effects). This is equivalent to running the regression in equation (6) quintile by quintile.

The results of this regression are given in column 2 of Table 3 (for comparison, column 1 replicates column 3 of Table 2 ). The coefficient $\beta_{1}$ increases monotonically across quintiles from 2.65 for the first quintile (banks with the lowest CDA ratio) to 8.02 for the last quintile (banks with the highest CDA ratio). This implies that the aggregate regression masks important heterogeneity across quintiles of the CDA ratio. By contrast, the coefficient for the policy rate above $\tilde{\iota}$, which is given by $\beta_{1}+\beta_{2}$, is very similar for quintiles 2 through 5 , at a level of between 0.85 and 0.95 . These results conform well to the predictions of the model, and support the notion that having a high CDA ratio leads to a higher impact of the policy rate on ROAE below the threshold $\tilde{\iota}$, but a similar impact above the threshold.

In this section I estimated the parameter $\tilde{\iota}$ to be around 50 basis points, and successfully tested four predictions of the model in Section 2. First, once the policy rate falls below $\tilde{\iota}$, the deposit rate stops reacting to it. Second, the lending rate continues to decline with the policy rate even below $\tilde{\iota}$. Third, bank return on equity is more affected by a cut in the

policy rate below $\tilde{\iota}$ than above it. Finally, the higher sensitivity of bank return on equity to the policy rate below $\tilde{\iota}$ is more pronounced for banks that rely heavily on customer deposits.

\section{The Extended Model}

The model in Section 2 serves to convey useful intuitions but, due to its partial equilibrium nature, cannot speak to the overall effectiveness of setting NNIR. In this section, I develop a richer, general equilibrium, dynamic model where bank equity matters. This will provide a useful laboratory to study the effects of NNIR on the economy, taking into consideration its effects on bank profitability.

There are five types of agents in the model: households, intermediate goods producers, capital producers, retailers, and banks. In addition, there is a government, and a central bank that conducts monetary policy. The model for the capital producers, intermediate good producers, and retailers builds on features from GK, while the model for the banks is 
Table 3: Regressions to test the deposit channel

\begin{tabular}{lcc}
\hline \hline & $(1)$ & $(2)$ \\
& Baseline & Q by Q \\
\hline Policy Rate & $5.004^{* * *}$ & \\
Quintile$=1 \times$ Policy Rate & & $2.653^{* *}$ \\
Quintile$=2 \times$ Policy Rate & & $3.555^{* * *}$ \\
Quintile$=3 \times$ Policy Rate & & $4.013^{* *}$ \\
Quintile$=4 \times$ Policy Rate & & $5.816^{* * *}$ \\
Quintile$=5 \times$ Policy Rate & & $8.026^{* * *}$ \\
$(i-\tilde{\iota}) * \mathbb{1}(i \geq \tilde{\iota})$ & & \\
Quintile$=1 \times(i-\tilde{\iota}) * \mathbb{1}(i \geq \tilde{\iota})$ & & $-2.539^{* *}$ \\
Quintile$=2 \times(i-\tilde{\iota}) * \mathbb{1}(i \geq \tilde{\iota})$ & & $-2.605^{* * *}$ \\
Quintile$=3 \times(i-\tilde{\iota}) * \mathbb{1}(i \geq \tilde{\iota})$ & & $-3.068^{* *}$ \\
Quintile$=4 \times(i-\tilde{\iota}) * \mathbb{1}(i \geq \tilde{\iota})$ & & $-4.968^{* * *}$ \\
Quintile$=5 \times(i-\tilde{\iota}) * \mathbb{1}(i \geq \tilde{\iota})$ & & $-7.131^{* * *}$ \\
\hline$\beta_{1}+\beta_{2}$ & $0.810^{* * *}$ & \\
Quintile$=1 \times\left(\beta_{1}+\beta_{2}\right)$ & & 0.113 \\
Quintile$=2 \times\left(\beta_{1}+\beta_{2}\right)$ & $0.950^{* * *}$ \\
Quintile$=3 \times\left(\beta_{1}+\beta_{2}\right)$ & & $0.945^{* * *}$ \\
Quintile$=4 \times\left(\beta_{1}+\beta_{2}\right)$ & & $0.848^{* * *}$ \\
Quintile$=5 \times\left(\beta_{1}+\beta_{2}\right)$ & & $0.895^{* * *}$ \\
$\mathrm{~N}$ & & 78710 \\
$\mathrm{R}^{2}$ & 80199 & $\mathrm{Y}-\mathrm{Q}$ \\
Other $\mathrm{FE}$ & 0.407 & Year \\
\hline \hline
\end{tabular}

Notes: Column (1) reports the results of the regression in equation (6) where the dependent variable is return on average equity (ROAE) and column (2) reports the results of the regression in equation (7). Quintile 1 includes banks with the lowest CDA ratio, while quintile 5 includes those with the highest. Clustering is done at the country-year level. Bank fixed effects are included. Stars: * for $\mathrm{p}<.10$, ** for $\mathrm{p}<.05$, and $* * *$ for $\mathrm{p}<.01$.

a more complicated version of the one described in Section 2.

Retailers are included in order to introduce price rigidity into the model in a tractable way, and they are kept separate from intermediate good firms to avoid complications related to firm specific capital described in Woodford (2005) and Sveen and Weinke (2005). ${ }^{26}$ Capital good producers are introduced to be able to have a price of capital that is not fixed at unity, by giving them the capital adjustment costs without encumbering the intermediate good

\footnotetext{
${ }^{26}$ Having a rental market for capital instead of firm specific capital would also suffice, but since the market for capital is crucially interrelated to banks, it is simpler to keep retailers separate from intermediate good firms.
} 
producer's problem with these costs. Having several sectors and adding realistic features, like habit formation and investment adjustment costs, allows the model to capture business cycles in a realistic way, in the tradition of papers like Christiano, Eichenbaum, and Evans (2005) and Smets and Wouters (2007). ${ }^{27}$ Since one of the objectives of this paper is a quantitative analysis of the welfare impact of setting negative nominal interest rates, it is important to have a model that is rich enough to match quantitatively the behavior of realworld economies.

\section{$4.1 \quad$ Households}

There is a continuum of households of measure one. Each household consumes, saves and supplies labor. They save by depositing their money in a continuum of banks, or by holding cash. Household's preferences are given by

$$
\mathbb{E}_{0} \sum_{t=0}^{\infty} \beta^{t} \varphi_{t}\left(\frac{\left(C_{t}-h C_{t-1}\right)^{1-\sigma}-1}{1-\sigma}-\chi \frac{N_{t}^{1+\frac{1}{\eta}}}{1+\frac{1}{\eta}}\right)
$$

with $0<\beta<1,0<h<1$, and $\sigma, \chi, \eta>0$. $\beta$ is the discount factor, $\sigma$ is the inverse of the intertemporal elasticity of substitution, $\chi$ governs the importance of labor in the utility function, $\eta$ is the Frisch elasticity of labor supply, and $\varphi_{t}$ is a shock to the discount factor. $C_{t}$ is consumption and $N_{t}$ is labor supply. I allow for habit formation in the consumption behavior of households, captured by the parameter $h$. Household's deposits in banks are one period nominal contracts that pay the gross nominal interest $\left(1+i_{t-1}^{d}\right)$ from $t-1$ to $t$. Let $D_{t}$ be the total quantity of deposits that the household lends to banks from period $t$ to period $t+$ $1, M_{t}$ be the amount of cash that households have in period $t, W_{t}$ be the nominal wage, $\Pi_{t}$ be the net nominal payouts to the household from ownership of both nonfinancial and financial firms, and $T_{t}$ be nominal lump sum taxes. Then the household's budget constraint is given by

$$
P_{t} C_{t}+D_{t}+M_{t}=W_{t} N_{t}+\Pi_{t}-T_{t}+\left(1+i_{t-1}^{d}\right) D_{t-1}+M_{t-1}
$$

The household's optimality conditions are standard and are given in Appendix C.1.

\subsection{Intermediate Goods Firms}

On the production side of the economy nonfinancial firms make intermediate inputs using capital and labor. At the end of period $t-1$, an intermediate goods firm borrows an amount

\footnotetext{
${ }^{27} \mathrm{~A}$ version of the model that also includes variable capital utilization and a different price for new and refurbished capital is available from the author upon request. The results are similar to the baseline model.
} 
of capital $K_{t}$ from the banks for use in production during period $t$. After using capital to produce intermediate goods during $t$, the firm returns the capital to the bank. There are no capital adjustment costs at the intermediate good producer level, since they simply rent capital.

Let $Y_{t}^{m}$ be the amount produced of intermediate goods, $K_{t}$ be capital, $A_{t}$ denote total factor productivity and $\xi_{t}$ denote the quality of capital. The production function is given by

$$
Y_{t}^{m}=A_{t}\left(\xi_{t} K_{t}\right)^{\alpha} N_{t}^{1-\alpha}
$$

Let $P_{t}^{m}$ be the price of intermediate goods output. Then at time $t$, the firm chooses labor to maximize nominal profits, which are given by

$$
\Pi_{t}^{m}=P_{t}^{m} Y_{t}^{m}-W_{t} N_{t}-Z_{t} K_{t}
$$

These are nominal profits at time $t$ because the firm produces $Y_{t}^{m}$ and obtains a price $P_{t}^{m}$ for each of those units. It pays $W_{t}$ to each worker and borrows capital from financial intermediaries. In particular, it borrowed $K_{t}$ units of effective capital (in the previous period) and pays a dividend of $Z_{t}$ to each of those units. The optimality condition with respect to labor is

$$
(1-\alpha) \frac{P_{t}^{m}}{P_{t}} \frac{Y_{t}^{m}}{N_{t}}=\frac{W_{t}}{P_{t}} .
$$

The dividend $Z_{t}$ ensures that the profits of intermediate firms are equal to zero:

$$
Z_{t}=P_{t}^{m} \alpha \frac{Y_{t}^{m}}{K_{t}}
$$

Consequently, the stochastic, nominal, gross return for banks of having a unit of effective capital is

$$
1+i_{t+1}^{l}=\frac{Q_{t+1} \xi_{t+1}(1-\delta)+P_{t+1}^{m} \alpha \frac{Y_{t+1}^{m}}{K_{t+1}}}{Q_{t}}
$$

Notice that there are no financial frictions between intermediate good firms and banks, that is why intermediate good producers transfer all their residual stochastic returns to banks. This setup, where banks are the residual claimants of intermediate good firms, is used in GK. Additionally, this approach is motivated by two considerations. First, this is meant to capture the Great Recession, where the originating shock, a fall in housing prices, had an important negative effect on bank equity. In my model, the shock originating the recession 
will be a fall in capital efficiency $\left(\xi_{t}\right)$; if banks just loaned money to intermediate good firms at a deterministic rate this shock would have no major effect on bank equity, and this is not consistent with the experience during the Great Recession. Second, even if banks lend money to firms at a "deterministic" loan rate, the fact that firms might default means that banks end up absorbing some of the risk of intermediate good firms. This could be introduced through a probability of default for intermediate good firms, but that would unnecessarily complicate the analysis.

\subsection{Capital Producers}

The process of producing new capital is subject to flow adjustment costs. The value of newly produced capital is $Q_{t}$. Let $I_{t}$ be investment, then capital evolves according to

$$
K_{t+1}=(1-\delta) \xi_{t} K_{t}+I_{t}
$$

Discounted real profits for a capital-producing firm are

$$
\max \mathbb{E}_{t} \sum_{\tau=t}^{\infty} \beta^{\tau-t} \Lambda_{t, \tau}\left\{\left(\frac{Q_{\tau}}{P_{\tau}}-1\right) I_{\tau}-f\left(\frac{I_{\tau}}{I_{\tau-1}}\right) I_{\tau}\right\}
$$

where $\Lambda_{t, \tau}$ is the household's stochastic discount factor between periods $t$ and $\tau$ (excluding the discount factor $\beta$ ). Following Christiano et al. (2005) or GK, $f$ is a function that represents the costs of adjusting the level of investment and that satisfies $f(1)=f^{\prime}(1)=0$ and $f^{\prime \prime}(1)>0 .{ }^{28}$ The first order condition for investment, which determines $Q_{t} / P_{t}$, is given in Appendix C.1.

\subsection{Retail Firms}

Each retail firm uses intermediate inputs and costlessly transforms them into a differentiated variety of a retail good. These varieties are aggregated to a final good via a CES aggregator:

$$
Y_{t}=\left(\int_{0}^{1} Y_{t}(s)^{\frac{\theta-1}{\theta}} d s\right)^{\frac{\theta}{\theta-1}}
$$

Demand for a particular differentiated good and the price index are given by

$$
Y_{t}(s)=\left(\frac{P_{t}(s)}{P_{t}}\right)^{-\theta} Y_{t}, \quad P_{t}=\left(\int_{0}^{1} P_{t}(s)^{1-\theta} d s\right)^{\frac{1}{1-\theta}}
$$

\footnotetext{
${ }^{28}$ I use $f(x)=\zeta \frac{(x-1)^{2}}{2(1+\beta)}$. The derivative of the price of capital w.r.t. investment evaluated at the S.S. is $\zeta$.
} 
As in the traditional Calvo setup, a firm is able to freely adjust its price with probability $1-\gamma$. Thus, the pricing problem of retail firm $s$ is to choose the optimal reset price $P_{t}^{*}(s)$ to solve:

$$
\max \mathbb{E}_{t} \sum_{r=0}^{\infty} \gamma^{r} \beta^{r} \Lambda_{t, t+r} \frac{P_{t}}{P_{t+r}}\left[P_{t}^{*}(s)-P_{t+r}^{m}\right] Y_{t+r}(s)
$$

The optimality conditions describing the behavior of retail firms are given in Appendix C.1.

\subsection{Banks Redux}

The behavior of banks is similar to the one described in Section 2, but I introduce four modifications to make the framework richer, more realistic, and easier to match with the other elements of the extended model. I describe each of these changes sequentially.

First, banks are subject to a cost of deviating from a target level of loan-to-equity ratio. The bank pays a quadratic cost (parameterized by a coefficient $\kappa$ and proportional to outstanding bank equity) whenever the loan-to-equity ratio, $L_{t}(j) / F_{t}(j)$, deviates from the target value $\nu$. The part of the quadratic cost to the right of $\nu$ is motivated by the fact that regulators will increasingly discourage high levels of leverage. The part to the left of $\nu$ is motivated by the fact that investors will punish banks if they have too little leverage, and that bank managers are sometimes rewarded by the gross amount of money they manage. The quadratic cost is a modeling shortcut to capture the fact that bank capital is important in a tractable way, a common choice that has been adopted in several papers. e.g. Gerali et al. (2010), Campbell (1987), and Drechsler et al. (2017). ${ }^{29}$

Second, I allow banks to face exogenous costs of issuing loans, given by $\mu_{t}^{l}$, and benefits of issuing deposits, given by $\mu_{t}^{d}$. These are expressed per dollar of loan or deposit issued. The cost of issuing loans is positive (the bank has to monitor the borrowers, pay loan originators, etc), while the cost of issuing deposits could be negative, because it could be seen as a benefit that the bank receives for having a large deposit base, for example attracting more customers or obtaining more publicity (that is why I will depict them as a benefit in my notation). ${ }^{30}$

Third, I allow for the fact that banks can receive a stochastic return from firms, and this can affect their ROE. Banks will not set a deterministic loan rate, but will instead charge each firm a fraction of its total return on capital. In equilibrium, since all banks are symmetric, this fraction will be one, but banks will still face a well defined demand for

\footnotetext{
${ }^{29}$ The fact that bank equity matters can also be introduced as in Gertler and Karadi (2011), but the quadratic cost is more tractable and easier to implement, specially once the banks have monopoly power and endogenous reserves.

${ }^{30}$ The reasons to introduce $\mu_{t}^{l}$ and $\mu_{t}^{d}$ are to be able to decouple $\tilde{\iota}$ from $\varepsilon^{d}$, to give the model more flexibility looking forward to the calibration, and to potentially have exogenous variation in intermediation costs.
} 
"loans". The loan return of banks between periods $t$ and $t+1$ will be determined in period $t+1$ and it will contain expectations. This stochastic loan setup is described in Appendix A.6. As mentioned in Section 4.2, the reason to introduce stochastic loan returns for banks is so that the fall in capital efficiency (which will give rise to the recession I will analyze) has a significant impact on bank equity. This is meant to mimic the Great Recession, where the originating shock affected bank balance sheets substantially.

Finally, I also assume that each period a fraction $\varsigma$ of nominal bank net worth is used up operating the managerial side of the bank. This, together with the fact that banks cannot frictionlessly obtain the optimal amount of equity from households, implies that bank equity is relevant and can take a long time to replenish. With all these assumptions the nominal resources that bank $j$ will have next period (denoted $S_{t+1}(j)$ ) are given by

$S_{t+1}(j)=\left(1+i_{t+1}^{l}(j)-\mu_{t}^{l}\right) L_{t}(j)+\left(1+i_{t}\right) H_{t}(j)-\left(1+i_{t}^{d}(j)-\mu_{t}^{d}\right) D_{t}(j)-\varsigma F_{t}(j)-\frac{\kappa}{2}\left(\frac{L_{t}(j)}{F_{t}(j)}-\nu\right)^{2} F_{t}(j)$.

The bank balance sheet constraint can be used to rewrite this as

$S_{t+1}(j)=\left(1+i_{t}-\varsigma\right) F_{t}(j)+\left(i_{t+1}^{l}(j)-\mu_{t}^{l}-i_{t}\right) L_{t}(j)+\left(i_{t}+\mu_{t}^{d}-i_{t}^{d}(j)\right) D_{t}(j)-\frac{\kappa}{2}\left(\frac{L_{t}(j)}{F_{t}(j)}-\nu\right)^{2} F_{t}(j)$,

which is an extension of equation (5), and encapsulates the same 3 ways of making profits, plus the cost of deviating from the target level of loan-to-equity ratio, the exogenous costs of issuing loans and deposits, and the managerial cost of operating the bank. In Appendices A.5 and A.6 I show that, with the changes mentioned above for the banking sector, the loan rate is given by:

$$
\mathbb{E}_{t}\left(1+i_{t+1}^{l}\right)=\frac{\varepsilon^{l}}{\varepsilon^{l}-1}\left(1+i_{t}+\mu_{t}^{l}\right)+\kappa \frac{\varepsilon^{l}}{\varepsilon^{l}-1}\left(\frac{L_{t}}{F_{t}}-\nu\right) .
$$

This is similar to the expression in Section 2, with three changes:

1. The loan rate is set as a mark-up over the gross policy rate plus the cost of issuing loans.

2. The amount of bank equity is now relevant; if the loan-to-equity ratio is higher than its target then the expected loan return required by the bank is higher. This occurs because the bank wants to disincentivize lending, in order to lower its leverage.

3. The expression contains expectations due to the stochastic nature of the loan return. The expression for the deposit rate is given by

$$
1+i_{t}^{d}=\frac{\varepsilon^{d}}{\varepsilon^{d}-1}\left(1+i_{t}+\mu_{t}^{d}\right)
$$

when $\tilde{\iota}<i$. This is the same expression in Section 2, except for the appearance of the benefit of issuing deposits $\left(\mu_{t}^{d}\right)$. Once the policy rate falls below $\tilde{\iota}$ banks either set a zero 
deposit rate, or set a negative deposit rate and receive no deposits. Appendix A.5 defines the thresholds $\tilde{\iota}$ and $\underline{i}$ for this extended model.

Next, I describe the way bank capital evolves over time. Denote nominal resources net of management costs, previous period equity, and an adjustment for inflation, by $X_{t+1}$ :

$$
\begin{aligned}
X_{t+1}(j) & \equiv i_{t} F_{t}(j)+\left(i_{t+1}^{l}(j)-\mu_{t}^{l}-i_{t}\right) L_{t}(j)+\left(i_{t}+\mu_{t}^{d}-i_{t}^{d}(j)\right) D_{t}(j) \\
& -\frac{\kappa}{2}\left(\frac{L_{t}(j)}{F_{t}(j)}-\nu\right)^{2} F_{t}(j)-F_{t}(j)(1-\varsigma) \pi_{t+1}
\end{aligned}
$$

Notice that this is not a traditional accounting concept, it is simply an intermediate object that will be useful to describe the sluggish evolution of bank capital under the specific framework chosen in this paper. Later on it will become clear why I chose to include the adjustment for inflation in equation (14). With this definition of $X_{t+1}$, next period resources of a bank can be described as

$$
S_{t+1}(j)=(1-\varsigma) F_{t}(j)\left(1+\pi_{t+1}\right)+X_{t+1}(j)
$$

I assume that a fraction $\omega$ of $X_{t+1}(j)$ is kept in the bank and the remaining fraction $1-\omega$ is distributed to the households. Nominal bank net worth next period is then given by

$$
F_{t+1}(j)=(1-\varsigma) F_{t}(j)\left(1+\pi_{t+1}\right)+\omega X_{t+1}(j)
$$

while the bank pays dividends: $D I V_{t+1}^{B}(j)=(1-\omega) X_{t+1}(j)$; hence, the sum of all the resources in the bank is used either for accumulating net worth or distributing dividends: $S_{t+1}(j)=F_{t+1}(j)+D I V_{t+1}^{B}(j)$, and real bank resources in period $t+1$ are given by

$$
\frac{F_{t+1}(j)}{P_{t+1}}=(1-\varsigma) \frac{F_{t}(j)}{P_{t}}+\omega \frac{X_{t+1}(j)}{P_{t+1}} .
$$

It should be emphasized that this particular specification for the evolution of bank capital is not crucial for the implications of the model, the important feature is that it captures the idea of "slow moving" capital, in the sense that banks cannot simply obtain their ideal level of capital frictionlessly. ${ }^{31}$ The specific form I have chosen emphasizes the idea that $\omega$ governs the

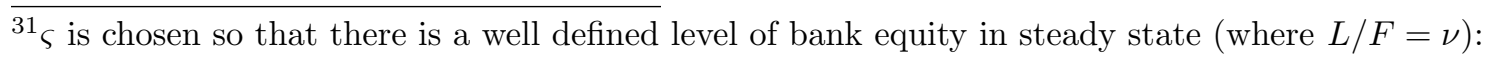

$$
\varsigma=\omega\left(i+\left(i^{l}-\mu^{l}-i\right) \nu+\left(i+\mu^{d}-i^{d}\right) \frac{D}{F}\right) .
$$

This equation can be interpreted as determining $\varsigma$ for a given level of $\omega$ (as well as $i, i^{l}, i^{d}, \nu, D / F, \mu^{l}$ and $\mu^{d}$ ), or as determining $\omega$ for a given level of $\varsigma$. It is based on the requirement than in steady state there is 
effect that "profits" (i.e., $X_{t+1}$ ) have on a bank's real resources. If $\omega=\varsigma=0$, then a bank's real resources are constant, in the sense that they are not affected by any shocks; this is why I chose to incorporate the adjustment for inflation in equation (14). The higher $\omega$, the higher the fraction of fluctuations in bank's profits that have to be absorbed by banks themselves.

\subsection{Resource Constraint, Policy and Shocks}

Output is divided between consumption, investment, government expenditure, $G_{t}$, and adjustment costs. The economy-wide resource constraint is thus given by

$$
Y_{t}=C_{t}+I_{t}+G_{t}+f\left(\frac{I_{t}}{I_{t-1}}\right) I_{t}+\mu_{t}^{l} \frac{L_{t-1}}{P_{t}}-\mu_{t}^{d} \frac{D_{t-1}}{P_{t}}+\varsigma \frac{F_{t-1}}{P_{t}}+\frac{\kappa}{2}\left(\frac{L_{t-1}}{F_{t-1}}-\nu\right)^{2} \frac{F_{t-1}}{P_{t}},
$$

additionally, total loans by banks have to equal the total value of capital:

$$
L_{t}=Q_{t} K_{t+1}
$$

I assume monetary policy is characterized by a Taylor rule with interest-rate smoothing. Let $i_{t}$ be the net nominal interest rate and $\bar{\imath}$ the steady state nominal rate, then

$$
i_{t}=\left(1-\rho_{i}\right)\left(\bar{\iota}+\psi_{\pi}\left(\pi_{t}-\bar{\pi}\right)\right)+\rho_{i} i_{t-1}+\epsilon_{t}^{i}
$$

where $\rho_{i} \in[0,1]$, and where $\epsilon_{t}^{i}$ is an exogenous shock to monetary policy. ${ }^{32}$ The processes for the shocks are described in Appendix C.1. Technology, discount factor, and government shocks are standard in dynamic New Keynesian models, but will not be emphasized in this paper. The capital efficiency shock will be used to generate the recession which is the object of study. Finally, shocks to reserves are introduced to capture the fact that during the Great Recession most central banks increased their balance sheet by an order of magnitude, and this led to a big increase in the amount of reserves held by commercial banks. This is important because these reserves were later subjected to NNIR. In the main exercise I will keep the level of reserves fixed after the recession, but I will explore different scenarios in extensions. In the baseline model, the exogenous costs and benefits of issuing loans and deposits will be kept constant, i.e., $\mu_{t}^{l}=\mu^{l}$ and $\mu_{t}^{d}=\mu^{d}$.

a constant level of bank equity consistent with the law of motion for bank equity given in the text.

${ }^{32}$ Lump sum transfers from the government to consumers include the proceeds from seignorage (both base money and reserves at the central bank) and subtract government expenditure in goods:

$$
T_{t}=M_{t}-M_{t-1}+H_{t}-\left(1+i_{t-1}\right) H_{t-1}-P_{t} G_{t} .
$$


The equilibrium is characterized by the relevant equations for each of the types of agents in the model, collected in Appendix C.1. Appendix C.2 describes the steady state of the model.

\section{Calibration}

Given that the objective of this paper is to have a quantitative framework to study the effects of NNIR on the economy, calibrating the values of the parameters in the model is very important. Since the contribution of this paper is concentrated in the banking sector, the parameters in the financial block of the model are the ones that require more discussion, as well as the ones where less inference can be drawn from the literature. I first focus on estimating the value of $\kappa$, and then turn to the remaining parameters.

\subsection{Importance of Bank Equity for Lending}

Recall that $\kappa$ measures the impact of deviating from the target level of the loan-to-equity ratio on the objective function of the bank, and hence also on its lending rate and amount of loans extended. Therefore, a way to learn about $\kappa$ is by using the cross-section, and studying how banks with different levels of equity differ in their lending behavior.

In the model so far all banks have been homogeneous, which makes it hard to understand the effects of equity on lending. I will now develop a simple model with bank heterogeneity. The current specification for the cost of deviating from the target level of loan-toequity ratio, $-\kappa / 2\left(L_{j} / F_{j}-\nu\right)^{2}$, does not allow for a closed form solution to the heterogeneous bank problem. This motivates a change to the following logarithmic specification:

$$
-\kappa \nu \frac{L_{j}}{F_{j}}\left(\ln \left(\frac{L_{j}}{F_{j}}\right)-\ln \nu-1\right)-\kappa \nu^{2},
$$

which is convenient because it allows the heterogeneous bank model to be solved in closed form. In Appendix A.7 I prove that the quadratic specification used so far is the secondorder approximation to the logarithmic one around the steady state, which implies that both specifications deliver virtually the same solution to the model with homogeneous banks. ${ }^{33} \mathrm{I}$ also show that, with the logarithmic specification for the cost of deviating from the target level of leverage, the solution for bank-level log loan amount and loan rate in terms of log

\footnotetext{
${ }^{33}$ The quadratic specification has been used up to this point to convey intuitions easily and to facilitate comparison with other papers, but it would make no difference if the logarithmic specification had been used all along.
} 
bank equity can be written as

$$
\begin{aligned}
i_{j}^{l} & =\alpha+\beta i-\frac{\kappa \nu}{1+\kappa \nu \varepsilon^{l}} \ln \left(F_{j}\right) \\
\ln \left(L_{j}\right) & =\alpha^{\prime}+\beta^{\prime} i+\frac{\kappa \nu \varepsilon^{l}}{1+\kappa \nu \varepsilon^{l}} \ln \left(F_{j}\right)
\end{aligned}
$$

where the expressions for $\alpha, \alpha^{\prime}, \beta$, and $\beta^{\prime}$ are given in Appendix A.7. Thus, a regression of $i_{j}^{l}$ on a constant, the policy rate, and $\ln \left(F_{j}\right)$, yields a coefficient on $\log$ bank equity of $-\frac{\kappa \nu}{1+\kappa \nu \varepsilon^{l}}$; and a regression of $\ln \left(L_{j}\right)$ on a constant, the policy rate, and $\ln \left(F_{j}\right)$, yields a coefficient on $\log$ bank equity of $\frac{\kappa \nu \varepsilon^{l}}{1+\kappa \nu \varepsilon^{l}}$. From these two regressions it is possible to back-out two coefficients, $\kappa \nu$ and $\varepsilon^{l}$. Denote the coefficient on log bank equity on the loan rate regression by $\gamma_{l r}$, and the one on the log loan amount regression by $\gamma_{l a}$, then

$$
-\frac{\gamma_{l a}}{\gamma_{l r}}=\varepsilon^{l}=-\frac{\operatorname{Cov}\left(\ln \left(L_{j}\right), \ln \left(F_{j}\right)\right)}{\operatorname{Cov}\left(i_{j}^{l}, \ln \left(F_{j}\right)\right)}, \quad \frac{\gamma_{l r}}{\gamma_{l a}-1}=\kappa \nu=\frac{\operatorname{Cov}\left(i_{j}^{l}, \ln \left(F_{j}\right)\right)}{\operatorname{Cov}\left(\ln \left(L_{j} / F_{j}\right), \ln \left(F_{j}\right)\right)}
$$

Hence, these two regressions can be used to obtain estimates of $\kappa \nu$ and $\varepsilon^{l}$ jointly. When actually estimating these regressions in the data, it is important to include lags of the dependent variable, since there appears to be sluggishness in loan rates and loan amounts (since the data I have is on total loans outstanding and not on newly issued loans). It is also important to have bank fixed effects that control for time-invariant bank level characteristics (other than equity) that lead to differences in loan rate or log loan amount. Consequently, I run the following regressions:

$$
y_{b, t}=\alpha_{b}+\beta i_{c(b), t}+\eta_{1} y_{b, t-1}+\eta_{2} y_{b, t-2}+\gamma \ln \left(F_{b, t-1}\right)+\varepsilon_{b, t}
$$

where the dependent variable $\left(y_{b, t}\right)$ is either the log loan amount or the loan rate of an individual bank. The two parameters of interest are the two $\gamma^{\prime}$ s $\left(\gamma_{l r}\right.$ when $y_{b}=i_{b}^{l}$ and $\gamma_{l a}$ when $y_{b}=\ln \left(L_{b}\right)$ ), which are the coefficients on the log level of lagged equity. In the theoretical framework the log level of equity was dated $t$, as were the log loan amount and loan rate. It is important to keep in mind that in that framework equity in period $t$ was predetermined, while the loan amount and the loan rate were endogenous. In my data this cannot be guaranteed, so I lag equity by one period. ${ }^{34}$ Since the regression includes lags of the dependent variable, I can lag equity more than one period, or instrument it with additional lags of itself, to avoid endogeneity concerns. Given the inclusion of lags of the dependent

\footnotetext{
${ }^{34}$ Since data is annual, it is hard to argue that equity in a particular year is independent from the loan rate and the loan amount in that same year.
} 
Table 4: Structural estimation of $\kappa$ and $\varepsilon^{l}$, part 1

\begin{tabular}{lccccc}
\hline \hline & $(1)$ & $(2)$ & $(3)$ & $(4)$ & $(5)$ \\
& USD & JPY & EUR & CHF & GBP \\
\hline \hline$\gamma_{l a}$ & 0.5357 & 0.3757 & 0.3833 & 0.7360 & 0.4208 \\
$\gamma_{l r}$ & -0.0203 & -0.0094 & -0.0102 & -0.0072 & -0.0107 \\
$\kappa$ & 0.0049 & 0.0017 & 0.0018 & 0.0030 & 0.0021 \\
$\varepsilon^{l}$ & 26.4049 & 40.0239 & 37.5096 & 102.5313 & 39.1907 \\
$\mathrm{i}^{l}-i$ & 0.0386 & 0.0253 & 0.0270 & 0.0098 & 0.0258 \\
\hline \hline
\end{tabular}

Notes: This table contains the results of the country-level structural estimation of $\kappa$ and $\varepsilon^{l}$ described in equation (20). It contains the 5 largest regions in terms of amount of banks present in the sample: USA (USD), Japan (JPY), the Euro Area (EUR), Switzerland (CHF), and UK (GBP). Table 19 in the appendix contains the remaining 5 regions.

variable, the relevant coefficient for calculating $\kappa \nu$ and $\varepsilon^{l}$ is not $\gamma$, but $\frac{\gamma}{1-\eta_{1}-\eta_{2}}$ instead.

Appendix B.7 contains the results of the regressions in (20) for the full sample, and its implications for the values of $\varepsilon^{l}$ and $\kappa$, for different specifications of the regression equation. The baseline specification contains two lags of the dependent variable, as equation (20), but instruments $F_{b, t-1}$ with $F_{b, t-3}$ to avoid endogeneity concerns. The regressions yield an estimate of $\varepsilon^{l}$ of 45 , which implies an annual spread between the loan rate and the policy rate of about $2.3 \%$, and an estimate of $\kappa$ of 20 basis points. The estimates for $\varepsilon^{l}$ are realistic, since they imply loan spreads that are close to those observed in the data (i.e. between $2 \%$ and $4 \%$ ).

The heterogeneous bank model allows me to obtain region-specific estimates for $\kappa$ and $\varepsilon^{l}$, this will help answer the question of how efficient NNIR are in each region. The results for the biggest regions, using the baseline specification described above, are given in Table 4, while the ones for smaller countries are given in appendix Table 19. The estimates of $\kappa$ range between 17 basis points for Japan and 50 basis points for the U.S., while the estimates of $\varepsilon^{l}$ are between 26 for the U.S. and 100 for Switzerland. I use these parameter estimates to inform my calibration.

\subsection{Additional Parameter Values}

Table 5 describes the calibrated parameter values. Most of the parameters in the blocks pertaining the households, the intermediate good firms, and the capital producing firms are taken directly from GK. The values in the retail block are standard.

The average value for the annual level of the loan rate, the policy rate, and the deposit rate in my database are $6 \%, 3 \%$ and $2.5 \%$ respectively. The quarterly value of 0.9937 for $\beta$ delivers a value of $i^{d}$ in steady state of $2.5 \%$ at the yearly level (0.62\% at a quarterly level). 
$\varepsilon^{d}=-268$ and $\mu^{d}=0.25 \%$ then imply a value of $i$ of $3 \%$ at a yearly level $(0.75 \%$ at the quarterly level). Finally $\varepsilon^{l}=203$ and $\mu^{l}=0.25 \%$ then imply a value of $i^{l}$ of $6 \%$ at a yearly level (1.5\% at the quarterly level). For the baseline calibration I assume that the $\mu$ 's and $\varepsilon$ 's are constant. In this calibration the spread between the policy rate and the deposit rate $\left(i-i^{d}\right)$ is $0.5 \%$ annually, the spread between the lending rate and the policy rate $\left(i^{l}-i\right)$ is $3 \%$ annually, and the value for $\tilde{\iota}$ is $0.5 \%$, consistent with the evidence presented in Section 3.3.

With the gross rate specification for loan demand and deposit supply, reproduced here:

$$
L(j)=\left(\frac{1+i^{l}(j)}{1+i^{l}}\right)^{-\varepsilon^{l}} L, \quad D(j)=\left(\frac{1+i^{d}(j)}{1+i^{d}}\right)^{-\varepsilon^{d}} D,
$$

or the stochastic version of loan demand in the extended model (described in Appendix A.6), the elasticities of substitution, $\varepsilon^{d}$ and $\varepsilon^{l}$, depend on the time horizon. Specifically, the annual elasticities are a fourth of the quarterly elasticities. Hence, the annual levels of these elasticities in the baseline calibration are $\varepsilon^{d}=-268 / 4=-67$ and $\varepsilon^{l}=203 / 4 \approx 50$. The value of $\varepsilon^{l}$ used at the annual level $(\approx 50)$ is very close to the one estimated in Section 5.1.

Given my specification for the evolution of real bank equity described in equations (14) and (16), the effect of a change in the return on capital $\left(i_{t+1}^{l}\right)$ on the percentage change on bank equity is $\omega \nu$. I choose $\omega$ so that the total effect $(\omega \nu)$ is equal to one, since $\nu$ is calibrated to 9 , this implies that $\omega=1 / 9 \approx 0.1111$. This is a normalization, and changing it does not affect the quantitative predictions of the model. ${ }^{35}$ The managerial cost of operating the bank, $\varsigma$, is chosen to be consistent with steady state, this gives a quarterly cost of operating the bank of $1 \%$ of equity. $\nu$ is chosen to be 9 , which is the mean loan-to-equity ratio in my dataset. Likewise, $\bar{H} / \bar{F}$ is chosen to match the $20 \%$ reserve-to-asset ratio in my database.

The most important parameter of the model is $\kappa$. The reason this parameter is so important is that, when deciding whether to set NNIR, the central bank has to weigh the fact that it will affect bank profits more than usual. How much bank's profits matter is governed by the importance of deviating from the target level of loan-to-equity ratio, namely $\kappa$. This is the parameter that was estimated in Section 5.1, there I obtained the value of 50 basis points for the United States at the annual frequency, but this value has to be divided by 4 to convert it into the quarterly frequency. That is why 12.5 basis points was chosen as the baseline value for $\kappa$. The full sample delivered a value of $\kappa=20$ basis points at the annual frequency, which translates to 5 basis points at the quarterly frequency. Since this parameter is so important,

\footnotetext{
${ }^{35}$ Provided that the shock originating the recession is also modified to keep the total effect of the shock constant. A greater $\omega$ implies that a given shock to $\xi$ (capital productivity) has a greater impact on banks and hence also on the overall economy.
} 
Table 5: Calibrated parameter values

\begin{tabular}{|c|c|c|c|}
\hline Parameter & Value & Description & Target or source \\
\hline \multicolumn{4}{|l|}{ Households } \\
\hline$\beta$ & 0.9937 & Discount rate & Annual dep. rate of $2.5 \%$ \\
\hline$h$ & 0.8150 & Habit formation & GK \\
\hline$\chi$ & 3.4090 & Importance of leisure & GK \\
\hline$\eta$ & 1.0000 & Frisch elasticity of labor supply & Chetty et al. (2011) \\
\hline$\sigma$ & 1.0000 & Inverse of the I.E.S. & Balanced Growth \\
\hline \multicolumn{4}{|c|}{ Intermediate good firms } \\
\hline$\alpha$ & 0.3333 & Capital share & GK \\
\hline$\delta$ & 0.0250 & Depreciation rate & GK \\
\hline \multicolumn{4}{|c|}{ Capital producing firms } \\
\hline$\zeta$ & 1.7280 & Elasticity of $Q$ to investment & GK \\
\hline \multicolumn{4}{|c|}{ Retail firms } \\
\hline$\theta$ & 6.0000 & Elasticity of subs. among goods & S.s. mark-up of $20 \%$ \\
\hline$\gamma$ & 0.7500 & Prob. of keeping prices fixed & 1 year average price spell \\
\hline \multicolumn{4}{|c|}{ Financial intermediaries } \\
\hline$\omega$ & 0.1111 & Fraction of resources staying in bank & Normalization \\
\hline$\varsigma$ & 0.0100 & Bank managerial cost & Consistent with s.s. \\
\hline$\nu$ & 9.0000 & Loan-to-equity ratio target & Average in my dataset \\
\hline$\kappa$ & 0.0012 & Cost of deviating from lev. target & Estimation \\
\hline$\varepsilon^{d}$ & -268 & Elasticity of substitution for deposits & Annual policy rate of $3 \%$ \\
\hline$\varepsilon^{l}$ & 203 & Elasticity of substitution for loans & Annual lending rate of $6 \%$ \\
\hline$\mu^{d}$ & $0.25 \%$ & Benefits of issuing deposits & Annual policy rate of $3 \%$ \\
\hline$\mu^{l}$ & $0.25 \%$ & Cost of issuing loans & Annual lending rate of $6 \%$ \\
\hline $\bar{H} / \bar{F}$ & 2.0000 & Reserves over Equity in S.S. & Average in my dataset \\
\hline \multicolumn{4}{|c|}{ Government } \\
\hline$\overline{\psi_{\pi}}$ & 3.5000 & Inflation coefficient, Taylor rule & Suggestive \\
\hline$\rho_{i}$ & 0.8000 & Smoothing parameter, Taylor rule & Standard parameter \\
\hline$g$ & 0.2000 & Steady state $G / Y$ & GK \\
\hline
\end{tabular}

Notes: This table contains the parameter values used in the calibration, together with their description and the source where they are taken from or the objective they target.

I will illustrate the effectiveness of monetary policy for different values of $\kappa$ in Section 7 , and I will relate this to the estimates of $\kappa$ obtained in Section 5.1 for different countries.

Now I explore how economically important the cost of deviating from the target level of leverage might be. Consider a change in leverage from 9 (the level in steady state) to 9.9 , i.e., an increase of $10 \%$. This decreases available resources next period, via the cost of 
deviating from target leverage, by a magnitude of:

$$
\frac{\kappa}{2}\left(\frac{L}{F}-\nu\right)^{2} F=\frac{\kappa}{2} \cdot 0.9^{2} \cdot F
$$

By dividing this by $F$ I obtain the change in return on equity from one period to the next. But this is given at a quarterly frequency, so I multiply it by 400 to turn it into annual percentage terms. This means the change in ROE due to the change in leverage is given by $162 \cdot \kappa$, so an increase in leverage of $10 \%$ decreases bank return on equity by around 8 basis points annually when $\kappa$ is 5 basis points, 20 basis points when $\kappa$ is 12.5 basis points, and 40 basis points when $\kappa$ is 25 basis points.

Another way to judge the significance of $\kappa$ in my model is to analyze its effects on the loan rate (instead of on $\mathrm{ROE}$ ). In the absence of uncertainty and $\mu^{l}$, the loan rate is given by $1+i^{l}=\frac{\varepsilon^{l}}{\varepsilon^{l}-1}(1+i+\kappa(L / F-\nu))$, and so an increase in leverage of $10 \%$ would lead to an increase in the loan rate of 50 basis points at the annual frequency, this is essentially the moment that was used to identify $\kappa$ in the regressions done in Section 5.1.

I set the response of the policy rate to inflation in the Taylor rule $\left(\psi_{\pi}\right)$, to 3.5 , which is higher than the traditional value of 1.5. I do this because having a higher response to inflation can help the stability properties of the model when the economy hits the ZLB. Changing this value does not have big quantitative implications for the model, provided the size of the shock originating the recession is adjusted to keep the effect on output constant. The value of $\rho_{i}=0.8$ is standard.

\section{Recession Under a Taylor Rule}

I now analyze how the model economy behaves under three scenarios. The scenario which has been emphasized so far in this paper is the one where the policy rate can be negative but the deposit rate is constrained to being nonnegative, this is denoted the "Modified ZLB" scenario. I also analyze two scenarios that are more traditional in the literature, the "No ZLB" scenario, where the policy rate and the deposit rate are both unconstrained, and the "Traditional ZLB" scenario, where both the policy and deposit rates are constrained to being nonnegative.

In the No ZLB scenario I log-linearize the model and solve it using traditional methods. In the case of the Modified ZLB scenario I solve the model using the methodology described in Guerrieri and Iacoviello (2015), since the ZLB on the deposit rate represents an occasionally binding constraint. This methodology log-linearizes the model in a piece-wise fashion (one piece when the constraint binds and the other piece when it does not), and then uses perturbation methods to find the period where the economy transitions from one regime to the other. In the case of the Traditional ZLB scenario the same methodology is used, but now 
there are two occasionally binding constraints, the deposit rate ZLB and the policy rate ZLB.

I study the response of the model economy after a shock to capital productivity; $\xi_{t}$ falls by $2.5 \%$ and this shock is relatively long lived $\left(\rho_{\xi}=0.9\right)$. In the No ZLB scenario this shock will generate a fall in output of roughly $3.5 \%$, a fall in the policy rate, which remains negative for roughly 6 quarters, a fall in the deposit rate, which remains negative for roughly 8 quarters, and a fall in the net worth of financial intermediaries.

Figures 4 and 5 display the impulse response functions of some the most important variables in the model to the capital productivity shock under the three scenarios mentioned above. The No ZLB scenario corresponds to the dotted blue line, the Traditional ZLB to the solid purple line and the Modified ZLB to the dashed red line. IRFs are expressed as percent deviations from steady state for all variables except for the deposit rate $\left(i_{t}^{d}\right)$, the policy rate $\left(i_{t}\right)$, the spread between the expected loan rate and the policy rate $\left(\mathbb{E}_{t}\left(i_{t+1}^{l}-i_{t}\right)\right)$, and inflation, whose values are plotted in annualized levels in percentage points. Figures 4 and 5 display responses for $\kappa=12.5$ basis points, which is the baseline value (recall that $\kappa$ governs the importance of deviations from the target loan-to-equity ratio). Appendix Figure 17 shows the IRFs of additional variables.

Figure 4 demonstrates that, on the onset of the recession, both the policy rate and the deposit rate are negative in the No ZLB scenario, the policy rate is negative but the deposit rate is stuck at zero in the Modified ZLB scenario, and both the policy rate and the deposit rate are stuck at zero in the Traditional ZLB scenario. Recall that, in this section, the monetary authority is following a given Taylor Rule, where it reacts to inflation. When the economy is in the Modified ZLB scenario and the deposit rate gets stuck at zero, the instrument of the monetary authority (i.e., the nominal policy rate) has less power compared to the No ZLB scenario, and hence the central bank lowers the policy rate by more to achieve a comparable effect. This explains why the policy rate becomes more negative in this scenario than in the No ZLB one.

The lower policy rate under the Modified ZLB scenario is the reason why output falls by slightly less in that case compared to the No ZLB scenario in the first few periods. Very quickly however, output in the No ZLB scenario overtakes output in the modified ZLB scenario and remains higher than in both other scenarios for most of the relevant quarters of study. It is also possible to observe that initially output falls by more in the Traditional ZLB scenario compared to the Modified ZLB, since in the latter the central bank can still stimulate the economy using the policy rate. But after some time, roughly around quarter 8, output under the Traditional ZLB nearly catches up to output under the Modified ZLB and stays just slightly below it for the following quarters. Regarding consumption, the three scenarios are not that different, but consumption under the Traditional ZLB remains lower throughout. 

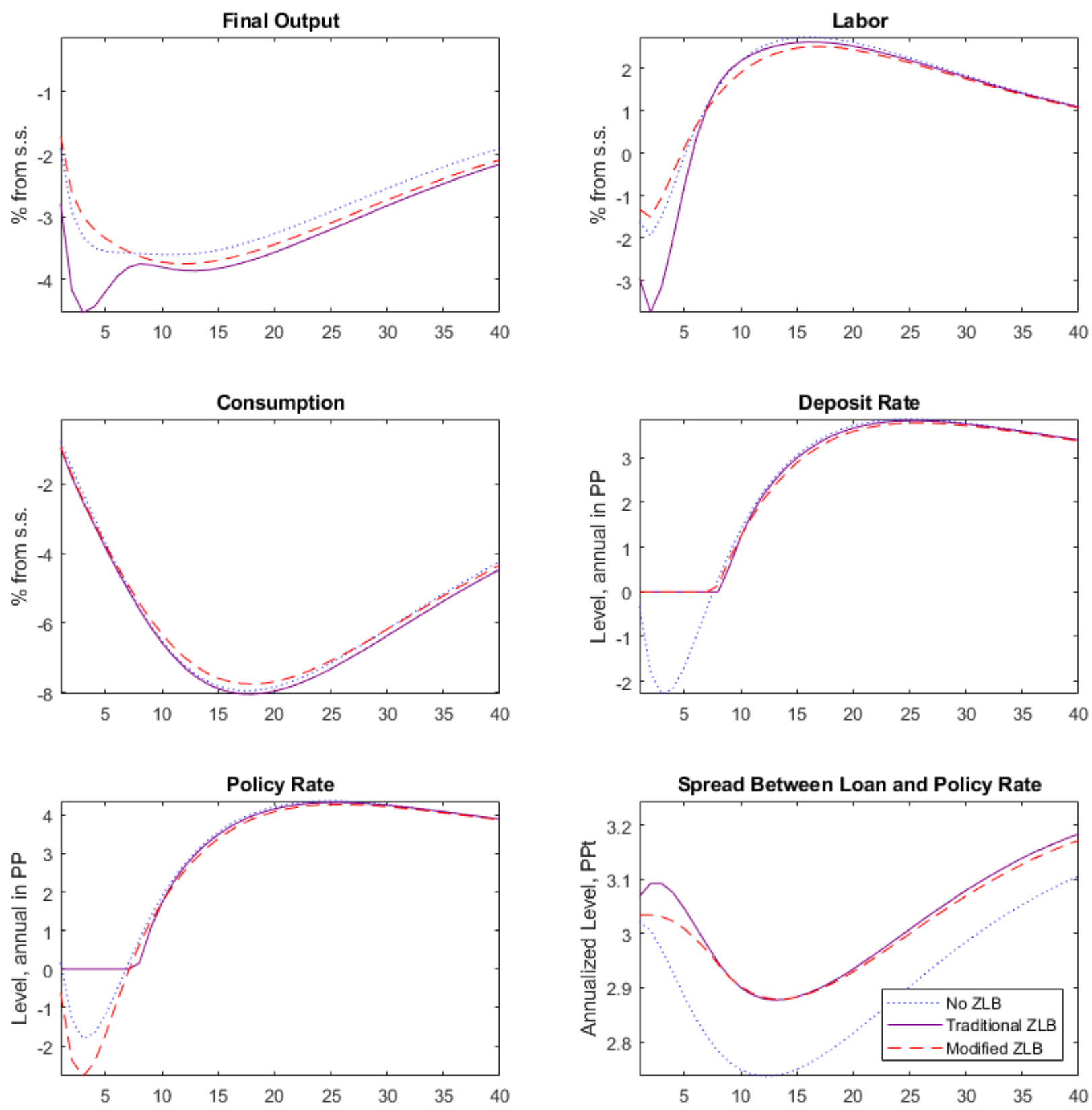

Figure 4: IRF's to a capital productivity shock

Notes: This figure depicts the IRF's of some of the main variables in the full model to a capital productivity shock under the "No ZLB" (blue dotted line), "Traditional ZLB" (purple solid line), and "Modified ZLB" (red dashed line) scenarios when $\kappa=12.5$ basis points. The $x$ axis is given in quarters and the $y$ axis is given in percent deviation from steady state for output, labor and consumption, and in annualized percentage points for the three rates (deposit rate, policy rate, and the spread between loan return and the policy rate). 

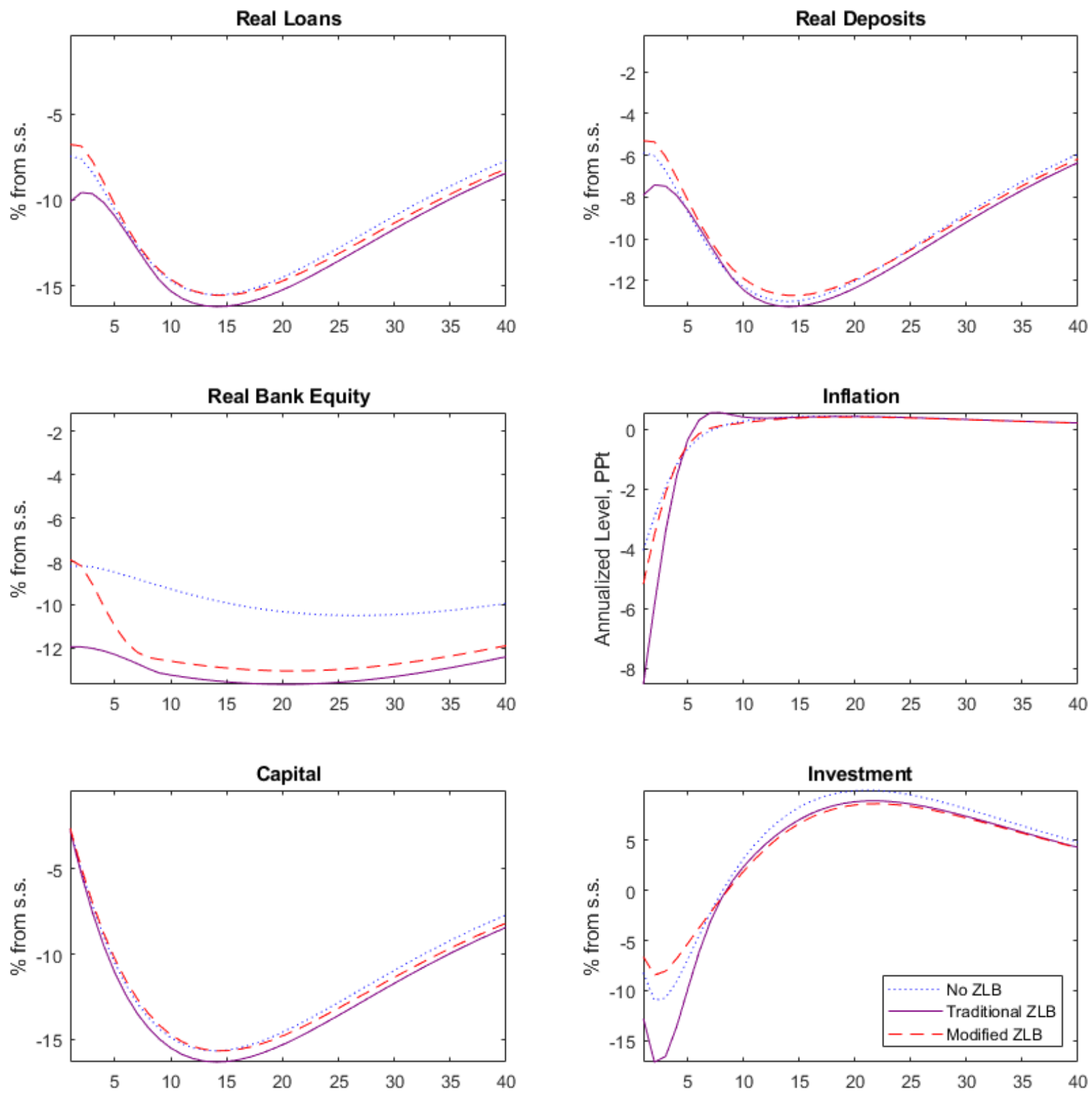

Figure 5: More IRF's to a capital productivity shock

Notes: This figure depicts the IRF's of some of the main variables in the full model to a capital productivity shock under the "No ZLB" (blue dotted line), "Traditional ZLB" (purple solid line), and "Modified ZLB" (red dashed line) scenarios when $\kappa=12.5$ basis points. The $x$ axis is given in quarters and the $y$ axis is given in percent deviation from steady state for everything but inflation (which is given in annualized percentage points). 
Importantly, bank equity starts off at a similar level in the No ZLB scenario and the Modified ZLB. However, after the periods when the policy rate is negative and the deposit rate is stuck at zero, bank equity in the Modified ZLB scenario falls by almost 4\%, and subsequently stays much closer to bank equity under the Traditional ZLB scenario. The loan spread starts at a similar level for the No ZLB and Modified ZLB scenario. However, after the deterioration of bank equity brought about by NNIR, the spread in the Modified ZLB increases relative to the one under the No ZLB scenario, and stays close to the one under the Traditional ZLB scenario.

When I compute the change in welfare from the recession (relative to a situation without the shock) I obtain that the welfare cost of the recession is 98 basis points (of lifetime welfare) under the No ZLB scenario, 101 basis points under the Modified ZLB scenario, and 104 basis points under the Traditional ZLB scenario. Hence, setting negative nominal interest rates in the Modified ZLB is helpful (in the sense that welfare falls less than in the Traditional ZLB), but is not equivalent to having no constraint at all (in the sense that welfare falls more than under the No ZLB scenario). The fact that the differences in welfare between the scenarios are small should not be of concern, this has to do with the fact that I am calculating lifetime welfare (using a low discount rate), whereas the effects of the recession are concentrated in a few quarters after the shock. The fact that the recession has significant welfare effects under the No ZLB scenario is mainly due to the fact that the shock affects capital productivity and is fairly long lived, which implies that it would have serious effects on welfare even under a perfectly efficient economy with no pricing frictions. ${ }^{36}$

In this section I have analyzed the response of the model economy to a recession under a given Taylor rule for the three scenarios described above, and a given value of $\kappa$. This exercise illustrates the differences between the Traditional and the Modified ZLB. However, given that the Modified ZLB seems to be the relevant empirical case, a more interesting exercise is to analyze the response of the model economy to the recession under different stances of monetary policy and different levels of $\kappa$, which is what I proceed to do next.

\section{$7 \quad$ Effects Under Different Monetary Policy Responses}

In this section I keep the size of the recessionary shock the same as in the previous section ( $\xi_{t}$ falls by $2.5 \%$ with persistence $\rho_{\xi}=0.9$ ), but focus on the effects of the recession just under the Modified ZLB scenario for different levels of $\kappa$ and different responses of monetary

\footnotetext{
${ }^{36}$ The fact that the recession has significant welfare effects under the No ZLB scenario is also due to the fact that the central bank does not know the natural rate of interest, divine coincidence does not hold, and the model has several new features compared to the traditional NK model.
} 


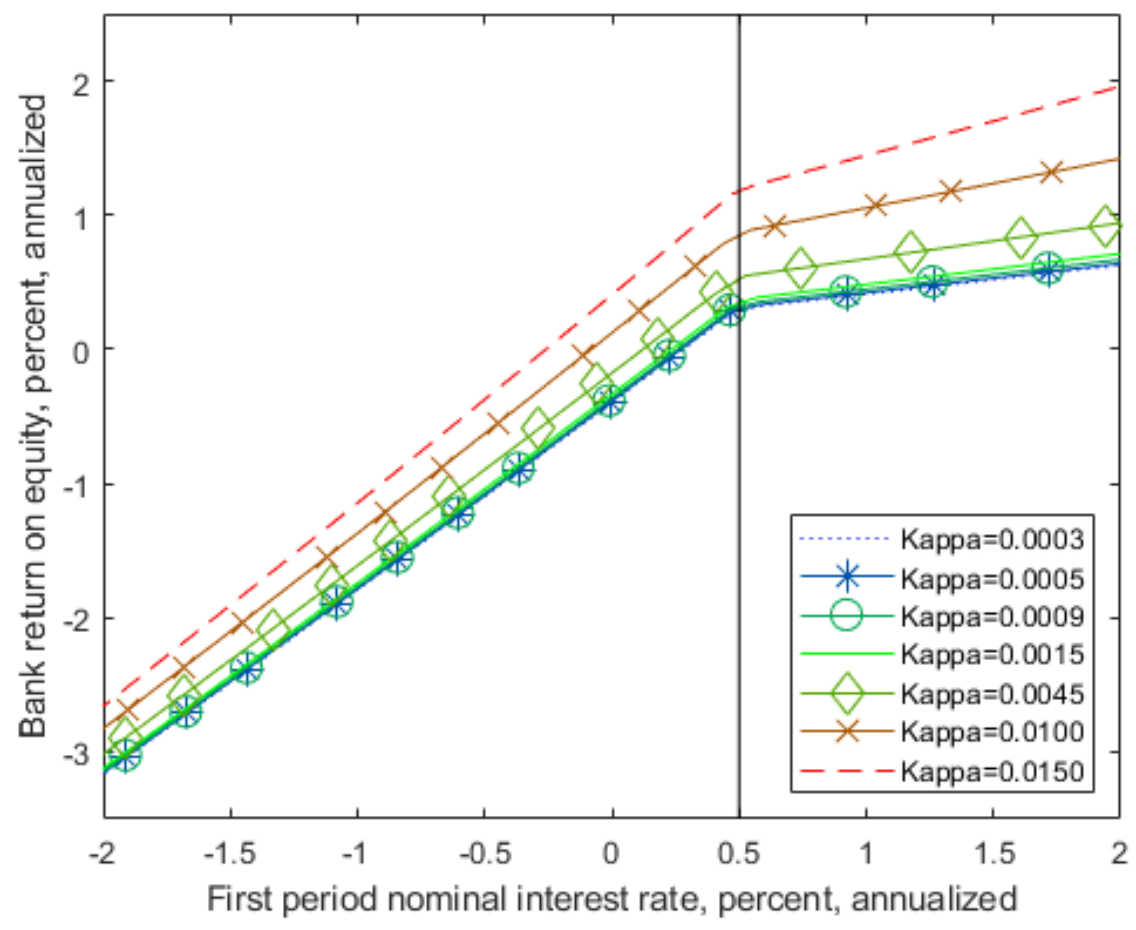

Figure 6: Bank ROE vs the policy rate

Notes: This figure plots bank return on equity as a function of the policy rate in the first period after the recessionary capital efficiency shock, for different values of the parameter $\kappa$, which parametrizes the cost of deviating from the target level of leverage.

policy. To analyze different monetary policy stances I look at the level of the policy rate in the first quarter after the recession hits. The central bank can decide to be accommodative by setting very low (including negative) rates, or more restrictive, by setting higher rates. The central bank has this choice in all periods, but to keep the analysis simple I focus on the first period and assume that from period 2 onwards, the central bank simply follows the Taylor rule. Since the Taylor rule has smoothing $\left(\rho_{i}=0.8\right)$ an accommodative stance is translated to the following periods anyway.

First I provide an example of the setup, by illustrating how Figure 2 works in the context of the full model. Figure 6 shows the policy rate in the first period after the shock, in percentage annualized terms, on the $x$ axis, and bank ROE in percentage annualized terms, on the $y$ axis. The different lines represent different values of $\kappa$, from 3 basis points to 150 basis points. Notice that this figure looks similar to Figure 2, even though there the setup for the banks was simpler and the amounts of deposits and loans were assumed to be independent of the policy rate. In other words, the mechanisms described in Section 2 survive in the richer general equilibrium setup described in Section 4. The kink in the figure occurs at the annualized value of $0.5 \%$, which is precisely the value of $\tilde{\iota}$ given the parameters 


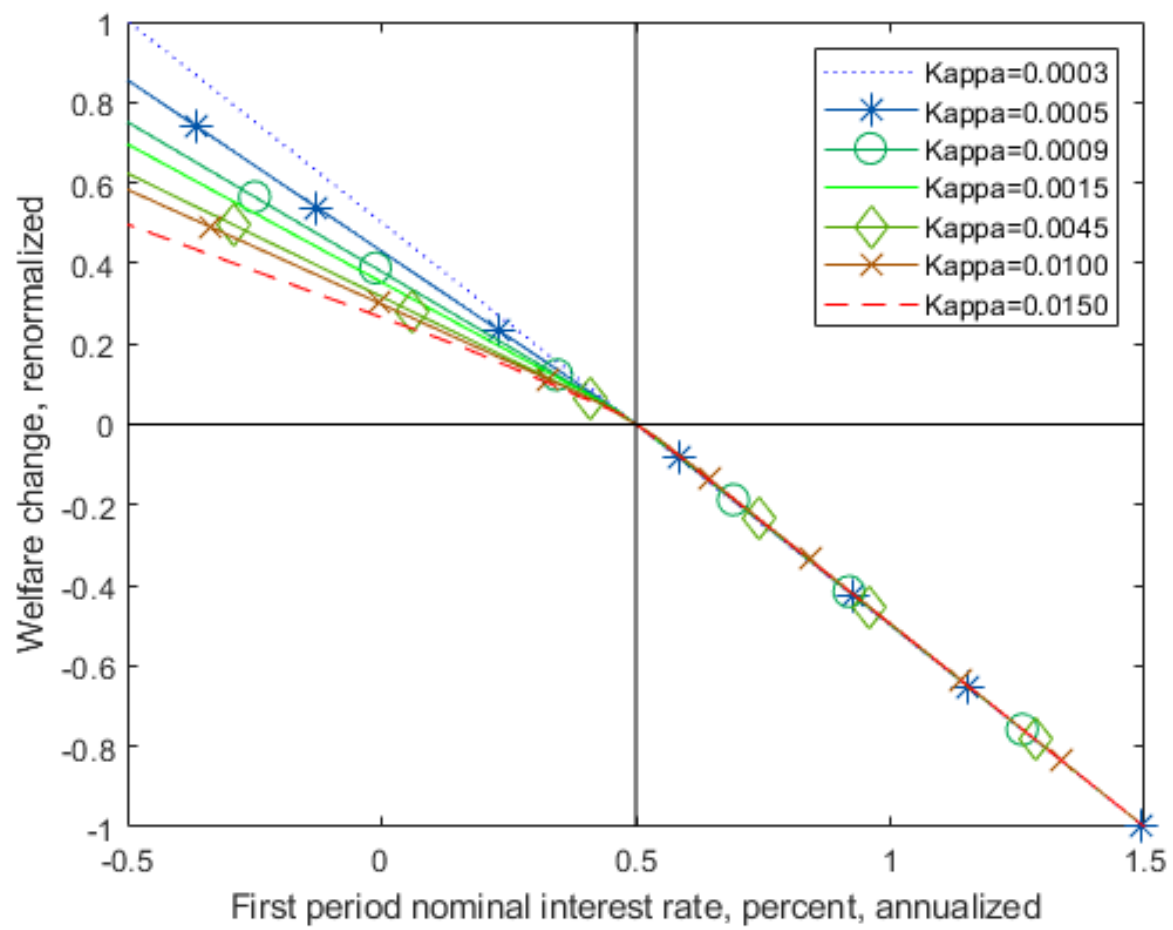

Figure 7: Welfare vs the policy rate

Notes: This figure plots a renormalized measured of the change in lifetime welfare as a function of the policy rate in the first period after the recessionary capital efficiency shock, for different values of the parameter $\kappa$. The welfare renormalization in the $y$ axis is such that the change in welfare is zero at $i=\tilde{\iota}$ (i.e., 50 basis points) and minus one at $i=1+\tilde{\iota}$ (i.e., 150 basis points). The baseline value of $\rho_{i}=0.8$ is used for the reaction of the policy rate to inflation in this figure.

in the baseline calibration. ${ }^{37}$

Figure 6 illustrates the fact that under the Modified ZLB the central bank has to worry about hurting bank's profits more than usual when setting negative rates (actually rates smaller than $0.5 \%$ ). This means that negative rates can be helpful or harmful for the economy as a whole, depending on how important bank equity is. This is studied in Figure 7, where the $x$ axis is the same as the one in Figure 6 , but the $y$ axis represents the change in welfare from its steady state value in percentage terms. The levels of the welfare measure are similar to the ones mentioned in Section 6 (i.e., a fall of between 98 and 104 basis points from the recession). However, in Figure 7 the values of the welfare measure have been renormalized so that the welfare change is zero at $\tilde{\iota}$ (which is illustrated by the vertical black line), and so that a one percentage point (annualized) fall in the policy rate from $1.5 \%$ to

\footnotetext{
${ }^{37}$ The section where $i<\underline{i}$ does not appear in Figure 6 because in the baseline calibration the value for $\underline{i}$ is around $-2.2 \%$ at the annual level.
} 


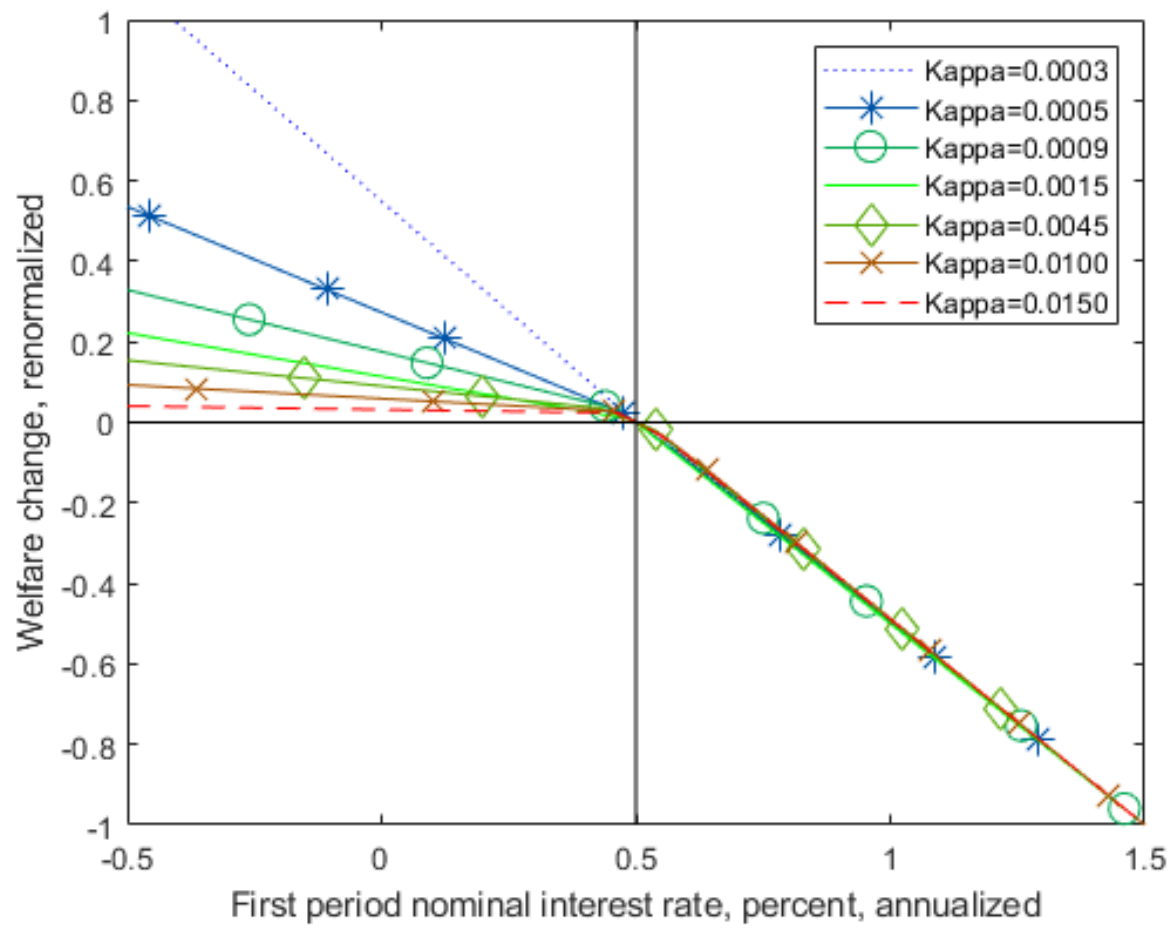

Figure 8: Welfare vs the policy rate, low $\rho_{i}$

Notes: This figure reproduces Figure 7, but uses a smaller value of $\rho_{i}=0.4$ for the reaction of the policy rate to inflation (instead of the 0.8 used in Figure 7).

$0.5 \%$ increases welfare in one unit. These two normalizations imply that the value of the $y$ axis when the policy rate equals $-0.5 \%$ measures the relative efficiency (in welfare terms) of a cut in the policy rate from $0.5 \%$ to $-0.5 \%$ compared to one from $1.5 \%$ to $0.5 \%$.

Figure 7 shows that for very low values of $\kappa$ (like 3 basis points), for which bank equity is almost irrelevant, the efficiency of monetary policy is basically the same under positive and negative rates. For very high values of $\kappa$ (like 150 basis points), for which bank equity is very important, the efficacy of monetary policy below $\tilde{\iota}$ is roughly half the one above $\tilde{\iota}$, since eroding bank profits is costly. For the baseline value of $\kappa=12.5$ basis points, the relative efficiency of monetary policy below $\tilde{\iota}$ is roughly $70 \%$ of the one above $\tilde{\iota}$.

It is important to point out that the values in Figure 7 depend on the value of $\rho_{i}$, while the other parameters do not have a big impact on the configuration of this figure. To illustrate the impact of $\rho_{i}$ on the results, Figure 8 reproduces Figure 7 but for $\rho_{i}=0.4$ instead of 0.8 . The lower the $\rho_{i}$, the faster the relative efficiency of monetary policy in negative territory falls with $\kappa$. With $\rho_{i}=0.4$ setting negative rates is basically a wash in terms of welfare when $\kappa=$ $1.5 \%$. For $\kappa$ 's even higher than $1.5 \%$, setting negative rates can be detrimental for welfare.

Why does a lower $\rho_{i}$ lead to lower relative efficiency of a cut in the policy rate below $\tilde{\iota}$ for all but the smallest $\kappa$ 's? Notice that the detrimental effects of NNIR on bank 
Table 6: Relative efficiency of monetary policy below $\tilde{\iota}$

\begin{tabular}{l|ccccc}
\hline \multicolumn{1}{c|}{$\rho_{i}$} & 0.4 & 0.5 & 0.6 & 0.7 & 0.8 \\
Country & & & & & \\
\hline \hline United States & $30.29 \%$ & $40.23 \%$ & $50.35 \%$ & $60.70 \%$ & $74.70 \%$ \\
Switzerland & $42.52 \%$ & $48.39 \%$ & $60.62 \%$ & $68.24 \%$ & $80.43 \%$ \\
United Kingdom & $56.36 \%$ & $60.63 \%$ & $71.81 \%$ & $77.37 \%$ & $86.40 \%$ \\
Europe & $65.21 \%$ & $68.77 \%$ & $78.32 \%$ & $82.66 \%$ & $89.60 \%$ \\
Japan & $69.20 \%$ & $72.42 \%$ & $81.08 \%$ & $84.88 \%$ & $90.89 \%$ \\
\hline \hline
\end{tabular}

Notes: This table provides the relative efficiency of monetary policy below $\tilde{\iota}$ (described in detail in the text) for different countries and values of $\rho_{i}$.

profitability are concentrated at the onset of the recession, when the policy rate is negative but the deposit rate is stuck at zero. Those periods are also when banks are specially vulnerable after having suffered a fall in their equity that originates from the decline in capital efficiency. Consequently, the negative effects of the contractionary bank net worth channel are concentrated in the few periods after the recession. With a low $\rho_{i}$ the beneficial effects of the expansionary bank lending channel are also concentrated in just a few periods; it is not as useful to hurt banks when they are the most vulnerable for just a few quarters of lower lending rates. By contrast, when $\rho_{i}$ is high, the beneficial effects of NNIR (expressed through the bank lending channel) extend for more periods, and this increases the relative efficiency of cuts in the policy rate below $\tilde{\iota}$. The takeaway is that hurting banks via NNIR is more useful if the low rate environment engendered by negative rates persists even after banks are starting to rebuild their equity.

After understanding the effects of $\kappa$ and $\rho_{i}$ on the efficiency of monetary policy in negative territory relative to that in positive territory, this can be related to the findings in Section 5.1 about the differences in $\kappa$ 's across countries. Table 6 presents the relative efficiency for the $\kappa$ 's estimated in Section 5.1, for different $\rho_{i}$ 's between 0.4 and 0.8. In that table countries are arranged from those with the higher $\kappa$ (United States, with $\kappa=49$ basis points at the annual level or 12.25 basis points at the quarterly level) to those with the lowest $\kappa$ (Japan, with $\kappa=17$ basis points annually or 4.25 basis points quarterly). The table shows that countries with a lower $\kappa$ suffer less from hurting their banks through NNIR and hence they end up having a higher relative efficiency of monetary policy below $\tilde{\iota}$. Additionally, within any country, the higher the $\rho_{i}$, the higher the relative efficiency of monetary policy below $\tilde{\iota}$. Since traditional estimates of $\rho_{i}$ tend to be above 0.7 , this justifies my range of values for the relative efficiency of negative rates between $60 \%$ and $90 \%$.

The previous table indicates that negative rates are relatively effective in regions like 
Japan or Europe and less so in countries like the United States. Notice that the model in this paper does not incorporate any open economy considerations like the ones discussed in Amador et al. (2017) which could be especially relevant for small open economies like Switzerland, and could move its relative position in the previous table. It is natural to assume that different countries, or a particular economy at different points in time, will have different values of $\kappa$. Therefore, the usefulness of setting negative rates to fight a deep recession will be specific to a particular context, and each country will have to estimate how useful NNIR would be in its particular context.

There are two reasons why the relative efficiency of a cut in the policy rate below $\tilde{\iota}$ is high despite the existence of the contractionary bank net-worth channel. First, the estimates of the importance of bank equity for lending are relatively small. This is informed by the fact that, after controlling for bank fixed effects, a decline in the equity of a particular bank does not have a big effect on that bank's lending amount or its loan rate. Second, in the full model, when the policy rate and the loan rate fall, aggregate loan demand increases and banks can switch reserves for loans, decreasing the impact of negative rates on their ROE (this mechanism is not operational in the static model of Section 2). This result has also been emphasized in an empirical context by Lopez et al. (2018) and Demiralp et al. (2017).

\section{Conclusion}

This paper argues that the ability to set negative policy rates while deposit rates are constrained to being nonnegative is different from not being subject to the ZLB altogether. The former scenario has implications for bank profitability, as it leads to a decline in banks' net worth, which can hinder investment and output growth. Central banks around the world must then be careful when setting negative policy rates and they must take steps to minimize their negative impact on banks' profits. However, the estimates in this paper for the relative efficiency of monetary policy in negative territory are relatively high, and indicate that the effect on commercial bank equity could be less detrimental than previously thought.

The main contribution of this paper is to provide a fully specified DSGE model where the question of negative interest rates and their effects on the economy, and bank profitability, can be studied. Relative to the few previous theoretical papers on NNIR, like Rognlie (2015) and Eggertsson et al. (2017), my paper can capture both beneficial and detrimental effects of negative rates in a monetary general equilibrium model with bank profitability concerns, and determine the relative efficiency of monetary policy in negative territory compared to that in positive territory.

The main finding of this paper is that lowering interest rates below zero can be less effective than lowering them in positive territory, since deposit rates remain stuck at zero 
and hence bank profits are squeezed. The efficiency of negative nominal rates is then very tightly linked to the importance of bank equity in the economy. For reasonable estimates of this parameter I conclude that the efficiency of monetary policy when the interest rate is below 50 basis points is between $60 \%$ and $90 \%$ of its value above 50 basis points. The importance of bank equity for lending, and for the overall economy, differs across countries due to different institutional settings, therefore the usefulness of monetary policy in negative territory also differs between countries. For Japan or the Euro Area setting NNIR seems to be relatively efficient, while the US has a lower efficiency.

While this paper strives to provide a comprehensive quantitative model to assess the effects of negative rates on the economy, it makes some simplifications in the interest of parsimony. In what follows I describe several extensions that could improve the realism of the model, but that are beyond the scope of this paper and are therefore left for future research. First, negative rates flatten the yield curve, so they might have effects on bank profitability that cannot be captured in the current framework, where all assets and liabilities have a duration of one period. Allowing for differences in the duration of financial instruments can lead to revaluation effects, as described in Brunnermeier and Koby (2017). Second, negative rates and the associated decline in loan rates can have an effect on the default probability of borrowers. As mentioned in Cœuré (2016), a fall in rates, even in negative territory, can decrease default probabilities, and this would increase the efficiency of monetary policy. Third, the fall in bank profitability can lead to a search for yield, and an increase in risk taking by banks, which can have a negative impact on financial stability and decrease the beneficial effects of negative rates. Fourth, the impact of NNIR on bank profitability depends on the exact fraction of a bank's reserves that are subject to the negative rate. This fraction varies if central banks set an exemption threshold for reserves below which commercial banks earn a zero interest rate. This is something that most central banks setting NNIR already do, by implementing a tiered structure of reserve remuneration.

Understanding the effects of negative rates is a critical task for economists and policy makers in the current environment of persistently low global interest rates. Having a realistic framework that can incorporate both the beneficial and detrimental aspects of negative rates is a good start. Extending that framework to allow for even more realistic aspects of negative rates is an important next step. 


\section{References}

Alsterlind, J., H. Armelius, D. Forsman, B. Jonsson, and A.-L. Wretman (2015): "How far can the repo rate be cut?" Economic Commentaries 11, Sveriges Riksbank.

Amador, M., J. Bianchi, L. Bocola, and F. Perri (2017): "Exchange Rate Policies at the Zero Lower Bound," NBER Working Papers 23266, National Bureau of Economic Research, Inc.

Ampudia, M. And S. Van den Heuvel (2017): "Monetary Policy and Bank Equity Values in a Time of Low Interest Rates," Unpublished manuscript.

Anderson, S. P., A. de Palma, And J.-F. Thisse (1988): "The CES and the logit: Two related models of heterogeneity," Regional Science and Urban Economics, 18, 155-164.

Anderson, S. P., A. D. Palma, And J.-F. Thisse (1989): "Demand for Differentiated Products, Discrete Choice Models, and the Characteristics Approach," Review of Economic Studies, 56, 21-35.

Andrews, D. W. K. (1993): "Tests for Parameter Instability and Structural Change with Unknown Change Point," Econometrica, 61, 821-856.

Bank of Japan (2016): "Key Points of Today's Policy Decisions," Tech. rep., Bank of Japan.

Basten, C. And M. Mariathasan (2018): "How Banks Respond to Negative Interest Rates: Evidence from the Swiss Exemption Threshold," CESifo Working Paper Series 6901, CESifo Group Munich.

Bean, C. (2013): "Note on Negative Interest Rates for Treasury Committee," Tech. rep., Bank of England.

Bech, M. And A. Malkhozov (2016): "How have central banks implemented negative policy rates?" Quarterly review, BIS.

Berger, A. N., A. Demirguç-Kunt, R. Levine, and J. G. Haubrich (2004): "Bank Concentration and Competition: An Evolution in the Making," Journal of Money, Credit and Banking, 36, 433-451. 
Bernanke, B. S., M. Gertler, and S. Gilchrist (1999): "The financial accelerator in a quantitative business cycle framework," in Handbook of Macroeconomics, ed. by J. B. Taylor and M. Woodford, Elsevier, vol. 1 of Handbook of Macroeconomics, chap. 21, 13411393.

Borio, C., L. Gambacorta, and B. Hofmann (2017): "The influence of monetary policy on bank profitability," International Finance, 20, 48-63.

Brunnermeier, M. K. And Y. Koby (2017): "The Reversal Interest Rate: An Effective Lower Bound on Monetary Policy," Unpublished manuscript.

Campbell, J. Y. (1987): "Money Announcements, the Demand for Bank Reserves, and the Behavior of the Federal Funds Rate within the Statement Week," Journal of Money, Credit and Banking, 19, 56-67.

Chay, K. And K. Munshi (2015): "Black Networks After Emancipation: Evidence from Reconstruction and the Great Migration," mimeo.

Chetty, R., A. Guren, D. Manoli, and A. Weber (2011): "Are Micro and Macro Labor Supply Elasticities Consistent? A Review of Evidence on the Intensive and Extensive Margins," American Economic Review, 101, 471-475.

Christiano, L. and D. Ikeda (2014): "Leverage Restrictions in a Business Cycle Model," in Macroeconomic and Financial Stability: challenges for Monetary Policy, ed. by S. Bauducco, L. Christiano, and C. Raddatz, Central Bank of Chile, vol. 19 of Central Banking, Analysis, and Economic Policies Book Series, chap. 7, 215-216.

Christiano, L. J., M. Eichenbaum, and C. L. Evans (2005): "Nominal Rigidities and the Dynamic Effects of a Shock to Monetary Policy," Journal of Political Economy, 113, $1-45$.

Claessens, S., N. Coleman, And M. S. Donnelly (2017): "Low-For-Long; Interest Rates and Banks' Interest Margins and Profitability: Cross-Country Evidence," International Finance Discussion Papers 1197, Board of Governors of the Federal Reserve System (U.S.).

Ceeuré, B. (2016): "Assessing the implications of negative interest rates," Speech at the Yale Financial Crisis Forum, Yale School of Management, New Haven, 28 July 2016.

Curdia, V. And M. Woodford (2015): "Credit Frictions and Optimal Monetary Policy," NBER Working Papers 21820, National Bureau of Economic Research, Inc. 
DANMARKS NATiOnALBAnK (2015): "Negative interest rates and their impact on credit institutions earnings," Tech. Rep. 1st Half 2015, Danmarks Nationalbank.

Degryse, H. And S. Ongena (2008): "Competition and Regulation in the Banking Sector: A Review of the Empirical Evidence on the Sources of Bank Rents," in Handbook of Financial Intermediation and Banking, ed. by A. V. Thakor and A. W. Boot, San Diego: Elsevier, Handbooks in Finance, 483-554.

Demiralp, S., J. Eisenschmidt, And T. Vlassopoulos (2017): "Negative Interest Rates, Excess Liquidity and Bank Business Models: Banks' Reaction to Unconventional Monetary Policy in the Euro Area," Koç University-TUSIAD Economic Research Forum Working Papers 1708.

Drechsler, I., A. Savov, And P. Schnabl (2017): "The Deposits Channel of Monetary Policy," The Quarterly Journal of Economics, 132, 1819-1876.

(2018): "Banking on Deposits: Maturity Transformation without Interest Rate Risk," NBER Working Papers 24582, National Bureau of Economic Research, Inc.

Eggertsson, G., R. Juelsrud, And E. Wold (2017): "Are Negative Nominal Interest Rates Expansionary?" Working Paper 24039, National Bureau of Economic Research.

Eisenschmidt, J. And F. Smets (2018): "Negative interest rates: Lessons from the Euro Area," mimeo, ECB.

Gerali, A., S. Neri, L. Sessa, and F. M. Signoretti (2010): "Credit and Banking in a DSGE Model of the Euro Area," Journal of Money, Credit and Banking, 42, 107-141.

Gertler, M. AND P. Karadi (2011): "A model of unconventional monetary policy," Journal of Monetary Economics, 58, 17-34.

Gertler, M. And N. Kiyotaki (2010): "Financial Intermediation and Credit Policy in Business Cycle Analysis," in Handbook of Monetary Economics, ed. by B. M. Friedman and M. Woodford, Elsevier, vol. 3 of Handbook of Monetary Economics, chap. 11, 547-599.

Guerrieri, L. AND M. Iacoviello (2015): "OccBin: A toolkit for solving dynamic models with occasionally binding constraints easily," Journal of Monetary Economics, 70, 22-38.

Hansen, B. E. (1999): "Threshold effects in non-dynamic panels: Estimation, testing, and inference," Journal of Econometrics, 93, 345-368. 
Jackson, H. (2015): "The International Experience with Negative Policy Rates," Tech. Rep. 2015-13, Bank of Canada.

Kiley, M. T. And J. M. Roberts (2017): "Monetary Policy in a Low Interest Rate World," Brookings Papers on Economic Activity, 48, 317-372.

Kiyotaki, N. And J. Moore (2012): "Liquidity, Business Cycles, and Monetary Policy," NBER Working Papers 17934, National Bureau of Economic Research, Inc.

Laeven, L. And F. Valencia (2013): "Systemic Banking Crises Database," IMF Economic Review, 61, 225-270.

Lopez, J. A., A. K. Rose, And M. M. Spiegel (2018): "Why Have Negative Nominal Interest Rates Had Such a Small Effect on Bank Performance? Cross Country Evidence," Working Paper 25004, National Bureau of Economic Research.

McFadden, D. (1973): "Conditional logit analysis of qualitative choice behavior," Frontiers in Econometrics, 105-142.

Reinhart, C. M. and K. S. Rogoff (2014): "Recovery from Financial Crises: Evidence from 100 Episodes," American Economic Review, 104, 50-55.

Rognlie, M. (2015): "What Lower Bound? Monetary Policy with Negative Interest Rates," Mimeo.

Romer, C. D. And D. H. Romer (2017): "New Evidence on the Aftermath of Financial Crises in Advanced Countries," American Economic Review, 107, 3072-3118.

Smets, F. And R. Wouters (2007): "Shocks and Frictions in US Business Cycles: A Bayesian DSGE Approach," American Economic Review, 97, 586-606.

Sveen, T. and L. Weinke (2005): "New perspectives on capital, sticky prices, and the Taylor principle," Journal of Economic Theory, 123, 21-39.

The Economist (2016): "Negative Creep," The Economist Magazine. Interest Rates. February 4, 2016.

Woodford, M. (2005): "Firm-Specific Capital and the New Keynesian Phillips Curve," International Journal of Central Banking, 1. 


\section{For Online Publication}

\section{Appendices}

\section{A Bank Related Derivations}

\section{A.1 Loan Market}

Here I solve the problem of an agent (in the model described in Section 4 it would represent a firm) that has to decide how much to borrow from each bank subject to a CES constraint. As discussed by GNSS, and in Appendix A.3, there are several ways to justify the CES constraint, some of them are: switching costs, asymmetric information, menu costs and regulatory restrictions. Agent $s$ seeks a total amount of real loans equal to $l_{t}(s)$, he borrows an amount $l_{t}(s, j)$ from each bank $j$ and faces the following constraint:

$$
\left[\int_{0}^{1} l_{t}(s, j)^{\left(\varepsilon_{t}^{l}-1\right) / \varepsilon_{t}^{l}} d j\right]^{\varepsilon_{t}^{l} /\left(\varepsilon_{t}^{l}-1\right)} \geq l_{t}(s)
$$

which indicates that the loans he gets from individual banks are aggregated via a CES aggregator into the total loans he obtains. $\varepsilon_{t}^{l}$ is the elasticity of substitution between banks, which for now I allow to vary with time. This elasticity will be assumed to be greater than one, as traditional in the monopolistic competition framework. Each bank charges the agent a net interest rate $i_{t}^{l}(j)$. Demand for this agent can be derived from minimizing over $l_{t}(s, j)$ the total repayment (including principal) due to the continuum of banks $j$ :

$$
\int_{0}^{1}\left(1+i_{t}^{l}(j)\right) l_{t}(s, j) d j
$$

subject to the constraint given above. I assume that loan customers minimize total repayment to banks $\left(1+i^{l}\right)$ instead of net interest payments $\left(i^{l}\right)$. Total payments are more suitable that interest payments, since in the full dynamic model there is a time difference between when loans are taken out and when they are repaid. The gross formulation also leads to expressions that are a lot more suitable in a ZLB context.

The Lagrangian for this problem is:

$$
\mathcal{L}=\int_{0}^{1}\left(1+i_{t}^{l}(j)\right) l_{t}(s, j) d j-\lambda\left(\left[\int_{0}^{1} l_{t}(s, j)^{\left(\varepsilon_{t}^{l}-1\right) / \varepsilon_{t}^{l}} d j\right]^{\varepsilon_{t}^{l} /\left(\varepsilon_{t}^{l}-1\right)}-l_{t}(s)\right)
$$


The F.O.C. w.r.t. $l_{t}(s, j)$ yields:

$$
l_{t}(s, j)=\left(\frac{1+i_{t}^{l}(j)}{\lambda}\right)^{-\varepsilon_{t}^{l}} l_{t}(s)
$$

where:

$$
\lambda=\left(\int_{0}^{1}\left(1+i_{t}^{l}(j)\right)^{1-\varepsilon_{t}^{l}} d j\right)^{\frac{1}{1-\varepsilon_{t}^{l}}} .
$$

So, denoting $1+i_{t}^{l} \equiv \lambda$, one can write demand for a particular bank $j$ coming from client $s$ as:

$$
l_{t}(s, j)=\left(\frac{1+i_{t}^{l}(j)}{1+i_{t}^{l}}\right)^{-\varepsilon_{t}^{l}} l_{t}(s)
$$

\section{A.2 Deposit Market}

Now I analyze the problem of an agent that instead of needing to borrow from banks wants to lend to banks via deposits (this will represent households in the full model). Assume that households want to maximize total repayment from deposits subject to total deposits (as aggregated through a CES aggregator) being smaller or equal to the amount available to deposit. In this case demand by agent $s$ seeking an amount of real deposits equal to $d_{t}(s)$ can be derived from maximizing over $d_{t}(s, j)$ the total amount obtained from the continuum of banks $j$ :

$$
\int_{0}^{1}\left(1+i_{t}^{d}(j)\right) d_{t}(s, j) d j
$$

subject to:

$$
\left[\int_{0}^{1} d_{t}(s, j)^{\left(\varepsilon_{t}^{d}-1\right) / \varepsilon_{t}^{d}} d j\right]^{\varepsilon_{t}^{d} /\left(\varepsilon_{t}^{d}-1\right)} \leq d_{t}(s)
$$

where the elasticity $\varepsilon_{t}^{d}$ is required to be smaller than -1 , which means that the exponent of the terms inside the integral is greater than one, implying this function is convex. The Lagrangian for this problem is:

$$
\mathcal{L}=\int_{0}^{1}\left(1+i_{t}^{d}(j)\right) d_{t}(s, j) d j-\lambda\left(\left[\int_{0}^{1} d_{t}(s, j)^{\left(\varepsilon_{t}^{d}-1\right) / \varepsilon_{t}^{d}} d j\right]^{\varepsilon_{t}^{d} /\left(\varepsilon_{t}^{d}-1\right)}-d_{t}(s)\right) .
$$


This is exactly the same problem as in the loan case, which means that the solution will be the same. In this case the solution can be written as:

$$
d_{t}(s, j)=\left(\frac{1+i_{t}^{d}(j)}{1+i_{t}^{d}}\right)^{-\varepsilon_{t}^{d}} d_{t}(s) .
$$

But remember that now $\varepsilon_{t}^{d}$ is negative (in particular smaller than -1 ), which means that customers put more deposits in a particular bank the higher that bank's deposit rate is.

\section{A.3 Microfoundation of Bank CES}

Here I provide simple microfoundations for the use of a CES aggregator across individual banks. One possible objection to such a setup could be that it is implausible that all consumers borrow from all banks, since a more accurate representation of reality probably is that each consumer borrows from one (or at most two) banks. Here I show how a model where each consumer chooses to borrow from a single bank and is subject to an stochastic utility of borrowing from each bank can deliver the same demand for loans as the one that emerges from the CES approach. The different stochastic utilities across individuals of borrowing from specific banks can represent proximity, switching costs, tastes, or asymmetric information. The presentation is inspired by Anderson et al. (1988) and Anderson et al. (1989).

Assume that there is an individual consumer that lives for two periods, denoted 0 and 1. This consumer has a total income of $\bar{Y}$ in the second period and he can consume in both periods. To consume in period 1 is easy for this consumer, he can do it directly, but to consume in period 0 he most borrow against his future income $\bar{Y}$ through one of a continuum of banks between zero and one (indexed with $j$ ). The decision process of this consumer happens in two stages. In the first stage, the consumer decides which bank he wants to borrow from, and in the second stage he chooses the amount he wants to borrow. Suppose that the outcome of the first stage is that the consumer decides to borrow from bank $j$. Assume that the direct utility function of the consumer conditional on his choice of bank $j$ is:

$$
U\left(C_{0 j}, C_{1}\right)=\ln \left(C_{0 j}\right)+\beta \ln \left(C_{1}\right),
$$

Where $\beta$ is the discount factor between periods. The first period, second period, and aggregate budget constraints of the consumer (again conditional on the choice of bank $j$ ) are:

$$
\begin{aligned}
C_{0 j} & =B_{j} \\
C_{1} & =\bar{Y}-\left(1+i_{j}^{l}\right) B_{j} \\
\left(1+i_{j}^{l}\right) C_{0 j}+C_{1} & =\bar{Y},
\end{aligned}
$$


where $1+i_{j}^{l}$ is the interest rate charged between periods 0 and 1 by bank $j$ (which is known by the consumer with certainty). The solution to this problem is:

$$
C_{0 j}=\frac{\bar{Y}}{1+\beta} \frac{1}{1+i_{j}^{l}}, \quad C_{1}=\frac{\beta}{1+\beta} \bar{Y}
$$

and the indirect utility function conditional on borrowing from bank $j$ is:

$$
v\left(1+i_{j}^{l}\right)=(1+\beta)(\ln (\bar{Y})-\ln (1+\beta))+\beta \ln (\beta)-\ln \left(1+i_{j}^{l}\right) .
$$

Then, as in Anderson et al. (1988), assume that the first stage (the bank choice stage), is described by a stochastic utility approach:

$$
V_{i}=v\left(1+i_{j}^{l}\right)+\mu \varepsilon_{j}
$$

where $\mu$ is a positive constant and $\varepsilon_{j}$ is a random variable with zero mean and unit variance. Assuming that the $\varepsilon_{j}$ random variables are independently and identically distributed with type-1 extreme value distribution (Gumbel), then the probability for a consumer of choosing bank $j$ is given by:

$$
\operatorname{Pr}(j)=\operatorname{Pr}\left(V_{j}=\max _{r} V_{r}\right)=\frac{e^{v\left(1+i_{j}^{l}\right) / \mu}}{\int_{0}^{1} e^{v\left(1+i_{r}^{l}\right) / \mu} d r}=\frac{\left(1+i_{j}^{l}\right)^{-\frac{1}{\mu}}}{\int_{0}^{1}\left(1+i_{r}^{l}\right)^{-\frac{1}{\mu}} d r},
$$

as in McFadden (1973). Substituting $1 / \mu$ for $\varepsilon^{l}-1$ (which is positive since $\varepsilon^{l}>1$ ) the previous expression can be rewritten as:

$$
\operatorname{Pr}(j)=\frac{\left(1+i_{j}^{l}\right)^{1-\varepsilon^{l}}}{\int_{0}^{1}\left(1+i_{r}^{l}\right)^{1-\varepsilon^{l}} d r}=\left(\frac{1+i_{j}^{l}}{1+i^{l}}\right)^{1-\varepsilon^{l}}
$$

where $i^{l}$ is the aggregate loan rate defined in Appendix A.1. Multiplying $C_{0 j}$ by this probability one obtains:

$$
C_{0 j} \operatorname{Pr}(j)=\frac{\bar{Y}}{1+\beta} \frac{1}{1+i^{l}}\left(\frac{1+i_{j}^{l}}{1+i^{l}}\right)^{-\varepsilon^{l}}
$$

Interpret $\frac{\bar{Y}}{1+\beta} \frac{1}{1+i^{l}}$ as aggregate borrowing and denote it $L$. Additionally, interpret $C_{0 j} \operatorname{Pr}(j)$ as the amount borrowed from bank $j$ once the whole population of consumers are taken into 
account, and denote this by $L_{j}$. Then:

$$
L_{j}=\left(\frac{1+i_{j}^{l}}{1+i^{l}}\right)^{-\varepsilon^{l}} L,
$$

which is the same expression that one obtains directly from the CES aggregator. This shows that a heterogeneous borrower approach with stochastic utility and extreme value shocks works as a microfoundation for the CES aggregator in the case of a homogeneous borrower. A similar process can be followed to microfound deposit supply.

\section{A.4 Solution to the Simple Bank Problem}

Recall the following maximization problem for an individual bank $j$ (which is one out of a continuum of identical banks between zero and one) described in Section 2:

$$
\begin{aligned}
& \max _{i_{j}^{l}, L_{j}, i_{j}^{d}, D_{j}, H_{j}}\left(1+i_{j}^{l}\right) L_{j}+(1+i) H_{j}-\left(1+i_{j}^{d}\right) D_{j} \\
& L_{j}=\left(\frac{1+i_{j}^{l}}{1+i^{l}}\right)^{-\varepsilon^{l}} L \\
& D_{j}= \begin{cases}\left(\frac{1+i_{j}^{d}}{1+i^{d}}\right)^{-\varepsilon^{d}} D & \text { if } i_{j}^{d} \geq 0 \\
0 & \text { if } i_{j}^{d}<0\end{cases} \\
& L_{j}+H_{j}=F_{j}+D_{j} \\
& H_{j} \geq 0 .
\end{aligned}
$$

Proposition 1: Consider the bank problem described in equation (21), additionally assume that $\varepsilon^{l}>1, \varepsilon^{d}<-1$, and $D>L>F$. The solution is described by several regimes that apply depending on the level of the policy rate $i$. Regime 1 applies when $i \geq \tilde{\iota}$, Regime 2 applies when $\underline{i} \leq i<\tilde{\imath}$, Regime $3 A$ applies when $\underline{\underline{i}} \leq i<\underline{i}$, and Regime $3 B$ applies when $i<\underline{\underline{i}}$. The thresholds are given by:

$$
\begin{aligned}
\tilde{\iota} & =-\frac{1}{\varepsilon^{d}}>0 \\
\underline{i} & =\frac{\left(\frac{L}{F}\right)^{\frac{1}{\varepsilon^{l}}} \frac{\varepsilon^{l}}{\varepsilon^{l}-1}-\frac{1}{\varepsilon^{l}-1} \frac{L}{F}-1}{1+\frac{1}{\varepsilon^{l}-1} \frac{L}{F}+\frac{D}{F}-\left(\frac{L}{F}\right)^{\frac{1}{\varepsilon^{l}}} \frac{\varepsilon^{l}}{\varepsilon^{l}-1}}<0 \\
\underline{\underline{i}} & =\frac{\left(1+\frac{D}{F}\right)^{\frac{1}{\varepsilon^{l}}}-1-\frac{D}{\varepsilon^{l} F}}{1+\frac{D}{F}-\left(1+\frac{D}{F}\right)^{\frac{1}{\varepsilon^{l}}}}<\underline{i},
\end{aligned}
$$


Regime 1: In this regime all banks obtain an amount of deposits $D_{j}=D$, lend out an amount $L_{j}=L$, and hold an amount of reserves $H_{j}=F+D-L>0$. All banks set the same loan rate and deposit rate, whose expressions are given by:

$$
1+i_{j}^{l}=\frac{\varepsilon^{l}}{\varepsilon^{l}-1}(1+i), \quad 1+i_{j}^{d}=\frac{\varepsilon^{d}}{\varepsilon^{d}-1}(1+i)
$$

Bank return on equity is given by:

$$
R O E_{j} \equiv \frac{F_{j}^{\prime}}{F_{j}}-1=(1+i)\left(1+\frac{1}{\varepsilon^{l}-1} \frac{L}{F}+\frac{1}{1-\varepsilon^{d}} \frac{D}{F}\right)-1 .
$$

Regime 2: In this regime all banks obtain an amount of deposits $D_{j}=D$, lend out an amount $L_{j}=L$, and hold an amount of reserves $H_{j}=F+D-L>0$. All banks set the same loan rate and deposit rate, whose expressions are given by:

$$
1+i_{j}^{l}=\frac{\varepsilon^{l}}{\varepsilon^{l}-1}(1+i), \quad i_{j}^{d}=0
$$

Bank return on equity is given by:

$$
R O E_{j}=\frac{1}{\varepsilon^{l}-1} \frac{L}{F}+i\left(1+\frac{1}{\varepsilon^{l}-1} \frac{L}{F}+\frac{D}{F}\right) .
$$

Regime 3A: In this regime a fraction of banks $\mu(i)$ sets a negative deposit rate, doesn't obtain any deposits and lends out its equity at the loan rate:

$$
1+i_{N D}^{l}=\left(\frac{F}{L}\right)^{-\frac{1}{\varepsilon}}\left(1+i^{l}\right)
$$

where ND stands for "No Deposits" and $i^{l}$ is the aggregate loan rate, given by:

$$
1+i^{l}=\frac{\varepsilon^{l}}{\varepsilon^{l}-1}(1+i)\left(\frac{1-\mu(i)}{1-\mu(i)(F / L)^{\frac{\varepsilon^{l}-1}{\varepsilon^{l}}}}\right)^{\frac{1}{1-\varepsilon^{l}}} .
$$

These banks don't keep any reserves at the central bank. The remaining fraction of banks $(1-\mu(i))$ sets a zero deposit rate and obtains an amount of deposits $D$, lends out an amount:

$$
L_{D}=\left(\frac{L^{\frac{\varepsilon-1}{\varepsilon}}-\mu(i) F^{\frac{\varepsilon-1}{\varepsilon}}}{1-\mu(i)}\right)^{\frac{\varepsilon}{\varepsilon-1}}
$$


at a rate: $1+i_{D}^{l}=\frac{\varepsilon^{l}}{\varepsilon^{l}-1}(1+i)$, and keeps an amount of reserves at the central bank given by: $H_{D}=F+D-L_{D}$. The fraction of banks not taking deposits $\mu(i)$ is defined implicitly by the following expression:

$$
\frac{\varepsilon^{l}}{\varepsilon^{l}-1}(1+i) \frac{L_{D}}{L}\left(\left(\frac{L_{D}}{L}\right)^{\frac{1-\varepsilon^{l}}{\varepsilon^{l}}}-1\right)=\mu \cdot(1+i) \cdot\left(\frac{F}{L}+\frac{D}{L}-\frac{L_{D}}{L}\right)-\mu \cdot \frac{D}{L} .
$$

Regime 3B: In this regime a fraction of banks $\mu^{*}$ sets a negative deposit rate, doesn't obtain any deposits and just lends out its equity at the loan rate $i_{N D}^{l}$. These variables are given by:

$$
\begin{aligned}
\mu^{*} & =\frac{(1+D / F)^{\frac{\varepsilon^{l}-1}{\varepsilon^{l}}}-(L / F)^{\frac{\varepsilon^{l}-1}{\varepsilon^{l}}}}{(1+D / F)^{\frac{\varepsilon^{l}-1}{\varepsilon^{l}}}-1} \\
1+i_{N D}^{l} & =\frac{\frac{D}{F}}{\left(1+\frac{D}{F}\right)^{\frac{\varepsilon^{l}-1}{\varepsilon^{l}}}-1},
\end{aligned}
$$

These banks don't keep any reserves at the central bank. The remaining fraction of banks $\left(1-\mu^{*}\right)$ sets a zero deposit rate and obtains an amount of deposits $D$, lends out an amount $L_{D}=F+D$ at a rate $i_{D}^{l}$, where:

$$
1+i_{D}^{l}=\frac{\frac{1}{F / D+1}}{1-\left(1+\frac{D}{F}\right)^{\frac{1-\varepsilon^{l}}{\varepsilon^{l}}}}
$$

These banks also don't keep any reserves at the central bank. In this case the aggregate loan rate is given by:

$$
1+i^{l}=\frac{\frac{D}{F}\left(\frac{F}{L}\right)^{\frac{1}{\varepsilon^{l}}}}{\left(1+\frac{D}{F}\right)^{\frac{\varepsilon^{l}-1}{\varepsilon^{l}}}-1}
$$

Proof: First verify the claims about the thresholds. Since $\varepsilon^{d}<0$ it is obvious that $\tilde{\iota}>0$. To prove that $\underline{i}$ is negative I will prove that the denominator is positive and the numerator is negative. First the denominator:

$$
1+\frac{1}{\varepsilon^{l}-1} \frac{L}{F}+\frac{D}{F}-\left(\frac{L}{F}\right)^{\frac{1}{\varepsilon^{l}}} \frac{\varepsilon^{l}}{\varepsilon^{l}-1}>\frac{1}{\varepsilon^{l}-1} \frac{L}{F}\left(1-\left(\frac{L}{F}\right)^{\frac{1-\varepsilon^{l}}{\varepsilon^{l}}}\right)+\frac{D}{F}-\left(\frac{L}{F}\right)^{\frac{1}{\varepsilon^{l}}}
$$

The last expression is positive because $D / F>L / F>(L / F)^{1 / \varepsilon^{l}}$ and $L / F>1$ which implies $\left(\frac{L}{F}\right)^{\frac{1-\varepsilon^{l}}{\varepsilon^{l}}}<1$. The numerator of $\underline{i}$ is negative, to see this write it as a function of $L / F$, 
numerator $_{\underline{i}}=f(L / F)$, where:

$$
f(x)=x^{1 / \varepsilon^{l}} \frac{\varepsilon^{l}}{\varepsilon^{l}-1}-\frac{x}{\varepsilon^{l}-1}-1
$$

Since the second derivative is always negative for $x>1$, the function is maximized where $f^{\prime}(x)=0$, which is at $x=1$. Additionally $f(1)=0$, which implies that the function is always negative for values of $x$ greater than 1 . Since $L / F>1$ this means that the numerator of $\underline{i}$ is always negative. In the explanation for Regime $3 \mathrm{~A}$ I will prove that $\underline{i}>\underline{\underline{i}}$. Now I proceed to prove the claims about the regimes.

Regime 1: In this regime both rates are set according to their unconstrained F.O.C.s, which due to the concavity of the objective function guarantees that banks achieve a maximum. The loan and deposit subproblems are independent, due to the presence of positive reserves. The unconstrained loan subproblem is to maximize $\left(i_{j}^{l}-i\right) L_{j}$ subject to loan demand. The solution is given by:

$$
1+i_{j}^{l}=\frac{\varepsilon^{l}}{\varepsilon^{l}-1}(1+i)
$$

Similarly, the unconstrained deposit subproblem is to maximize $\left(i-i_{j}^{d}\right) D_{j}$ subject to deposit supply. The solution is given by:

$$
1+i_{j}^{d}=\frac{\varepsilon^{d}}{\varepsilon^{d}-1}(1+i)
$$

No bank has incentives to deviate since they are all acting optimally. If a bank decided to stop keeping reserves at the central bank it would have to lend more and this requires lowering its loan rate, which is not optimal. If a bank decided to stop taking deposits it would stop earning its deposit spread, which is also suboptimal. The constrain $H>0$ is satisfied in this regime, since $H=F+D-L>0$. The deposit ZLB is satisfied as long as the deposit rate paid by banks is greater or equal than zero, which occurs as long as:

$$
i \geq-\frac{1}{\varepsilon^{d}} \equiv \tilde{\iota}
$$

In this regime:

$$
R O E_{j} \equiv \frac{F_{j}^{\prime}}{F_{j}}-1=(1+i)\left(1+\frac{1}{\varepsilon^{l}-1} \frac{L}{F}+\frac{1}{1-\varepsilon^{d}} \frac{D}{F}\right)-1
$$


Regime 2: In this regime the constraint that reserves are positive holds for the same reason as in the previous regime: $H_{j}=F+D-L>0$. All banks set a zero deposit rate, so the deposit ZLB also holds. Since banks still hold reserves at the central bank they solve the unconstrained loan subproblem, which yields the same solution as it did in Regime 1. In this regime ROE is given by:

$$
R O E_{j}=\frac{1}{\varepsilon^{l}-1} \frac{L}{F}+i\left(1+\frac{1}{\varepsilon^{l}-1} \frac{L}{F}+\frac{D}{F}\right) .
$$

Banks don't want to start taking deposits by setting a positive deposit rate, since their unconstrained problem would deliver a negative rate. Banks also don't want to deviate to stop having reserves at the central bank, since this would require deviating from their maximizing loan rate. An individual bank might want to deviate to set a negative deposit rate, obtain no deposits and just lend out its full equity at the rate that allows to do so. This deviating bank would need to lend out $F$, so it could charge a loan rate of:

$$
i_{j}^{l}=\left(\frac{F}{L}\right)^{-\frac{1}{\varepsilon^{l}}} \frac{\varepsilon^{l}}{\varepsilon^{l}-1}(1+i)-1 .
$$

Banks are better by not deviating if:

$$
\begin{aligned}
\left(\frac{F}{L}\right)^{-\frac{1}{\varepsilon^{l}}} \frac{\varepsilon^{l}}{\varepsilon^{l}-1}(1+i)-1 & \leq \frac{1}{\varepsilon^{l}-1} \frac{L}{F}+i\left(1+\frac{1}{\varepsilon^{l}-1} \frac{L}{F}+\frac{D}{F}\right) \\
i & \leq \frac{\left(\frac{L}{F}\right)^{\frac{1}{\varepsilon^{l}}} \frac{\varepsilon^{l}}{\varepsilon^{l}-1}-1-\frac{1}{\varepsilon^{l}-1} \frac{L}{F}}{1+\frac{1}{\varepsilon^{l}-1} \frac{L}{F}+\frac{D}{F}-\left(\frac{L}{F}\right)^{\frac{1}{\varepsilon^{l}}} \frac{\varepsilon^{l}}{\varepsilon^{l}-1}} \equiv \underline{i} .
\end{aligned}
$$

It is also easy to check than in this case banks that deviate to not taking deposits wouldn't want to keep reserves at the central bank, since the rate that they earn on loans is bigger than the policy rate.

Regime 3A: Since banks not taking deposits lend an amount equal to $F$, then the amount lent by banks taking deposits (denoted $L_{D}$ ) has to equal:

$$
L_{D}=\left(\frac{L^{\frac{\varepsilon^{l}-1}{\varepsilon^{l}}}-\mu F^{\frac{\varepsilon^{l}-1}{\varepsilon^{l}}}}{1-\mu}\right)^{\frac{\varepsilon^{l}}{\varepsilon^{l}-1}}
$$


Since banks taking deposits are still keeping reserves at the central bank they must still satisfy their unconstrained loan subproblem F.O.C. which delivers:

$$
\left(1+i_{D}^{l}\right)=\frac{\varepsilon^{l}}{\varepsilon^{l}-1}(1+i)
$$

Banks taking deposits must lend out $L_{D}$, which requires:

$$
1+i^{l}=\left(\frac{L_{D}}{L}\right)^{\frac{1}{\varepsilon^{l}}} \frac{\varepsilon^{l}}{\varepsilon^{l}-1}(1+i)
$$

Additionally, banks that do not take deposits must lend out $F$, which requires:

$$
1+i_{N D}^{l}=\left(\frac{L_{D}}{F}\right)^{\frac{1}{\varepsilon^{l}}} \frac{\varepsilon^{l}}{\varepsilon^{l}-1}(1+i)
$$

It is now possible to calculate the ROE for both types of banks:

$$
\frac{F_{N D}^{\prime}}{F_{N D}}-1=i_{N D}^{l}
$$

and:

$$
\frac{F_{D}^{\prime}}{F_{D}}-1=\frac{\varepsilon^{l}}{\varepsilon^{l}-1}(1+i) \frac{L_{D}}{F}+(1+i) \frac{F+D-L_{D}}{F}-\frac{D}{F}-1
$$

So, the profits of the two types of banks are equal when:

$$
\begin{aligned}
i_{N D}^{l} & =\frac{\varepsilon^{l}}{\varepsilon^{l}-1}(1+i) \frac{L_{D}}{F}+(1+i) \frac{F+D-L_{D}}{F}-\frac{D}{F}-1 \\
1+\frac{i}{1+i} \frac{D}{F} & =\frac{\varepsilon^{l}}{\varepsilon^{l}-1} \frac{L_{D}}{F}\left[\left(\frac{L_{D}}{F}\right)^{\frac{1-\varepsilon^{l}}{\varepsilon^{l}}}-\frac{1}{\varepsilon^{l}}\right]
\end{aligned}
$$

This expression of $i$ and $\mu$ can be written as $F(i, \mu)=0$, where:

$$
F(i, \mu)=1+\frac{i}{1+i} \frac{D}{F}-\frac{\varepsilon^{l}}{\varepsilon^{l}-1} g(\mu)^{\frac{1}{\varepsilon^{l}}}+\frac{g(\mu)}{\varepsilon^{l}-1},
$$

and:

$$
g(\mu)=\frac{L_{D}}{F}=\left(\frac{(L / F)^{\frac{\varepsilon^{l}-1}{\varepsilon^{l}}}-\mu}{1-\mu}\right)^{\frac{\varepsilon^{l}}{\varepsilon^{l}-1}}
$$


Since $g(\mu)$ is an increasing function of $\frac{a-\mu}{1-\mu}$, where $a=(L / F)^{\frac{\varepsilon^{l}-1}{\varepsilon^{l}}}>1$, it is evident that $g^{\prime}(\mu)>0$. Also notice that:

$$
\frac{\partial F}{\partial \mu}=\frac{g^{\prime}(\mu)}{\varepsilon^{l}-1} \frac{(L / F)^{\frac{\varepsilon^{l}-1}{\varepsilon^{l}}}-1}{(L / F)^{\frac{\varepsilon^{l}-1}{\varepsilon^{l}}}-\mu}>0 .
$$

Using the implicit function theorem this means that the expression $F(i, \mu)=0$ implicitly defines $\mu$ as a function of $i$. The derivative of $\mu(i)$ is given by:

$$
\frac{\partial \mu}{\partial i}=-\frac{\frac{\partial F}{\partial i}}{\frac{\partial F}{\partial \mu}}
$$

which is negative because:

$$
\frac{\partial F}{\partial i}=\frac{1+i-i}{(1+i)^{2}} \frac{D}{F}=\frac{1}{(1+i)^{2}} \frac{D}{F}>0 .
$$

The level $\mu(i)=0$ is a solution when:

$$
1+i+i \frac{D}{F}=(1+i) \frac{\varepsilon^{l}}{\varepsilon^{l}-1} \frac{L}{F}\left[\left(\frac{L}{F}\right)^{\frac{1-\varepsilon^{l}}{\varepsilon^{l}}}-\frac{1}{\varepsilon^{l}}\right]
$$

Which occurs when $i=\underline{i}$. The requirement that the amount of reserves held at the central bank by commercial banks taking deposits must be positive can be expressed as:

$$
\begin{aligned}
& 0 \leq F+D-\left(\frac{L^{\frac{\varepsilon^{l}-1}{\varepsilon^{l}}}-\mu F^{\frac{\varepsilon^{l}-1}{\varepsilon^{l}}}}{1-\mu}\right)^{\frac{\varepsilon^{l}}{\varepsilon^{l}-1}} \\
& \mu \leq \frac{(1+D / F)^{\frac{\varepsilon^{l}-1}{\varepsilon^{l}}}-(L / F)^{\frac{\varepsilon^{l}-1}{\varepsilon^{l}}}}{(1+D / F)^{\frac{\varepsilon^{l}-1}{\varepsilon^{l}}}-1} \equiv \bar{\mu} .
\end{aligned}
$$

It is easy to see that this limit level $\bar{\mu}$ is greater than zero and smaller than one. When $\mu=\bar{\mu}$ the amount lent by banks taking deposits is $1+D / F$, this is obvious from the fact that this limit was derived from $H_{D}=0$, and that occurs when $1+\frac{D}{F}=\frac{L_{D}}{F}$. This can be introduced into the expression for $\mu(i)$ to obtain the level of the policy rate that delivers $\bar{\mu}$ :

$$
1+\frac{i}{1+i} \frac{D}{F}=\frac{\varepsilon^{l}}{\varepsilon^{l}-1} \frac{L_{D}}{F}\left[\left(\frac{L_{D}}{F}\right)^{\frac{1-\varepsilon^{l}}{\varepsilon^{l}}}-\frac{1}{\varepsilon^{l}}\right]
$$




$$
i=\frac{\left(1+\frac{D}{F}\right)^{\frac{1}{\varepsilon^{l}}}-1-\frac{D}{\varepsilon^{l} F}}{1+\frac{D}{F}-\left(1+\frac{D}{F}\right)^{\frac{1}{\varepsilon^{l}}}} \equiv \underline{\underline{i}} .
$$

This interest rate is smaller than $\underline{i}$, since at $\underline{i}$ it is the case that $\mu=0$, at $\underline{\underline{i}}$ it is the case that $0<\mu<1$, and $\mu(i)$ is a decreasing function of $i$. Now I want to show that $i^{l}$ is a decreasing function of $i$. Recall that:

$$
1+i^{l}=\left(\frac{L_{D}}{L}\right)^{\frac{1}{\varepsilon^{l}}} \frac{\varepsilon^{l}}{\varepsilon^{l}-1}(1+i)
$$

which means that as $i$ increases, there are two effects on $i^{l}$, the increase in $i$ directly increases $i^{l}$, but the fall in $\mu$ brought about by the increase in $i$ lowers $L_{D} / F$ and this tends to lower $i^{l}$. To see which effect dominates take derivatives:

$$
\frac{\partial i^{l}}{\partial i}=\frac{1}{\varepsilon^{l}}\left(\frac{L_{D}}{L}\right)^{\frac{1-\varepsilon^{l}}{\varepsilon^{l}}} \frac{\partial\left(L_{D} / L\right)}{\partial i} \frac{\varepsilon^{l}}{\varepsilon^{l}-1}(1+i)+\left(\frac{L_{D}}{L}\right)^{\frac{1}{\varepsilon^{l}}} \frac{\varepsilon^{l}}{\varepsilon^{l}-1} .
$$

To obtain the derivative $\frac{\partial\left(L_{D} / F\right)}{\partial i}$ apply the implicit function theorem directly to:

$$
F\left(i, L_{D} / F\right)=1+\frac{i}{1+i} \frac{D}{F}-\frac{\varepsilon^{l}}{\varepsilon^{l}-1} \frac{L_{D}}{F}\left[\left(\frac{L_{D}}{F}\right)^{\frac{1-\varepsilon^{l}}{\varepsilon^{l}}}-\frac{1}{\varepsilon^{l}}\right],
$$

to obtain:

$$
\frac{\partial\left(L_{D} / F\right)}{\partial i}=-\frac{\frac{\partial F}{\partial i}}{\frac{\partial F}{\partial L_{D} / F}}=-\frac{\frac{1}{(1+i)^{2}} \frac{D}{F}}{\frac{1}{\varepsilon^{l}-1}\left(1-\left(\frac{L_{D}}{F}\right)^{\frac{1-\varepsilon^{l}}{\varepsilon^{l}}}\right)} .
$$

Introducing this in the expression for $\frac{\partial i^{l}}{\partial i}$ one gets:

$$
\frac{\partial i^{l}}{\partial i}=\left(\frac{L_{D}}{L}\right)^{\frac{1}{\varepsilon^{l}}} \frac{\varepsilon^{l}}{\varepsilon^{l}-1}-\left(\frac{L_{D}}{L}\right)^{\frac{1-\varepsilon^{l}}{\varepsilon^{l}}} \frac{\frac{1}{1+i} \frac{D}{L}}{1-\left(\frac{L_{D}}{F}\right)^{\frac{1-\varepsilon^{l}}{\varepsilon^{l}}}} .
$$

This is equal to zero if:

$$
\frac{\varepsilon^{l}}{\varepsilon^{l}-1}\left(1-\left(\frac{L_{D}}{F}\right)^{\frac{1-\varepsilon^{l}}{\varepsilon^{l}}}\right)=\frac{1}{1+i} \frac{D}{L_{D}}
$$


At $\underline{i}$, where $L_{D} / F=1+D / F$ the previous expression becomes:

$$
\begin{aligned}
(1+\underline{\underline{i}}) \frac{\varepsilon^{l}}{\varepsilon^{l}-1}\left(1-\left(1+\frac{D}{F}\right)^{\frac{1-\varepsilon^{l}}{\varepsilon^{l}}}\right) & =\frac{D}{L_{D}} \\
\frac{1}{1+\frac{D}{F}-\left(1+\frac{D}{F}\right)^{\frac{1}{\varepsilon^{l}}}}\left(1+\frac{D}{F}-\left(1+\frac{D}{F}\right)^{\frac{1}{\varepsilon^{l}}}\right) & =1
\end{aligned}
$$

Which is always true. This proves that at $i=\underline{\underline{i}}$, the derivative $\frac{\partial i}{\partial i}$ is equal to zero. It is also possible to show that the second derivative of $i^{l}$ w.r.t. $i$ is negative:

$$
\begin{aligned}
\frac{\partial^{2} i^{l}}{\partial i^{2}} & =-\frac{1}{\varepsilon^{l}}\left(\frac{L_{D}}{L}\right)^{\frac{1-\varepsilon^{l}}{\varepsilon^{l}}} \frac{\varepsilon^{l}}{\varepsilon^{l}-1} \frac{\frac{1}{(1+i)^{2}} \frac{D}{L}}{\frac{1}{\varepsilon^{l}-1}\left(1-\left(\frac{L_{D}}{F}\right)^{\frac{1-\varepsilon^{l}}{\varepsilon^{l}}}\right)}+\frac{1}{(1+i)^{2}} \frac{\frac{D}{L}}{\left(\frac{L_{D}}{L}\right)^{\frac{\varepsilon^{l}-1}{\varepsilon^{l}}}-\left(\frac{F}{L}\right)^{\frac{\varepsilon^{l}-1}{\varepsilon^{l}}}} \\
& -\frac{\frac{1}{1+i} \frac{D}{L}}{\left(\left(\frac{L_{D}}{L}\right)^{\frac{\varepsilon^{l}-1}{\varepsilon^{l}}}-\left(\frac{F}{L}\right)^{\frac{\varepsilon^{l}-1}{\varepsilon^{l}}}\right)^{2} \frac{\varepsilon^{l}-1}{\varepsilon^{l}}\left(\frac{L_{D}}{L}\right)^{-\frac{1}{\varepsilon^{l}}} \frac{\frac{1}{(1+i)^{2}} \frac{D}{L}}{\frac{1}{\varepsilon^{l}-1}\left(1-\left(\frac{L_{D}}{F}\right)^{\frac{1-\varepsilon^{l}}{\varepsilon^{l}}}\right)}}
\end{aligned}
$$

The first two terms cancel out and then it is clear than the second derivative of $i^{l}$ w.r.t. $i$ is negative, which means that throughout the whole Regime 3A the highest $i^{l}$ is achieved at $i=\underline{\underline{i}}$. In this regime ROE is given by:

$$
R O E_{j}=\frac{F_{j}^{\prime}}{F_{j}}-1=i_{N D}^{l}=\left(\frac{(L / F)^{\frac{\varepsilon^{l}-1}{\varepsilon^{l}}}-\mu(i)}{1-\mu(i)}\right)^{\frac{1}{\varepsilon^{l}-1}} \frac{\varepsilon^{l}}{\varepsilon^{l}-1}(1+i)-1
$$

Regime 3B: Banks not taking deposits lend out $F$ :

$$
1+i_{N D}^{l}=\left(\frac{F}{L}\right)^{-\frac{1}{\varepsilon}}\left(1+i^{l}\right)
$$

Banks taking deposits lend out $F+D$ :

$$
1+i_{D}^{l}=\left(\frac{F+D}{L}\right)^{-\frac{1}{\varepsilon}}\left(1+i^{l}\right)
$$

ROE for both types of banks must be equalized.

$$
\left(1+i_{N D}^{l}\right)=\left(1+i_{D}^{l}\right)\left(1+\frac{D}{F}\right)-\frac{D}{F}
$$




$$
1+i^{l}=\frac{\frac{D}{F}\left(\frac{F}{L}\right)^{\frac{1}{\varepsilon^{l}}}}{\left(1+\frac{D}{F}\right)^{\frac{\varepsilon^{l}-1}{\varepsilon^{l}}}-1}
$$

Recall that in Regime 3A, when $\mu=\bar{\mu}$, it is the case that:

$$
1+i^{l}=\left(\frac{L_{D}}{F}\right)^{\frac{1}{\varepsilon^{l}}}\left(\frac{F}{L}\right)^{\frac{1}{\varepsilon^{l}}} \frac{\varepsilon^{l}}{\varepsilon^{l}-1}(1+\underline{\underline{i}})=\frac{\frac{D}{F}\left(\frac{F}{L}\right)^{\frac{1}{\varepsilon^{l}}}}{\left(1+\frac{D}{F}\right)^{\frac{\varepsilon^{l}-1}{\varepsilon^{l}}}-1}
$$

This means that the highest loan rate charged in Regime $3 \mathrm{~A}$ is precisely the same rate charged in Regime 3B. It is easy to see that both types of banks satisfy all constraints and have no profitable deviations. ROE for all banks in this regime is given by:

$$
R O E_{j}=\frac{F_{j}^{\prime}}{F_{j}}-1=i_{N D}^{l}=\left(\frac{F}{L}\right)^{-\frac{1}{\varepsilon}}\left(1+i^{l}\right)-1=\frac{\left(1+\frac{D}{F}\right)^{\frac{1}{\varepsilon^{l}}}-1}{1-\left(1+\frac{D}{F}\right)^{\frac{1-\varepsilon^{l}}{\varepsilon^{l}}}}
$$

\section{A.5 Problem of the Bank with a Target Leverage Ratio}

In this section I describe a more general version of the bank model described in Section 2. Here, as in Section 4, banks are going to be subject to a cost of deviating from a target level of loan-to-equity ratio, the particular form of this cost is similar to the one in GNSS. The bank pays a quadratic cost (parameterized by a coefficient $\kappa$ and proportional to outstanding bank net worth) whenever the loan-to-equity ratio $L(j) / F(j)$ deviates from the target value $\nu$.

Banks also face costs of issuing loans given by $\mu^{l}$ and benefits of issuing deposits given by $\mu^{d}$, these are per dollar of loan or deposit issued, and they could be positive or negative. The cost of issuing loans is positive (the bank has to monitor the borrowers, pay loan originators, etc), while the cost of issuing deposits could plausibly be negative, as it could be seen as a benefit that the bank receives for having a large deposit base, for example attracting more customers or obtaining more publicity (that is why I will depict them as a benefit in my notation).

I will make the assumption that $D+F>L>F$, which indicates that the total amount of loans being demanded is possible to cover with the total amount of deposits being supplied plus total bank equity, but it is not possible to cover simply with bank equity. The problem of the bank is:

$$
\begin{array}{ll}
\max _{i^{l}(j), L(j), i^{d}(j), D(j), H(j)} & \left(1+i^{l}(j)-\mu^{l}\right) L(j)+(1+i) H(j)-\left(1+i^{d}(j)-\mu^{d}\right) D(j) \\
& -\frac{\kappa}{2}\left(\frac{L(j)}{F(j)}-\nu\right)^{2} F(j)
\end{array}
$$




$$
\begin{aligned}
\text { s.t. } & \\
L(j) & \leq\left(\frac{1+i^{l}(j)}{1+i^{l}}\right)^{-\varepsilon^{l}} L \\
D(j) & = \begin{cases}\left(\frac{1+i^{d}(j)}{1+i^{d}}\right)^{-\varepsilon^{d}} D & \text { if } i^{d}(j) \geq 0 \\
0 & \text { if } i^{d}(j)<0\end{cases} \\
L(j)+H(j) & =F(j)+D(j) \\
H(j) & \geq 0
\end{aligned}
$$

In Regime 1 all banks charge the same loan rate, which is set according to the unconstrained loan subproblem F.O.C.:

$$
1+i^{l}(j)=\varepsilon^{l}\left(i^{l}(j)-i-\mu^{l}\right)-\kappa \varepsilon^{l}\left(\left(\frac{1+i^{l}(j)}{1+i^{l}}\right)^{-\varepsilon^{l}} \frac{L}{F(j)}-\nu\right) .
$$

In equilibrium, since all the banks are symmetric, this becomes:

$$
1+i^{l}=\frac{\varepsilon^{l}}{\varepsilon^{l}-1}\left(1+i+\mu^{l}\right)+\kappa \frac{\varepsilon^{l}}{\varepsilon^{l}-1}\left(\frac{L}{F}-\nu\right) .
$$

So, it is clear that in this regime the loan interest rate increases not only with the policy rate and the cost of issuing loans, but also with the amount of loans being made $(L)$. So this is a type of loan supply curve. In this regime the F.O.C. for the deposit rate is:

$$
0=-\left(\frac{1+i^{d}(j)}{1+i^{d}}\right)^{-\varepsilon^{d}} D-\varepsilon^{d}\left(i+\mu^{d}-i^{d}(j)\right)\left(\frac{1+i^{d}(j)}{1+i^{d}}\right)^{-\varepsilon^{d}-1} \frac{D}{1+i^{d}}
$$

hence the solution for the deposit rate is:

$$
1+i^{d}(j)=\frac{\varepsilon^{d}}{\varepsilon^{d}-1}\left(1+i+\mu^{d}\right)
$$

Notice that this net deposit rate is only greater than zero if:

$$
-\frac{1}{\varepsilon^{d}}-\mu^{d} \leq i
$$

Defining $\tilde{\iota} \equiv-\frac{1}{\varepsilon^{d}}-\mu^{d}$, I can say that as long as $i \geq \tilde{\iota}$ commercial banks want to set nonnegative deposit rates. In this regime bank resources at the end of the period are given by:

$$
F^{\prime}=(1+i)\left(F+\frac{1}{\varepsilon^{l}-1} L+\frac{1}{1-\varepsilon^{d}} D\right)+\frac{\mu^{l}}{\varepsilon^{l}-1} L+\frac{\mu^{d}}{1-\varepsilon^{d}} D
$$




$$
+\kappa\left(\frac{L}{F}-\nu\right)\left(\frac{\varepsilon^{l}}{\varepsilon^{l}-1} L-\frac{L}{2}+\frac{\nu F}{2}\right) .
$$

I assume that $\left(\frac{L}{F}-\nu\right)$ is small enough and $\frac{\varepsilon^{l}}{\varepsilon^{l}-1}-1$ is also small enough that I can approximate $\left(\frac{L}{F}-\nu\right) \frac{\varepsilon^{l}}{\varepsilon^{l}-1}$ with $\left(\frac{L}{F}-\nu\right)$, then the previous expression can be written as:

$\frac{F^{\prime}}{F}=\left(1+\frac{1+\mu^{l}}{\varepsilon^{l}-1} \frac{L}{F}+\frac{1+\mu^{d}}{1-\varepsilon^{d}} \frac{D}{F}\right)+i\left(1+\frac{1}{\varepsilon^{l}-1} \frac{L}{F}+\frac{1}{1-\varepsilon^{d}} \frac{D}{F}\right)+\frac{\kappa}{2}\left(\frac{L}{F}-\nu\right)\left(\frac{L}{F}+\nu\right)$.

Once $i<\tilde{\imath}$ commercial banks start setting a deposit rate of exactly zero and continue to obtain deposits. In this case bank resources at the end of the period are given by:

$$
F^{\prime}=(1+i)\left(F+\frac{1}{\varepsilon^{l}-1} L\right)+\frac{\mu^{l}}{\varepsilon^{l}-1} L+\left(i+\mu^{d}\right) D+\kappa\left(\frac{L}{F}-\nu\right)\left(\frac{\varepsilon^{l}}{\varepsilon^{l}-1} L-\frac{L}{2}+\frac{\nu F}{2}\right),
$$

with the same approximation used above this becomes:

$$
\frac{F^{\prime}}{F}=\left(1+\frac{1+\mu^{l}}{\varepsilon^{l}-1} \frac{L}{F}+\mu^{d} \frac{D}{F}\right)+i\left(1+\frac{1}{\varepsilon^{l}-1} \frac{L}{F}+\frac{D}{F}\right)+\frac{\kappa}{2}\left(\frac{L}{F}-\nu\right)\left(\frac{L}{F}+\nu\right) .
$$

All banks setting a zero deposit rate and obtaining deposits continues to be an equilibrium until any single bank would have an incentive to deviate. This deviating bank would set its loan rate to lend out its full equity:

$$
1+i_{D E V}^{l}=\left(\frac{F}{L}\right)^{-\frac{1}{\varepsilon^{l}}}\left(1+i^{l}\right)
$$

Equity at the end of the period for the deviating bank would be given by:

$$
F_{D E V}^{\prime}=\left(1+i_{D E V}^{l}-\mu^{l}\right) F_{D E V}-\delta_{i} \frac{\kappa}{2}(1-\nu)^{2} F_{D E V}
$$

where $\delta_{i}$ is an indicator that can be set equal to 1 if one wishes to still include the cost of deviating from target leverage when banks are not taking deposits and equal to zero if one wishes not to include it. Since the "bank" is no longer taking household deposits it could be argued that it is no longer a "bank" and should not be subject to regulatory oversight. In order to discover the level of the policy rate at which it would start paying off to deviate I compare the ROE from the two scenarios:

$$
\left(1+\frac{1+\mu^{l}}{\varepsilon^{l}-1} \frac{L}{F}+\mu^{d} \frac{D}{F}\right)+i\left(1+\frac{1}{\varepsilon^{l}-1} \frac{L}{F}+\frac{D}{F}\right)+\frac{\kappa}{2}\left(\frac{L}{F}-\nu\right)\left(\frac{L}{F}+\nu\right)
$$




$$
=\left(\frac{L}{F}\right)^{\frac{1}{\varepsilon^{l}}}\left(\frac{\varepsilon^{l}}{\varepsilon^{l}-1}\left(1+i+\mu^{l}\right)+\kappa \frac{\varepsilon^{l}}{\varepsilon^{l}-1}\left(\frac{L}{F}-\nu\right)\right)-\mu^{l}-\delta_{i} \frac{\kappa}{2}(1-\nu)^{2},
$$

Defining:

$\underline{i}=-\frac{1+\frac{1+\mu^{l}}{\varepsilon^{l}-1} \frac{L}{F}+\mu^{d} \frac{D}{F}+\frac{\kappa}{2}\left(\frac{L}{F}-\nu\right)\left(\frac{L}{F}+\nu\right)-\left(\frac{L}{F}\right)^{\frac{1}{\varepsilon^{l}}} \frac{\varepsilon^{l}}{\varepsilon^{l}-1}\left(1+\mu^{l}+\kappa\left(\frac{L}{F}-\nu\right)\right)+\mu^{l}+\delta_{i} \frac{\kappa}{2}(1-\nu)^{2}}{1+\frac{1}{\varepsilon^{l}-1} \frac{L}{F}+\frac{D}{F}-\left(\frac{L}{F}\right)^{\frac{1}{\varepsilon^{l}}} \frac{\varepsilon^{l}}{\varepsilon^{l}-1}}$,

then it is possible to say that Regime 2 is active when $\tilde{\iota}>i \geq \underline{i}$. For my baseline calibration I obtain $\tilde{\iota}=0.5 \%$ and $\underline{i} \approx-2 \%$ at the annual level with $\delta_{i}=0$ (with $\delta_{i}=1 \underline{i}$ is much more negative). Notice that when $\mu^{d}=\mu^{l}=\kappa=0$ the expressions just given simplify to the ones given in Section 2.

\section{A.6 Loan Market Under Uncertainty}

Here I will modify the problem of the borrowing firm from the one described in Appendix A.1 so that it is consistent with the stochastic nature of loan returns described in the banking framework of Section 4. The reasons for this change are sketched in Section 4.5.

There will be a firm seeking to obtain a known amount of funding from a continuum of banks. Each bank $j$ will charge a multiple $\mu(j)$ of the return of the project (so they would earn $\mu(j)$ times the return of the project if they were allocated the whole project) and they will be allocated a fraction $\gamma(j)$ of the total project. Hence bank $j$ will have to be paid an amount $\mu(j) \gamma(j)$ of the total return of the project. The firm will want to minimize this amount subject to the CES aggregation of the $\gamma(j)$ being equal to one. That is, they want to minimize:

$$
\int_{0}^{1} \mu(j) \gamma(j) d j
$$

subject to:

$$
\left[\int_{0}^{1} \gamma(j)^{\left(\varepsilon_{t}^{b}-1\right) / \varepsilon_{t}^{b}} d j\right]^{\varepsilon_{t}^{b} /\left(\varepsilon_{t}^{b}-1\right)} \geq 1
$$

The F.O.C. implies that:

$$
\gamma(j)=\left(\frac{\mu(j)}{\lambda}\right)^{-\varepsilon_{t}^{b}}
$$

where:

$$
\lambda=\left[\int_{0}^{1} \mu(j)^{1-\varepsilon_{t}^{b}} d j\right]^{\frac{1}{1-\varepsilon_{t}^{b}}}
$$


so, denoting $\mu \equiv \lambda$, I can write demand for a particular bank $j$ coming from client $i$ as:

$$
\gamma(j)=\left(\frac{\mu(j)}{\mu}\right)^{-\varepsilon_{t}^{b}}
$$

Since all the banks will be symmetric, they will all charge $\mu(j)=\mu$ and they will all be allocated a fraction of 1 of the total project (remember there is a measure 1 of banks so this is consistent with the total fraction allocated being 1).

With this demand schedule and this setup the loan subproblem of the bank is:

$$
\begin{aligned}
& \max _{\gamma_{t}(j), \mu_{t}(j)} \quad\left[\mathbb{E}_{t}\left(1+i_{t+1}^{l}\right)\right] \mu_{t}(j) \gamma_{t}(j) L_{t}-\left(1+i_{t}+\mu^{l}\right) \gamma_{t}(j) L_{t}-\frac{\kappa}{2}\left(\frac{\gamma_{t}(j) L_{t}}{F_{t}(j)}-\nu\right)^{2} F_{t}(j) \\
& \text { s.t. } \\
& \gamma_{t}(j)=\left(\frac{\mu_{t}(j)}{\mu_{t}}\right)^{-\varepsilon^{l}} .
\end{aligned}
$$

Differentiating with respect to $\mu_{t}(j)$ I obtain the F.O.C.:

$$
0=\frac{\varepsilon^{l}-1}{\varepsilon^{l}}\left[\mathbb{E}_{t}\left(1+i_{t+1}^{l}\right)\right] \mu_{t}(j)-\left(1+i_{t}+\mu^{l}\right)-\kappa\left(\left(\frac{\mu_{t}(j)}{\mu_{t}}\right)^{-\varepsilon^{l}} \frac{L_{t}}{F_{t}(j)}-\nu\right) .
$$

In equilibrium, since all the banks are symmetric this becomes:

$$
0=\frac{\varepsilon^{l}-1}{\varepsilon^{l}}\left[\mathbb{E}_{t}\left(1+i_{t+1}^{l}\right)\right] \mu_{t}-\left(1+i_{t}+\mu^{l}\right)-\kappa\left(\frac{L_{t}}{F_{t}}-\nu\right)
$$

Also, since all the banks are symmetric $\mu_{t}(j)=\mu_{t}$, and since in equilibrium $\mu_{t}$ must always equal one (total returns on each unit of capital must always be $\left.\left(1+i_{t+1}^{l}\right)\right)$, then I set $\mu_{t}=1$ and obtain:

$$
\mathbb{E}_{t}\left(1+i_{t+1}^{l}\right)=\frac{\varepsilon^{l}}{\varepsilon^{l}-1}\left(1+i_{t}+\mu^{l}\right)+\kappa \frac{\varepsilon^{l}}{\varepsilon^{l}-1}\left(\frac{L_{t}}{F_{t}}-\nu\right)
$$

\section{A.7 Heterogeneous Bank Model}

The new logarithmic specification described in section 5.1 is:

$$
-\kappa \nu \frac{L_{j}}{F_{j}}\left(\ln \left(\frac{L_{j}}{F_{j}}\right)-\ln \nu-1\right)-\kappa \nu^{2}
$$


Denote this function by $f(x)$, where $x=L / F$, then:

$$
\begin{aligned}
f(x) & =-\kappa \nu x(\ln (x)-\ln \nu-1)-\kappa \nu^{2} \\
f^{\prime}(x) & =-\kappa \nu(\ln (x)-\ln \nu) \\
f^{\prime \prime}(x) & =-\frac{\kappa \nu}{x} .
\end{aligned}
$$

Hence the second order approximation to the new functional form (around $x=\nu$ which is the steady state value of $L / F)$ is the following:

$$
\begin{aligned}
f(x) & \approx^{2} f(\nu)+f^{\prime}(\nu)(x-\nu)+\frac{f^{\prime \prime}(\nu)}{2}(x-\nu)^{2} \\
& =-\frac{\kappa}{2}(x-\nu)^{2}
\end{aligned}
$$

This means that the quadratic specification that I have used so far is the second order approximation to the logarithmic specification around the steady state. The reason that the logarithmic specification is convenient is because it allows to solve the heterogeneous bank model in a simple way (after using an approximation). When using the specification in logs, the bank problem (abstracting from the managerial cost, the exogenous costs and benefits of issuing loans and deposits, the stochastic nature of the loan return, and the constraints that reserves are nonnegative and deposits rates are nonnegative) is:

$$
\begin{array}{cl}
\max _{H_{j}, L_{j}, D_{j}, i_{j}^{l}, i_{j}^{d}} & (1+i) H_{j}+\left(1+i_{j}^{l}\right) L_{j}-\left(1+i_{j}^{d}\right) D_{j}-\left[\kappa \nu \frac{L_{j}}{F_{j}}\left(\ln \left(\frac{L_{j}}{F_{j}}\right)-\ln (\nu)-1\right)+\kappa \nu^{2}\right] F_{j} \\
\text { s.t. } & L_{j}=\left(\frac{1+i_{j}^{l}}{1+i^{l}}\right)^{-\varepsilon^{l}} L, \quad D_{j}=\left(\frac{1+i_{j}^{d}}{1+i^{d}}\right)^{-\varepsilon^{d}} \quad D, \quad L_{j}+H_{j}=F_{j}+D_{j} .
\end{array}
$$

The F.O.C. with respect to the deposit rate is unchanged, and it implies that all banks set the same deposit rate. The F.O.C. w.r.t. the loan rate is now:

$$
1+i_{j}^{l}=\frac{\varepsilon^{l}}{\varepsilon^{l}-1}\left(1+i+\kappa \nu\left(\ln \left(\frac{L_{j}}{F_{j}}\right)-\ln (\nu)\right)\right)
$$

If I impose symmetry so that $L_{j}=L$ for all $j$, and $F_{j}=F$, I obtain:

$$
1+i^{l}=\frac{\varepsilon^{l}}{\varepsilon^{l}-1}\left(1+i+\kappa \nu\left(\ln \left(\frac{L}{F}\right)-\ln (\nu)\right)\right),
$$

which is very similar to what I had in the homogeneous bank model used before, except that $\nu(\ln (L / F)-\ln (\nu))$ has replaced $(L / F-\nu)$, but the second one is the first order approximation 
to the first. Taking natural logs in the expression before imposing symmetry one gets:

$$
\ln \left(1+i_{j}^{l}\right)=\ln \left(\frac{\varepsilon^{l}}{\varepsilon^{l}-1}\right)+\ln \left(1+i+\kappa \nu\left(\ln \left(\frac{L_{j}}{F_{j}}\right)-\ln (\nu)\right)\right) .
$$

I can approximate this as: ${ }^{38}$

$$
i_{j}^{l}=\ln \left(\frac{\varepsilon^{l}}{\varepsilon^{l}-1}\right)+i+\kappa \nu \ln \left(L_{j}\right)-\kappa \nu \ln \left(F_{j}\right)-\kappa \nu \ln (\nu) .
$$

This is linear in the net rates and the logs of quantities, which is convenient because demand is also linear in those things (after a similar approximation):

$$
\ln \left(L_{j}\right) \approx-\varepsilon^{l}\left(i_{j}^{l}-i^{l}\right)+\ln (L)
$$

Introduce this in the previous equation for the loan rate and simplify to obtain:

$$
i_{j}^{l}=\frac{1}{1+\kappa \nu \varepsilon^{l}}\left(\ln \left(\frac{\varepsilon^{l}}{\varepsilon^{l}-1}\right)+i+\kappa \nu \varepsilon^{l} i^{l}+\kappa \nu \ln (L)-\kappa \nu \ln \left(F_{j}\right)-\kappa \nu \ln (\nu)\right) .
$$

Now introduce $i_{j}^{l}$ in the expression for $\ln \left(L_{j}\right)$ to obtain:

$$
\ln \left(L_{j}\right)=-\frac{\varepsilon^{l}}{1+\kappa \nu \varepsilon^{l}}\left(\ln \left(\frac{\varepsilon^{l}}{\varepsilon^{l}-1}\right)+i-\kappa \nu \ln \left(F_{j}\right)-\kappa \nu \ln (\nu)-i^{l}-\frac{\ln (L)}{\varepsilon^{l}}\right) .
$$

It can also be shown that the aggregate loan rate is given by

$$
i^{l}=\ln \left(\frac{\varepsilon^{l}}{\varepsilon^{l}-1}\right)+i+\kappa \nu\left(\ln \left(\frac{L}{\tilde{F}}-\nu\right)\right)
$$

where:

$$
\tilde{F}=\left(\int_{0}^{1} F_{j}^{\frac{\varepsilon^{l}-1}{\varepsilon^{l}+1 /(\kappa \nu)}} d j\right)^{\frac{\varepsilon^{l}+1 /(\kappa \nu)}{\varepsilon^{l}-1}}
$$

Hence, the equations for bank-level loan rate and loan amount can be expressed as:

$$
i_{j}^{l}=\ln \left(\frac{\varepsilon^{l}}{\varepsilon^{l}-1}\right)+i+\kappa \nu\left(\ln \left(\frac{L}{\tilde{F}}-\nu\right)\right)-\frac{\kappa \nu}{1+\kappa \nu \varepsilon^{l}} \ln \left(\frac{F_{j}}{\tilde{F}}\right)
$$

${ }^{38}$ This assumes that interest rates are small and that $\kappa \nu\left(\ln \left(\frac{L_{j}}{F_{j}}\right)-\ln (\nu)\right)$ is also small, these are very plausible things to assume for all the parameter values and shock sizes that I will use. In numerical simulations I confirmed that the approximation works very well 


$$
\ln \left(L_{j}\right)=\ln (L)+\frac{\kappa \nu \varepsilon^{l}}{1+\kappa \nu \varepsilon^{l}} \ln \left(\frac{F_{j}}{\tilde{F}}\right) .
$$

These two equations can be rewritten as

$$
\begin{aligned}
i_{j}^{l} & =\alpha+\beta i-\frac{\kappa \nu}{1+\kappa \nu \varepsilon^{l}} \ln \left(F_{j}\right) \\
\ln \left(L_{j}\right) & =\alpha^{\prime}+\beta^{\prime} i+\frac{\kappa \nu \varepsilon^{l}}{1+\kappa \nu \varepsilon^{l}} \ln \left(F_{j}\right),
\end{aligned}
$$

where:

$$
\begin{aligned}
\alpha & =\ln \left(\frac{\varepsilon^{l}}{\varepsilon^{l}-1}\right)+\kappa \nu\left(\ln \left(\frac{L}{\tilde{F}}-\nu\right)\right)+\frac{\kappa \nu}{1+\kappa \nu \varepsilon^{l}} \ln (\tilde{F}) \\
\alpha^{\prime} & =\ln (L)-\frac{\kappa \nu \varepsilon^{l}}{1+\kappa \nu \varepsilon^{l}} \ln (\tilde{F}) \\
\beta & =1 \\
\beta^{\prime} & =0 .
\end{aligned}
$$




\section{B Additional Empirical Results}

\section{B.1 More Summary Statistics}

Table 7: Summary Statistics for Banking Variables 1990-2017

\begin{tabular}{lrrrrrr}
\hline \hline & \multicolumn{2}{c}{ All Countries } & \multicolumn{2}{c}{ NR Countries } & \multicolumn{2}{c}{ Other Countries } \\
& Mean & $\mathrm{N}$ & Mean & $\mathrm{N}$ & Mean & $\mathrm{N}$ \\
\hline Rate on Av. Earning Assets & 4.57 & 80086 & 4.17 & 56385 & 5.53 & 23701 \\
Deposit Rate & 1.02 & 31615 & 0.89 & 19884 & 1.24 & 11731 \\
Net Interest Margin & 2.46 & 80441 & 2.20 & 56408 & 3.07 & 24033 \\
ROAA & 0.48 & 80545 & 0.32 & 56481 & 0.84 & 24064 \\
ROAE & 5.78 & 80202 & 4.41 & 56455 & 9.03 & 23747 \\
Log of Net Loans & 6.60 & 84721 & 6.47 & 60239 & 6.91 & 24482 \\
Log of Total Customer Deposits & 6.71 & 83532 & 6.58 & 59388 & 7.04 & 24144 \\
Log of Equity & 4.48 & 85240 & 4.27 & 60568 & 5.00 & 24672 \\
Log of Total Assets & 7.13 & 85311 & 7.03 & 60605 & 7.39 & 24706 \\
Customer Deposits to Assets ratio & 0.72 & 83599 & 0.71 & 59446 & 0.75 & 24153 \\
Net Loans to Assets ratio & 0.62 & 84823 & 0.61 & 60291 & 0.66 & 24532 \\
\hline \hline
\end{tabular}

Notes: This table contains more summary statistics for banking variables in the period 1990-2017 split between negative rate and non-negative rates regions.

\section{B.2 Linear Results}

As a starting point to study the relationships between the policy rate and the variables of interest one could run linear regressions of the following type:

$$
y_{b, t}=\alpha_{b}+\delta_{t}+\beta i_{c(b), t}+\varepsilon_{b, t},
$$

where $y_{b, t}$ is some outcome variable for bank $b$, in country $c(b)$ and year $t$, and $i_{c(b), t}$ is the policy rate in that country and year. The regressions include a bank fixed effect $\left(\alpha_{b}\right)$ and a year fixed effect $\left(\delta_{t}\right)$. The results of these regressions without a lag of the dependent variable are given in Table 8, while the ones that include a lag are given in Table 9. In all these regressions the coefficient on the policy rate is positive and significant, which means that the loan rate, deposit rate and ROAE all move together with the policy rate and in the same direction. These results are well known in the literature. The first lag of the dependent variable is also positive and significant, while if a second lag is included (results not shown) it is generally nonsignificant. This indicates that roughly two-thirds of the effects of the policy rate on the loan rate and the deposit rate happens in the first year and the remaining one- 
third happens during the second year. With return on equity the first year effect is roughly $85 \%$ of the total.

The fact that movements in the policy rate do not fully translate to the deposit rate is qualitatively and quantitatively consistent with the idea of the "deposit channel of monetary policy" developed in Drechsler et al. (2017). In my results the spread between the policy rate and the deposit rate increases by 40 bps with a 100 bps increase in the policy rate, while in their results the increase in the policy rate is 54 bps. The numbers are very similar, and can easily be accounted for by the difference in time periods and countries being analyzed.

Table 8: Linear regressions for main variables of interest, no lag

\begin{tabular}{lccc}
\hline \hline & $(1)$ & $(2)$ & $(3)$ \\
& Loan Rate & Deposit Rate & ROAE \\
\hline Policy Rate & $0.428^{* * *}$ & $0.424^{* * *}$ & $0.928^{* * *}$ \\
& $(0.027)$ & $(0.039)$ & $(0.236)$ \\
\hline $\mathrm{N}$ & 80078 & 31554 & 80199 \\
$\mathrm{R}$ squared & 0.93 & 0.85 & 0.40 \\
Entity FE & Yes & Yes & Yes \\
Year FE & Yes & Yes & Yes \\
Clustering & $\mathrm{C}-\mathrm{Y}$ & $\mathrm{C}-\mathrm{Y}$ & $\mathrm{C}-\mathrm{Y}$ \\
Mean dep. var. & 4.58 & 1.01 & 5.78 \\
\hline \hline
\end{tabular}

Notes: This table contains the results of the linear regressions described in equation (22) for the main variables of interest. SE in parenthesis, clustering is done at the Country-Year Level. Stars: ${ }^{*}$ for $\mathrm{p}<.10,{ }^{* *}$ for $\mathrm{p}<.05$, and ${ }^{* * *}$ for $\mathrm{p}<.01$. 
Table 9: Linear regressions for main variables of interest, including a lag

\begin{tabular}{lccc}
\hline \hline & $(1)$ & $(2)$ & $(3)$ \\
& Loan Rate & Deposit Rate & ROAE \\
\hline Policy Rate & $0.322^{* * *}$ & $0.324^{* * *}$ & $0.729^{* * *}$ \\
& $(0.017)$ & $(0.032)$ & $(0.227)$ \\
L.Rate on Av. Earning Assets & $0.480^{* * *}$ & & \\
& $(0.023)$ & & \\
L.Deposit Rate & & & \\
& & $0.500^{* * *}$ & \\
L.ROAE & & $(0.046)$ & \\
& & & $0.333^{* * *}$ \\
N & & & $(0.033)$ \\
Entity FE & 74096 & 28209 & 74209 \\
Year FE & Yes & Yes & Yes \\
Clustering & Yes & Yes & Yes \\
Mean dep. var. & C-Y & C-Y & C-Y \\
\hline Notes: Iingr regression & 4.49 & 0.93 & 5.66 \\
\hline
\end{tabular}

Notes: Linear regressions for main variables of interest, including a lag. Clustering is done at the Country-Year Level. Stars: ${ }^{*}$ for $\mathrm{p}<.10,{ }^{* *}$ for $\mathrm{p}<.05$, and ${ }^{* * *}$ for $\mathrm{p}<.01$.

\section{B.3 Locally-Weighted Regressions}

The results of the locally weighted regressions described in section 3.2, with and without a lag of the dependent variable respectively, are shown in Figures 9 and 10. The results are consistent with the predictions of the model. The loan rate decreases with the policy rate both for high and low levels of the policy rate, and at a similar rate in both cases. The deposit rate does not react much to the policy rate at low levels of the policy rate but does react for high levels. Return on equity reacts strongly to the policy rate at low rates but reacts less at high rates.

While somewhat informative, this approach does not allow for the identification of the break point, because the residualized measure has no direct connection with the underlying policy rate. In the figures I draw a vertical line at certain level of the residualized policy, but this level varies depending on whether or not the regressions include a lag, and (even though it is informed by the average level at which the residualized measure would hit the 50 basis point threshold) it is chosen somewhat arbitrarily. That is why in the text I focus on the regression threshold framework which allows for a very clear analysis of the threshold. 

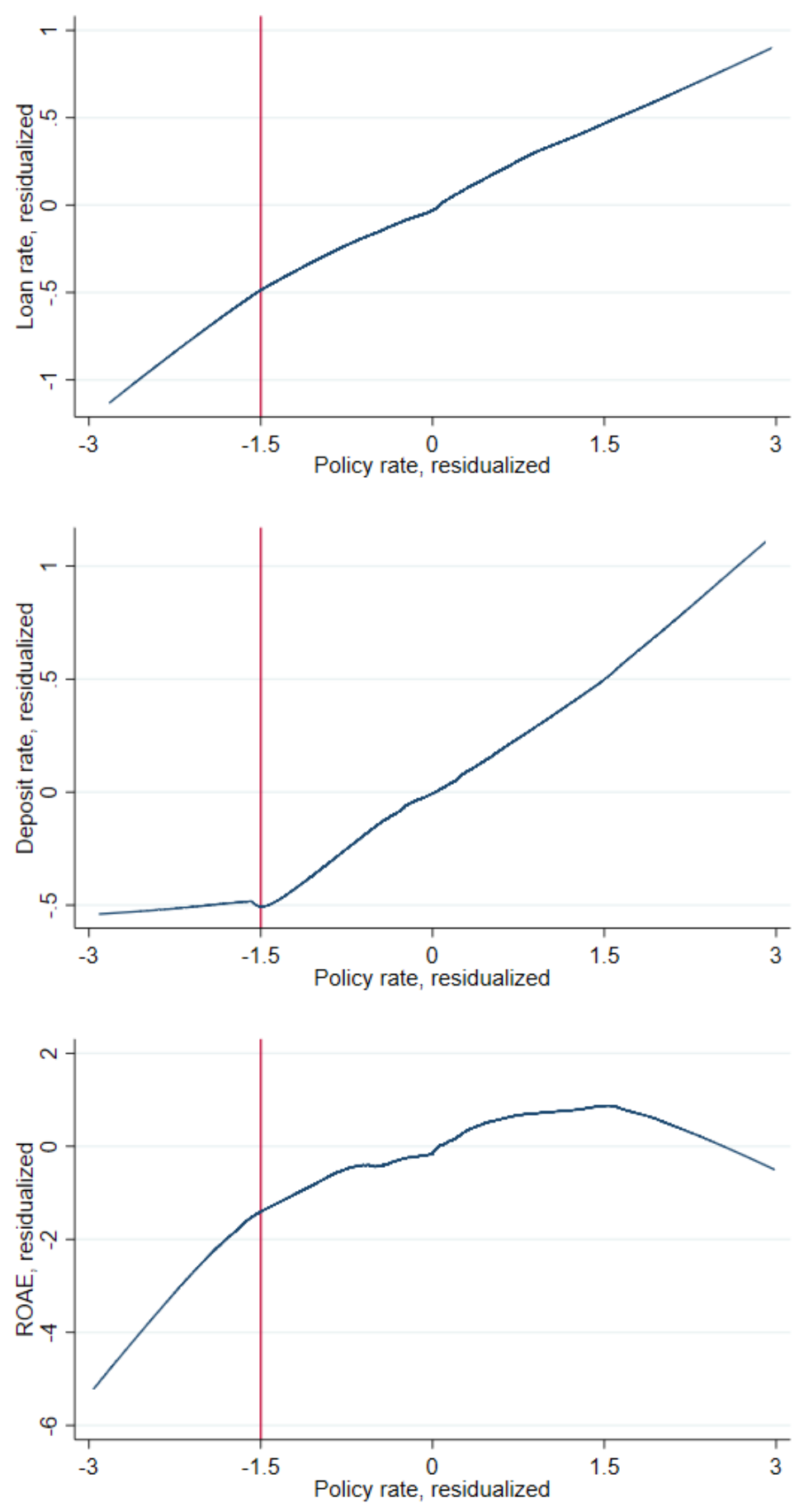

\section{Figure 9: Locally-weighted regressions, including a lag}

Notes: This figure contains the behavior of the loan rate, deposit rate and return on average equity (ROAE) with respect to the policy rate in the selected sample of banks. All quantities have been residualized using bank fixed effects, year fixed effects and one lag of the dependent variable, and clustered at the country level. The graphs show the line from a locally weighted regression using tricube weighting with 0.5 bandwidth. 

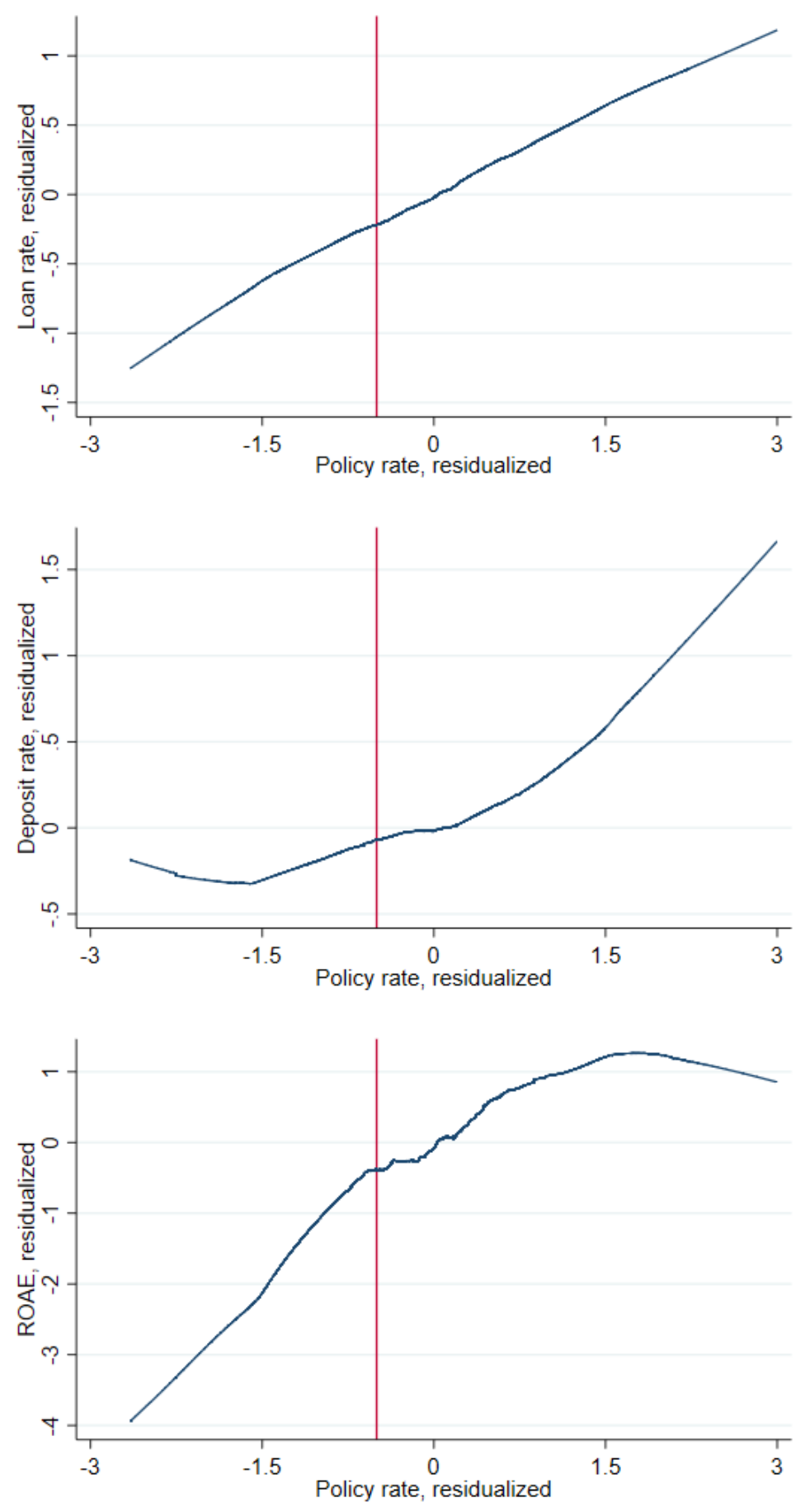

Figure 10: Locally-weighted regressions, no lag

Notes: This figure contains the behavior of the loan rate, deposit rate and return on average equity (ROAE) with respect to the policy rate in the selected sample of banks. All quantities have been residualized using bank fixed effects and year fixed effects, and clustered at the country level. The graphs show the line from a locally weighted regression using tricube weighting with 0.5 bandwidth. 


\section{B.4 Robustness of Threshold Effects}

In this appendix I document the robustness of the results presented in section 3.2 to different modifications of the baseline specification. Table 11 contains the results of the regressions that include a lag of the dependent variable. Tables 10 and 12 present the results of regressions that allow for a break in level at the threshold $\tilde{\iota}$. Table 13 contains the results of regressions that include bank-level time-varying characteristics, like the amount of bank equity or bank assets (either contemporaneous or lagged one period). Finally, Tables 14 and 15 present the results of regressions that control for indicators of banking or financial crises. The tables present the results for the Reinhart and Rogoff (2014) indicator for all crises, but the results are similar if one uses their systemic indicator, the indicators in Laeven and Valencia (2013) or the Romer and Romer (2017) indicator. In all of these cases the results are qualitatively similar to the ones from the baseline specification.

Table 10: Regressions for main variables of interest, change in level at $\tilde{\iota}$ and no lag

\begin{tabular}{lccc}
\hline \hline & $(1)$ & $(2)$ & $(3)$ \\
& Loan Rate & Deposit Rate & ROAE \\
\hline Policy Rate & $0.397^{* * *}$ & -0.197 & $4.809^{* * *}$ \\
& $(0.132)$ & $(0.156)$ & $(1.193)$ \\
$(i-\tilde{\iota}) * \mathbb{1}(i \geq \tilde{\iota})$ & 0.001 & $0.593^{* * *}$ & $-4.027^{* * *}$ \\
& $(0.127)$ & $(0.150)$ & $(1.115)$ \\
$\mathbb{1}(i \geq \tilde{\iota})$ & & & \\
& $0.336^{* * *}$ & $0.277^{* *}$ & 0.361 \\
$\beta_{1}+\beta_{2}$ & $(0.098)$ & $(0.121)$ & $(0.867)$ \\
s.e. $\left(\beta_{1}+\beta_{2}\right)$ & $0.397^{* * *}$ & $0.396^{* * *}$ & $0.782^{* * *}$ \\
$\mathrm{~N}$ & 0.026 & 0.044 & 0.224 \\
$\mathrm{R}$ squared & 80078 & 31554 & 80199 \\
Entity FE & 0.93 & 0.85 & 0.41 \\
Year FE & Yes & Yes & Yes \\
Clustering & Yes & Yes & Yes \\
Mean dep. var. & $\mathrm{C}-\mathrm{Y}$ & $\mathrm{C}-\mathrm{Y}$ & $\mathrm{C}-\mathrm{Y}$ \\
\hline \hline
\end{tabular}

SE in parenthesis, clustering is done at the Country-Year Level.

Stars: * for $\mathrm{p}<.10,{ }^{* *}$ for $\mathrm{p}<.05$, and ${ }^{* * *}$ for $\mathrm{p}<.01$. 
Table 11: Regressions for main variables of interest, lag of dependent variable

\begin{tabular}{|c|c|c|c|}
\hline & $\begin{array}{c}(1) \\
\text { Loan Rate }\end{array}$ & $\begin{array}{c}(2) \\
\text { Deposit Rate }\end{array}$ & $\begin{array}{c}(3) \\
\text { ROAE }\end{array}$ \\
\hline Policy Rate & $\begin{array}{c}0.389^{* * *} \\
(0.089)\end{array}$ & $\begin{array}{r}0.130^{*} \\
(0.077)\end{array}$ & $\begin{array}{c}3.499^{* * *} \\
(0.857)\end{array}$ \\
\hline$(i-\tilde{\iota}) * \mathbb{1}(i \geq \tilde{\iota})$ & $\begin{array}{r}-0.068 \\
(0.087)\end{array}$ & $\begin{array}{c}0.204^{* *} \\
(0.092)\end{array}$ & $\begin{array}{c}-2.853^{* * *} \\
(0.815)\end{array}$ \\
\hline L.Rate on Av. Earning Assets & $\begin{array}{l}0.480^{* * *} \\
(0.023)\end{array}$ & & \\
\hline L.Deposit Rate & & $\begin{array}{l}0.492^{\text {*** }} \\
(0.046)\end{array}$ & \\
\hline L.ROAE & & & $\begin{array}{l}0.326^{* * *} \\
(0.032)\end{array}$ \\
\hline$\beta_{1}+\beta_{2}$ & $0.320^{* * *}$ & $0.334^{* * *}$ & $0.646^{* * *}$ \\
\hline s.e. $\left(\beta_{1}+\beta_{2}\right)$ & 0.017 & 0.032 & 0.208 \\
\hline $\mathrm{N}$ & 74096 & 28209 & 74209 \\
\hline $\mathrm{R}$ squared & 0.95 & 0.92 & 0.48 \\
\hline Entity FE & Yes & Yes & Yes \\
\hline Year FE & Yes & Yes & Yes \\
\hline Clustering & $\mathrm{C}-\mathrm{Y}$ & $\mathrm{C}-\mathrm{Y}$ & $\mathrm{C}-\mathrm{Y}$ \\
\hline Mean dep. var. & 4.49 & 0.93 & 5.66 \\
\hline
\end{tabular}

Notes: SE in parenthesis, clustering is done at the Country-Year Level. Stars: ${ }^{*}$ for $\mathrm{p}<.10,{ }^{* *}$ for $\mathrm{p}<.05$, and ${ }^{* * *}$ for $\mathrm{p}<.01$. 
Table 12: Regressions for main variables of interest, change in level at $\tilde{\iota}$ and a lag of the dependent variable

\begin{tabular}{|c|c|c|c|}
\hline & $\begin{array}{c}(1) \\
\text { Loan Rate }\end{array}$ & $\begin{array}{c}(2) \\
\text { Deposit Rate }\end{array}$ & $\begin{array}{c}(3) \\
\text { ROAE }\end{array}$ \\
\hline Policy Rate & $\begin{array}{c}0.365^{* * *} \\
(0.106)\end{array}$ & $\begin{array}{c}0.143 \\
(0.099)\end{array}$ & $\begin{array}{l}3.494^{* * *} \\
(1.005)\end{array}$ \\
\hline$(i-\tilde{\iota}) * \mathbb{1}(i \geq \tilde{\iota})$ & $\begin{array}{r}-0.048 \\
(0.100)\end{array}$ & $\begin{array}{c}0.195^{*} \\
(0.102)\end{array}$ & $\begin{array}{c}-2.848^{* * *} \\
(0.927)\end{array}$ \\
\hline $\mathbb{1}(i \geq \tilde{\iota})$ & $\begin{array}{c}0.046 \\
(0.076)\end{array}$ & $\begin{array}{r}-0.023 \\
(0.083)\end{array}$ & $\begin{array}{c}0.010 \\
(0.844)\end{array}$ \\
\hline L.Rate on Av. Earning Assets & $\begin{array}{l}0.477^{* * *} \\
(0.023)\end{array}$ & & \\
\hline L.Deposit Rate & & $\begin{array}{l}0.494^{* * *} \\
(0.047)\end{array}$ & \\
\hline L.ROAE & & & $\begin{array}{l}0.326^{* * *} \\
(0.032)\end{array}$ \\
\hline$\beta_{1}+\beta_{2}$ & $0.317^{* * *}$ & $0.338^{* * *}$ & $0.645^{* * *}$ \\
\hline s.e. $\left(\beta_{1}+\beta_{2}\right)$ & 0.019 & 0.035 & 0.223 \\
\hline $\mathrm{N}$ & 74096 & 28209 & 74209 \\
\hline $\mathrm{R}$ squared & 0.95 & 0.92 & 0.48 \\
\hline Entity FE & Yes & Yes & Yes \\
\hline Year FE & Yes & Yes & Yes \\
\hline Clustering & $\mathrm{C}-\mathrm{Y}$ & $\mathrm{C}-\mathrm{Y}$ & $\mathrm{C}-\mathrm{Y}$ \\
\hline Mean dep. var. & 4.49 & 0.93 & 5.66 \\
\hline
\end{tabular}

SE in parenthesis, clustering is done at the Country-Year Level.

Stars: ${ }^{*}$ for $\mathrm{p}<.10,{ }^{* *}$ for $\mathrm{p}<.05$, and ${ }^{* * *}$ for $\mathrm{p}<.01$. 
Table 13: Regressions for main variables of interest, controlling for bank equity and assets

\begin{tabular}{|c|c|c|c|}
\hline & $\begin{array}{c}(1) \\
\text { Loan Rate }\end{array}$ & $\begin{array}{c}(2) \\
\text { Deposit Rate }\end{array}$ & $\begin{array}{c}(3) \\
\text { ROAE }\end{array}$ \\
\hline Policy Rate & $\begin{array}{c}0.380^{* * *} \\
(0.088)\end{array}$ & $\begin{array}{c}0.103 \\
(0.073)\end{array}$ & $\begin{array}{c}3.953^{* * *} \\
(0.930)\end{array}$ \\
\hline$(i-\tilde{\iota}) * \mathbb{1}(i \geq \tilde{\iota})$ & $\begin{array}{r}-0.059 \\
(0.086)\end{array}$ & $\begin{array}{l}0.236^{* * *} \\
(0.087)\end{array}$ & $\begin{array}{c}-3.307^{* * *} \\
(0.882)\end{array}$ \\
\hline Log of Equity & $\begin{array}{c}-0.054 \\
(0.038)\end{array}$ & $\begin{array}{c}-0.040 \\
(0.037)\end{array}$ & $\begin{array}{l}3.466^{* * *} \\
(0.787)\end{array}$ \\
\hline Log of Total Assets & $\begin{array}{c}0.072^{*} \\
(0.038)\end{array}$ & $\begin{array}{l}0.228^{* * *} \\
(0.048)\end{array}$ & $\begin{array}{c}-2.793^{* * *} \\
(0.661)\end{array}$ \\
\hline L.Rate on Av. Earning Assets & $\begin{array}{l}0.479^{* * *} \\
(0.023)\end{array}$ & & \\
\hline L.Deposit Rate & & $\begin{array}{l}0.485^{* * *} \\
(0.046)\end{array}$ & \\
\hline L.ROAE & & & $\begin{array}{l}0.310^{* * *} \\
(0.032)\end{array}$ \\
\hline$\beta_{1}+\beta_{2}$ & $0.321^{* * *}$ & $0.338^{* * *}$ & $0.646^{* * *}$ \\
\hline s.e. $\left(\beta_{1}+\beta_{2}\right)$ & 0.017 & 0.031 & 0.199 \\
\hline $\mathrm{N}$ & 74037 & 28185 & 74182 \\
\hline $\mathrm{R}$ squared & 0.95 & 0.92 & 0.48 \\
\hline Entity FE & Yes & Yes & Yes \\
\hline Year FE & Yes & Yes & Yes \\
\hline Clustering & $\mathrm{C}-\mathrm{Y}$ & $\mathrm{C}-\mathrm{Y}$ & $\mathrm{C}-\mathrm{Y}$ \\
\hline Mean dep. var. & 4.49 & 0.93 & 5.66 \\
\hline
\end{tabular}

SE in parenthesis, clustering is done at the Country-Year Level.

Stars: ${ }^{*}$ for $\mathrm{p}<.10,{ }^{* *}$ for $\mathrm{p}<.05$, and ${ }^{* * *}$ for $\mathrm{p}<.01$. 
Table 14: Regressions for main variables of interest, controlling for Reinhart and Rogoff's banking crisis indicators, no lag of the dependent variable

\begin{tabular}{lccc}
\hline \hline & $(1)$ & $(2)$ & $(3)$ \\
& Loan Rate & Deposit Rate & ROAE \\
\hline Policy Rate & $0.704^{* * *}$ & -0.244 & $9.110^{* * *}$ \\
& $(0.204)$ & $(0.217)$ & $(1.765)$ \\
$(i-\tilde{\iota}) * \mathbb{1}(i \geq \tilde{\iota})$ & & & \\
& -0.301 & $0.671^{* * *}$ & $-8.489^{* * *}$ \\
& $(0.205)$ & $(0.210)$ & $(1.745)$ \\
Reinhart and Rogoff BCI & 0.047 & $0.302^{* * *}$ & $-1.689^{* * *}$ \\
& $(0.075)$ & $(0.087)$ & $(0.633)$ \\
\hline$\beta_{1}+\beta_{2}$ & $0.403^{* * *}$ & $0.427^{* * *}$ & $0.621^{* * *}$ \\
s.e. $\left(\beta_{1}+\beta_{2}\right)$ & 0.028 & 0.038 & 0.210 \\
$\mathrm{~N}$ & 68960 & 24716 & 69049 \\
$\mathrm{R}$ squared & 0.93 & 0.86 & 0.42 \\
Entity FE & Yes & Yes & Yes \\
Year FE & Yes & Yes & Yes \\
Clustering & $\mathrm{C}-\mathrm{Y}$ & $\mathrm{C}-\mathrm{Y}$ & $\mathrm{C}-\mathrm{Y}$ \\
Mean dep. var. & 4.85 & 1.15 & 5.87 \\
\hline \hline
\end{tabular}

SE in parenthesis, clustering is done at the Country-Year Level.

Stars: ${ }^{*}$ for $\mathrm{p}<.10,{ }^{* *}$ for $\mathrm{p}<.05$, and ${ }^{* * *}$ for $\mathrm{p}<.01$. 
Table 15: Regressions for main variables of interest, controlling for Reinhart and Rogoff's banking crisis indicators, including a lag of the dependent variable

\begin{tabular}{|c|c|c|c|}
\hline & $\begin{array}{c}(1) \\
\text { Loan Rate }\end{array}$ & $\begin{array}{c}(2) \\
\text { Deposit Rate }\end{array}$ & $\begin{array}{c}(3) \\
\text { ROAE }\end{array}$ \\
\hline Policy Rate & $\begin{array}{c}0.369^{* *} \\
(0.154)\end{array}$ & $\begin{array}{r}-0.154 \\
(0.159)\end{array}$ & $\begin{array}{c}6.950^{* * *} \\
(1.540)\end{array}$ \\
\hline$(i-\tilde{\iota}) * \mathbb{1}(i \geq \tilde{\iota})$ & $\begin{array}{c}-0.044 \\
(0.152)\end{array}$ & $\begin{array}{l}0.486^{* * *} \\
(0.165)\end{array}$ & $\begin{array}{c}-6.384^{* * *} \\
(1.521)\end{array}$ \\
\hline Reinhart and Rogoff BCI & $\begin{array}{c}0.039 \\
(0.070)\end{array}$ & $\begin{array}{c}0.146^{* *} \\
(0.066)\end{array}$ & $\begin{array}{c}-1.435^{* *} \\
(0.675)\end{array}$ \\
\hline L.Rate on Av. Earning Assets & $\begin{array}{l}0.446^{* * *} \\
(0.025)\end{array}$ & & \\
\hline L.Deposit Rate & & $\begin{array}{l}0.442^{* * *} \\
(0.050)\end{array}$ & \\
\hline L.ROAE & & & $\begin{array}{l}0.301^{* * *} \\
(0.034)\end{array}$ \\
\hline$\beta_{1}+\beta_{2}$ & $0.324^{* * *}$ & $0.331^{* * *}$ & $0.565^{* * *}$ \\
\hline s.e. $\left(\beta_{1}+\beta_{2}\right)$ & 0.018 & 0.033 & 0.217 \\
\hline $\mathrm{N}$ & 63001 & 21418 & 63074 \\
\hline $\mathrm{R}$ squared & 0.95 & 0.92 & 0.48 \\
\hline Entity FE & Yes & Yes & Yes \\
\hline Year FE & Yes & Yes & Yes \\
\hline Clustering & $\mathrm{C}-\mathrm{Y}$ & $\mathrm{C}-\mathrm{Y}$ & $\mathrm{C}-\mathrm{Y}$ \\
\hline Mean dep. var. & 4.78 & 1.06 & 5.74 \\
\hline
\end{tabular}

SE in parenthesis, clustering is done at the Country-Year Level.

Stars: * for $\mathrm{p}<.10,{ }^{* *}$ for $\mathrm{p}<.05$, and ${ }^{* * *}$ for $\mathrm{p}<.01$. 
Table 16: Regressions for main variables of interest when $\tilde{\iota}=0$

\begin{tabular}{lccc}
\hline \hline & $(1)$ & $(2)$ & $(3)$ \\
& Loan Rate & Deposit Rate & ROAE \\
\hline Policy Rate & 0.463 & 0.032 & $3.586^{* * *}$ \\
& $(0.310)$ & $(0.324)$ & $(1.168)$ \\
$(i-\tilde{\iota}) * \mathbb{1}(i \geq \tilde{\iota})$ & -0.035 & 0.402 & $-2.675^{* *}$ \\
& $(0.304)$ & $(0.331)$ & $(1.113)$ \\
\hline$\beta_{1}+\beta_{2}$ & $0.428^{* * *}$ & $0.434^{* * *}$ & $0.911^{* * *}$ \\
s.e. $\left(\beta_{1}+\beta_{2}\right)$ & 0.027 & 0.039 & 0.232 \\
$\mathrm{~N}$ & 80078 & 31554 & 80199 \\
$\mathrm{R}$ squared & 0.93 & 0.85 & 0.40 \\
Entity FE & Yes & Yes & Yes \\
Year FE & Yes & Yes & Yes \\
Clustering & $\mathrm{C}-\mathrm{Y}$ & $\mathrm{C}-\mathrm{Y}$ & $\mathrm{C}-\mathrm{Y}$ \\
Mean dep. var. & 4.58 & 1.01 & 5.78 \\
\hline \hline
\end{tabular}

SE in parenthesis, clustering is done at the Country-Year Level.

Stars: $*$ for $\mathrm{p}<.10,{ }^{* *}$ for $\mathrm{p}<.05$, and ${ }^{* * *}$ for $\mathrm{p}<.01$. 


\section{B.5 Additional Threshold Tests}
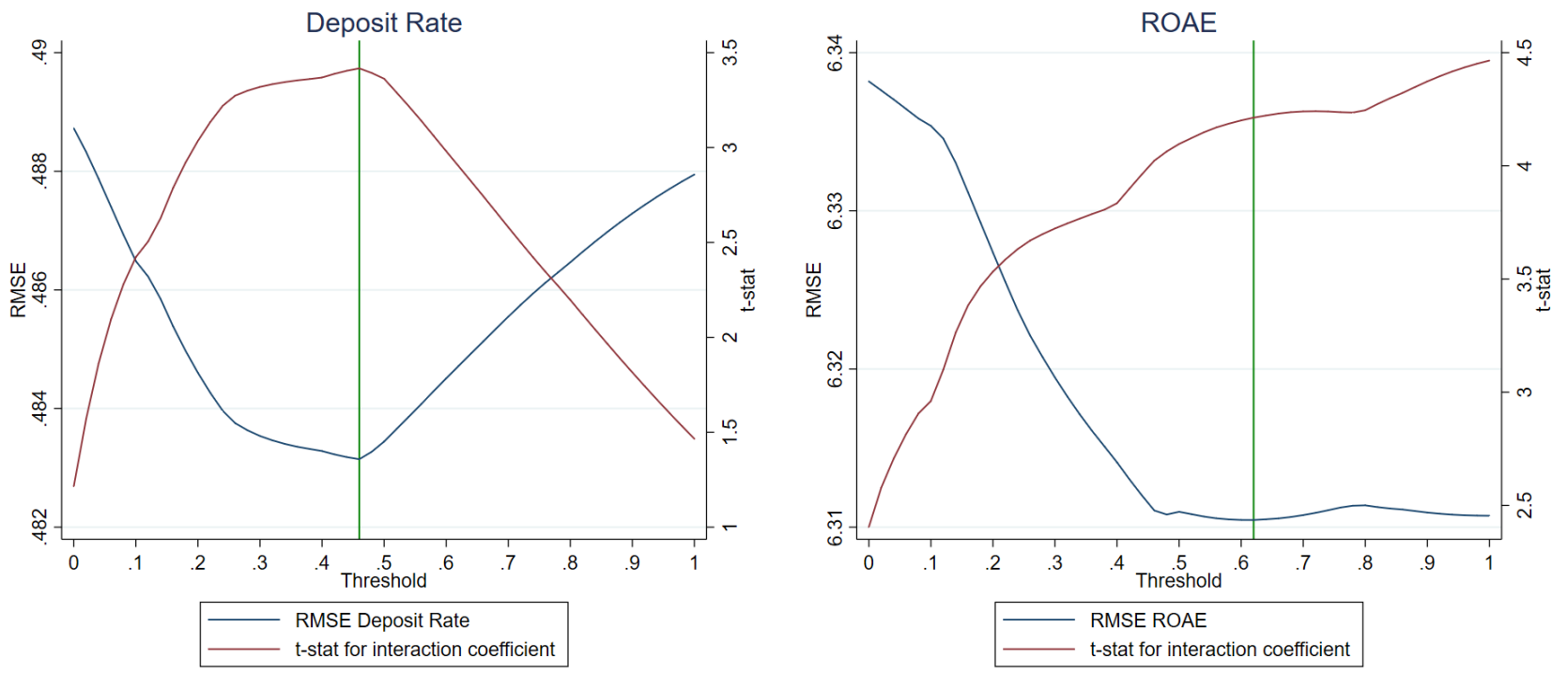

Figure 11: RMSE for threshold tests

Notes: This figure plots the root mean squared error (RMSE) and the t-stat on the interaction coefficient $\left(\beta_{2}\right)$ for the regression in (6) across different values of $\tilde{\iota}$. The dependent variable is the deposit rate in the left panel, and return on average equity (ROAE) in the right panel.
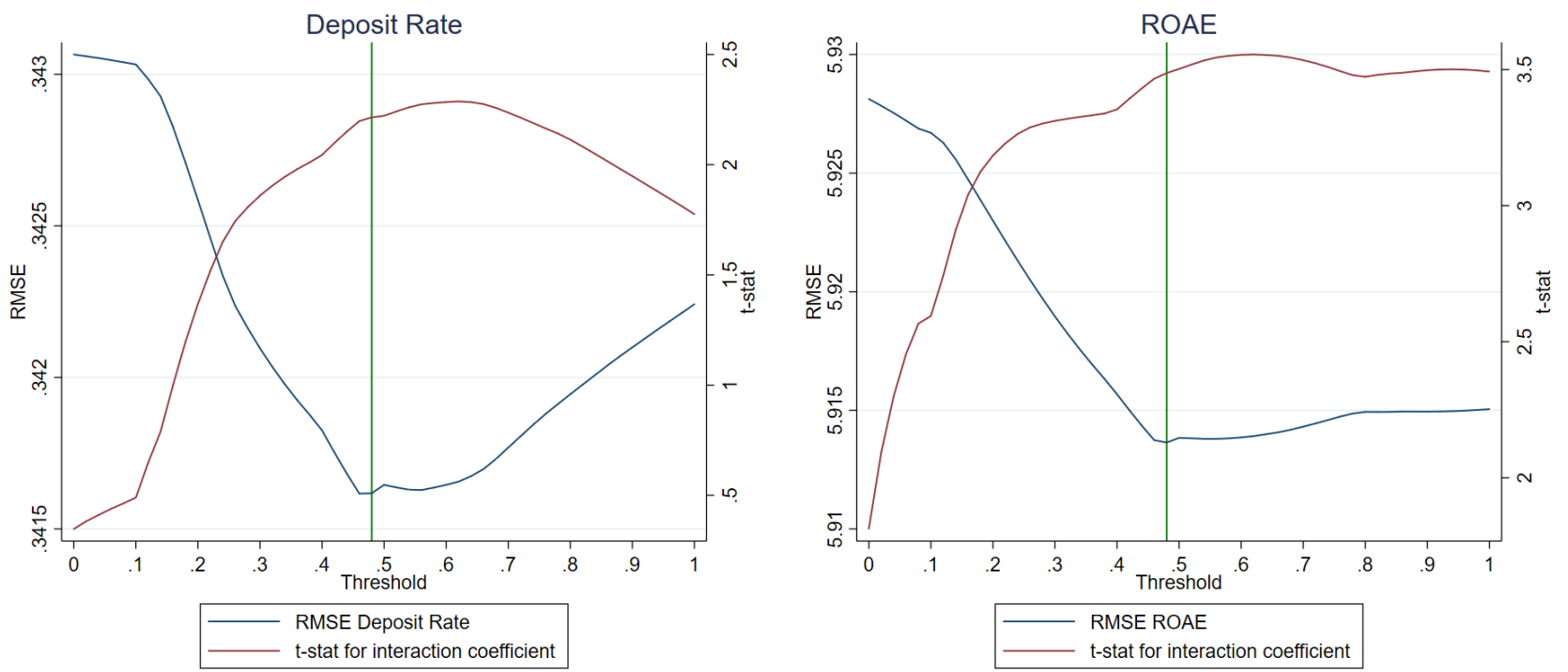

Figure 12: RMSE for threshold tests, lag

Notes: These figures contain the RMSE and t-stat on the interaction coefficient $\beta_{2}$ for Regression (6) with a lag of the dependent variable for the deposit rate and ROAE for different values of the threshold level $\tilde{\iota}$. 

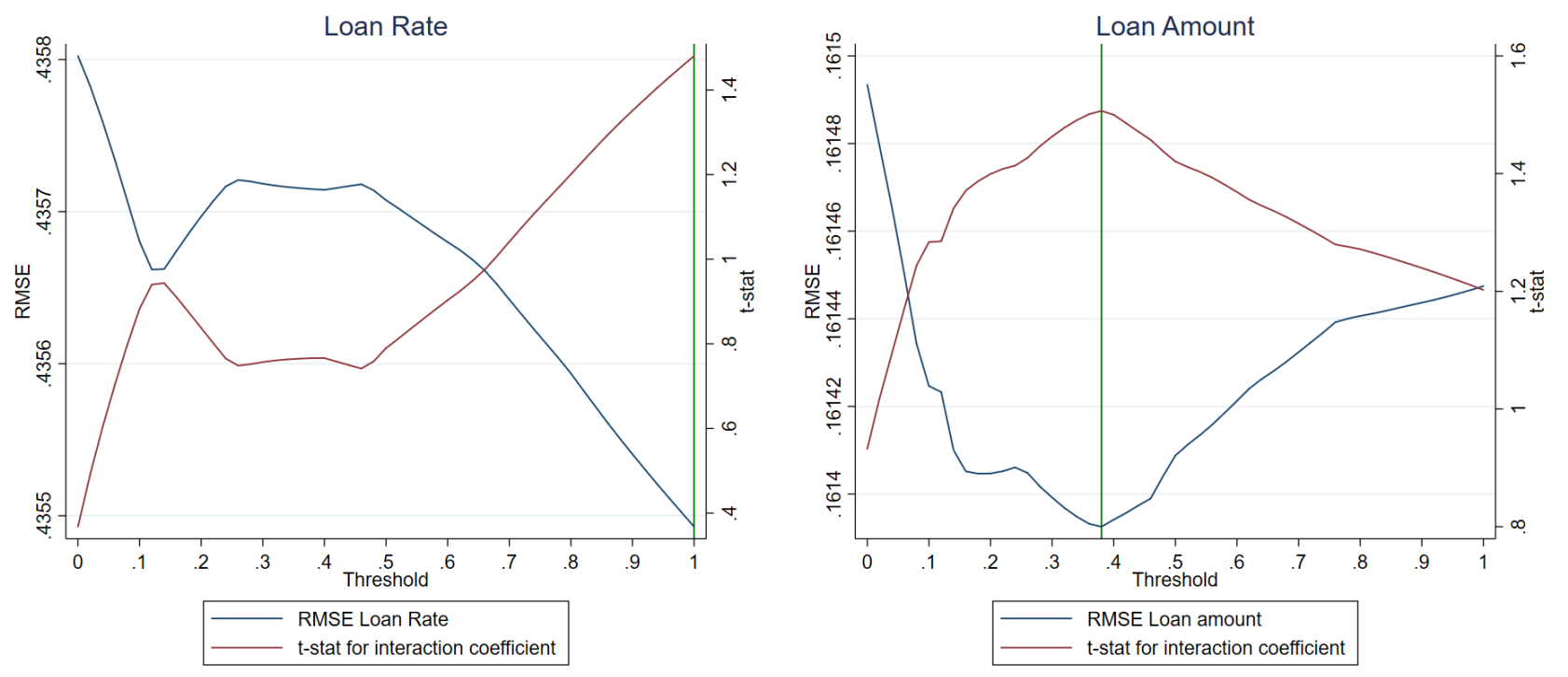

Figure 13: RMSE for threshold tests, other variables

Notes: These figures contain the RMSE and t-stat on the interaction coefficient $\beta_{2}$ for Regression (6) with a lag of the dependent variable for the loan rate and the loan amount for different values of the threshold level $\tilde{\iota}$.

As pointed out by Andrews (1993) and Hansen (1999), inference in the presence of an unknown threshold is complicated by the presence of a nuisance parameter, this comes from the fact that the break point is not present under the null-hypothesis. Andrews (1993) proposes the use of supremum statistics to solve this issue and Hansen (1999) proposes a bootstrap-based method. The Hansen methodology is only theoretically applicable for nondynamic panels and it requires a balanced panel, so to apply it in my context I turn my dataset into a balanced panel and do not include the lag of the dependent variable. Running the Hansen (1999) procedure on data for the deposit rate (a balanced panel between 2009 and 2016 with 1986 banks per year) identifies a break point at 62 basis points and rejects the null-hypothesis of no break point at the $1 \%$ level. Running it on data for ROAE (a balanced panel between 2006 and 2016 with 3401 banks per year) identifies a break point at 47 basis points and also rejects the null-hypothesis of no break point at the $1 \%$ level. $^{39}$

Another possible test for the threshold level using equation (6) for the deposit rate, that utilizes information on both $\beta_{1}$ and $\beta_{2}$, is based on Chay and Munshi (2015). In my setup, as in theirs, if the true threshold is picked, $\beta_{1}$ should be close to zero and $\beta_{2}$ should be positive. If a threshold candidate below the true threshold is picked, $\beta_{1}$ should still be

\footnotetext{
${ }^{39} \mathrm{I}$ choose the starting year of the panel to maximize the total number of observations remaining in the balanced panel. This year turns out to be 2009 for the case of the deposit rate and 2006 for ROAE. Running the test for the deposit rate starting the balanced panel in 2006 produces similar results.
} 
estimated as zero but $\beta_{2}$ should be estimated as a smaller quantity. If a threshold candidate above the true threshold is picked, $\beta_{1}$ should now be estimated as positive but $\beta_{2}$ should be estimated as a higher quantity. The authors develop a test for the joint hypothesis that $\beta_{1}=0$ and $\beta_{2}>0$ based on the test statistic:

$$
\Upsilon^{C M}=\frac{\left[\phi\left(\frac{\hat{\beta}_{1}}{h}\right)\right]^{2}}{[\phi(\epsilon)]^{2}} \frac{\hat{\beta}_{2}^{2}}{\hat{V}_{\beta_{2}}},
$$

where $\phi$ is a symmetric and continuous function that reaches its maximum value at zero (the authors use the normal p.d.f.), $h$ is a scale parameter, $\epsilon$ is the value below which the normalized baseline slope coefficient, $\frac{\hat{\beta}_{1}}{h}$, is treated as "zero", and $\hat{V}_{\beta_{2}}$ is the estimated variance of $\beta_{2}$. The authors use the normalization by $h$ because $\hat{\beta}_{1}$ will be further away from zero when the outcome variable has a larger mean or variance, the authors set $h$ to be the standard deviation of the outcome under consideration, in my case the standard deviation of the deposit rate. I will set $\epsilon=0$, as the authors do, to be conservative. The statistic is distributed as a chi-square with one degree of freedom. The statistic is presented in Figure 14 for the case that does not include a lag of the dependent variable, the statistic is maximized at $\tilde{\iota}=0.46$ (46 basis points). The p-value of the statistic is given in the secondary axis, and the green horizontal line indicates the $5 \%$ threshold for rejection of the null. This means that for thresholds between 10 and 80 basis points there is evidence that $\beta_{1}=0$ and $\beta_{2}>0$ which is what the model predicts. Like the Hansen (1999) procedure, the Chay and Munshi procedure was in theory developed for a nondynamic panel, that is why I do not include the lag of the dependent variable, but including it yields similar results.

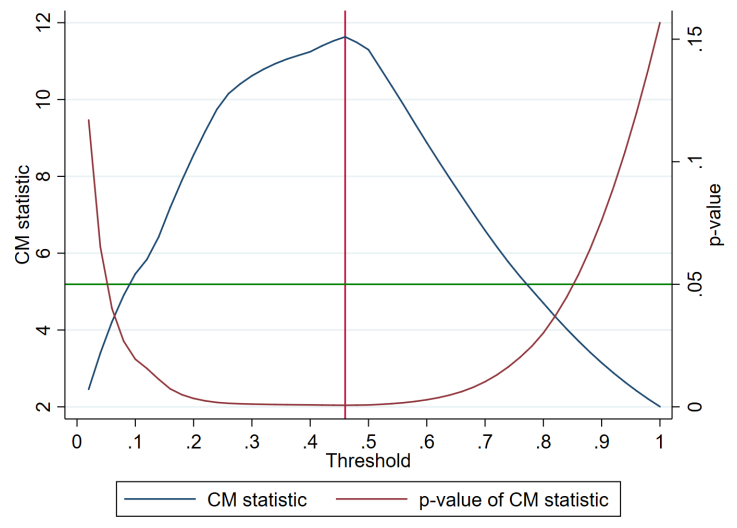

Figure 14: CM statistic for the deposit rate

Notes: This figure contains the Chay and Munshi (CM) statistic for the deposit rate based on equation (6) and its p-value, for different values of the threshold level $\tilde{\imath}$. 


\section{B.6 Quintile Description}

Table 17: CDA for different quintiles

\begin{tabular}{lccccc}
\hline \hline Quintile & Mean & Std. Dev. & Min. & Max. & N \\
\hline First & 0.43 & 0.18 & 0.01 & 0.63 & 16726 \\
Second & 0.70 & 0.03 & 0.63 & 0.75 & 16717 \\
Third & 0.78 & 0.02 & 0.75 & 0.82 & 16721 \\
Fourth & 0.85 & 0.02 & 0.82 & 0.88 & 16738 \\
Fifth & 0.91 & 0.02 & 0.88 & 0.96 & 16697 \\
\hline
\end{tabular}

Notes: Description of the CDA ratio variable for different quintiles

\section{B.7 Additional Structural Estimation Results}

The following table summarizes the results of the regressions in equation (20), when assuming that $\nu=9$ (which is the mean loan-to-equity ratio in my dataset). Column 1 presents the results when the regression includes two lags of the dependent variable and $F_{b, t-1}$ is instrumented with $F_{b, t-3}$, to avoid potential endogeneity with the two lags of the dependent variable. Column 2 presents the results when the regression includes just one lag of the dependent variable and $F_{b, t-1}$ is instrumented with $F_{b, t-2}$. Column 3 presents the results when the regression does not include any lags of the dependent variable and $F_{b, t-1}$ is not instrumented.

Table 18: Aggregate structural estimation of $\kappa$

\begin{tabular}{lccc}
\hline \hline & $(1)$ & $(2)$ & $(3)$ \\
\hline \hline$\gamma_{l a}$ & 0.4551 & 0.3586 & 0.6625 \\
$\gamma_{l r}$ & -0.0100 & -0.0086 & -0.0104 \\
$\kappa$ & 0.0020 & 0.0015 & 0.0034 \\
$\varepsilon^{l}$ & 45.4540 & 41.4951 & 63.7593 \\
$\mathrm{i}^{l}-i$ & 0.0222 & 0.0244 & 0.0158 \\
\hline \hline
\end{tabular}

Notes: This table contains the results of the aggregate structural estimation of $\kappa$ and $\varepsilon^{l}$ described in equation (20).

The results are similar for the three models and deliver an estimate of $\kappa$ between 15 and 35 basis points, together with an estimate of $\varepsilon^{l}$ between 40 and 60 (at the annual level). These estimates of $\varepsilon^{l}$ would deliver a steady state wedge between the loan rate and the policy rate of between $1.5 \%$ and $2.5 \%$ which is reasonable. The baseline specification will be the first one, since it is necessary to include the lags of the dependent variable to control for the sluggishness in rate setting and lending behavior. 
The following table contains the region-level results of the regressions for Denmark, Sweden, Canada, Australia and Norway.

Table 19: Structural estimation of $\kappa$ and $\varepsilon^{l}$, part 2

\begin{tabular}{lccccc}
\hline \hline & $(1)$ & $(2)$ & $(3)$ & $(4)$ & $(5)$ \\
& DKK & SEK & CAD & AUD & NOK \\
\hline \hline$\beta_{l a}$ & 0.7841 & 0.6053 & 1.2854 & 0.1653 & -0.5330 \\
$\beta_{l r}$ & -0.0047 & -0.0030 & 0.0588 & -0.0081 & 0.0099 \\
$\kappa$ & 0.0024 & 0.0008 & 0.0229 & 0.0011 & -0.0007 \\
$\varepsilon^{l}$ & 167.9998 & 202.4073 & -21.8763 & 20.3058 & 54.0099 \\
$\mathrm{i}^{l}-i$ & 0.0060 & 0.0050 & -0.0447 & 0.0505 & 0.0187 \\
\hline \hline
\end{tabular}

Notes: This table contains the results of the country level structural estimation of $\kappa$ and $\varepsilon^{l}$ described in equation (20). This table contains the 5 smallest regions (in terms of amount of banks present in the sample from that region) Denmark (DKK), Sweden (SEK), Canada (CAD), Australia (AUD) and Norway (NOK). 


\section{Model Solution}

\section{C.1 Equilibrium Equations}

The equilibrium is characterized by the relevant equations for each of the types of agents in the model. Households have an intratemporal condition for labor supply, an Euler equation, the definition of the marginal utility of consumption and the definition of the stochastic discount factor:

$$
\begin{aligned}
\chi N_{t}^{\frac{1}{\eta}} & =\phi_{t} \frac{W_{t}}{P_{t}} \\
1 & =\mathbb{E}_{t}\left(\beta \Lambda_{t, t+1}\left(1+i_{t}^{d}\right) \frac{P_{t}}{P_{t+1}}\right) \\
\phi_{t} & =\left(C_{t}-h C_{t-1}\right)^{-\sigma}-\beta h \frac{\varphi_{t+1}}{\varphi_{t}} \mathbb{E}_{t}\left(C_{t+1}-h C_{t}\right)^{-\sigma} \\
\Lambda_{t, t+1} & =\frac{\phi_{t+1}}{\phi_{t}} \frac{\varphi_{t+1}}{\varphi_{t}} .
\end{aligned}
$$

Intermediate goods firms have their production function, a labor demand equation and the definition of the return on capital:

$$
\begin{aligned}
Y_{t}^{m} & =A_{t}\left(\xi_{t} K_{t}\right)^{\alpha} N_{t}^{1-\alpha} \\
(1-\alpha) \frac{P_{t}^{m}}{P_{t}} \frac{Y_{t}^{m}}{N_{t}} & =\frac{W_{t}}{P_{t}} \\
1+i_{t}^{l} & =\frac{\frac{Q_{t}}{P_{t}} \xi_{t}(1-\delta)+\frac{P_{t}^{m}}{P_{t}} \alpha \frac{Y_{t}^{m}}{K_{t}}}{\frac{Q_{t-1}}{P_{t-1}}} \frac{P_{t}}{P_{t-1}} .
\end{aligned}
$$

Capital producing firms have the evolution of capital and the F.O.C. for the price of capital:

$$
\begin{aligned}
K_{t+1} & =(1-\delta) \xi_{t} K_{t}+I_{t} \\
\frac{Q_{t}}{P_{t}} & =1+f\left(\frac{I_{t}}{I_{t-1}}\right)+f^{\prime}\left(\frac{I_{t}}{I_{t-1}}\right) \frac{I_{t}}{I_{t-1}}-\mathbb{E}_{t} \beta \Lambda_{t, t+1} f^{\prime}\left(\frac{I_{t+1}}{I_{t}}\right)\left(\frac{I_{t+1}}{I_{t}}\right)^{2}
\end{aligned}
$$

Retail firms have equations for price setting, the evolution of prices, the dispersion of prices and the relationship between final output and intermediate output:

$$
\begin{aligned}
1 & =(1-\gamma)\left(\frac{P_{t}^{*}}{P_{t}}\right)^{1-\theta}+\gamma\left(\frac{P_{t-1}}{P_{t}}\right)^{1-\theta} \\
\theta \Gamma_{t}^{1} & =(\theta-1) \Gamma_{t}^{2} \\
\Gamma_{t}^{1} & =\phi_{t} \varphi_{t} \frac{P_{t}^{m}}{P_{t}} Y_{t}+\gamma \beta \mathbb{E}_{t}\left(\frac{P_{t}}{P_{t+1}}\right)^{-\theta} \Gamma_{t+1}^{1}
\end{aligned}
$$




$$
\begin{aligned}
\Gamma_{t}^{2} & =\phi_{t} \varphi_{t} \frac{P_{t}^{*}}{P_{t}} Y_{t}+\gamma \beta \mathbb{E}_{t} \frac{P_{t}^{*}}{P_{t+1}^{*}}\left(\frac{P_{t}}{P_{t+1}}\right)^{-\theta} \Gamma_{t+1}^{2} \\
Y_{t}^{m} & =Y_{t} v_{t}^{p} \\
v_{t}^{p} & =\gamma\left(\frac{P_{t-1}}{P_{t}}\right)^{-\theta} v_{t-1}^{p}+(1-\gamma)\left(\frac{P_{t}^{*}}{P_{t}}\right)^{-\theta} .
\end{aligned}
$$

Banks have equations for the deposit rate, the loan rate, bank profits, bank equity evolution and the bank balance sheet constraint:

$$
\begin{aligned}
1+i_{t}^{d} & =\frac{\varepsilon^{d}}{\varepsilon^{d}-1}\left(1+i_{t}+\mu_{t}^{d}\right) \\
\mathbb{E}_{t}\left(1+i_{t+1}^{l}\right) & =\frac{\varepsilon^{l}}{\varepsilon^{l}-1}\left(1+i_{t}+\mu_{t}^{l}\right)+\kappa \frac{\varepsilon^{l}}{\varepsilon^{l}-1}\left(\frac{L_{t}}{F_{t}}-\nu\right) \\
\frac{P_{t}}{P_{t-1}} \frac{X_{t}}{P_{t}} & =i_{t-1} \frac{F_{t-1}}{P_{t-1}}+\left(i_{t}^{l}-\mu_{t-1}^{l}-i_{t-1}\right) \frac{L_{t-1}}{P_{t-1}}+\left(i_{t-1}+\mu_{t-1}^{d}-i_{t-1}^{d}\right) \frac{D_{t-1}}{P_{t-1}} \\
& -\frac{\kappa}{2}\left(\frac{L_{t-1}}{F_{t-1}}-\nu\right)^{2} \frac{F_{t-1}}{P_{t-1}}-\frac{F_{t-1}}{P_{t-1}}(1-\varsigma) \pi_{t} \\
\frac{F_{t}}{P_{t}} & =(1-\varsigma) \frac{F_{t-1}}{P_{t-1}}+\omega \frac{X_{t}}{P_{t}} \\
\frac{L_{t}}{P_{t}}+\frac{H_{t}}{P_{t}} & =\frac{F_{t}}{P_{t}}+\frac{D_{t}}{P_{t}} .
\end{aligned}
$$

Finally one has the resource constraint, Taylor rule and the condition saying that total loans most equal the value of capital:

$$
\begin{aligned}
Y_{t} & =C_{t}+I_{t}+G_{t}+f\left(\frac{I_{t}}{I_{t-1}}\right) I_{t}+\mu_{t}^{l} \frac{P_{t-1}}{P_{t}} \frac{L_{t-1}}{P_{t-1}}-\mu_{t}^{d} \frac{P_{t-1}}{P_{t}} \frac{D_{t-1}}{P_{t-1}} \\
& +\varsigma \frac{P_{t-1}}{P_{t}} \frac{F_{t-1}}{P_{t-1}}+\frac{\kappa}{2}\left(\frac{L_{t-1}}{F_{t-1}}-\nu\right)^{2} \frac{P_{t-1}}{P_{t}} \frac{F_{t-1}}{P_{t-1}} \\
i_{t} & =\left(1-\rho_{i}\right)\left(\bar{\imath}+\psi_{\pi}\left(\pi_{t}-\bar{\pi}\right)+\psi_{y} \frac{Y_{t}-Y_{t}^{*}}{\bar{Y}}\right)+\rho_{i} i_{t-1}+\epsilon_{t}^{i} \\
\frac{L_{t}}{P_{t}} & =\frac{Q_{t}}{P_{t}} K_{t+1} .
\end{aligned}
$$

This is a system of 23 equations in 23 unknowns $\left(N, \phi, W / P, \Lambda, i^{d}, \pi, C, Y^{m}, K, P^{m} / P\right.$, $\left.i^{l}, Q / P, I, P^{*} / P, \Gamma^{1}, \Gamma^{2}, Y, v^{p}, i, L / P, F / P, X / P, D / P\right)$ which can be used to solve for the equilibrium. The processes for the shocks are given by:

$$
\begin{aligned}
& A_{t}=\bar{A}^{1-\rho_{a}} A_{t-1}^{\rho_{a}} e^{\epsilon_{t}^{a}} \\
& G_{t}=\bar{G}^{1-\rho_{g}} G_{t-1}^{\rho_{g}} e^{\epsilon_{t}^{g}}
\end{aligned}
$$




$$
\begin{aligned}
H_{t} & =\bar{H}^{1-\rho_{h}} H_{t-1}^{\rho_{h}} e^{\epsilon_{t}^{h}} \\
\xi_{t} & =\xi_{t-1}^{\rho_{\xi}} e^{\epsilon_{t}^{\xi}} \\
\varphi_{t} & =\varphi_{t-1}^{\rho_{\varphi}} e^{\epsilon_{t}^{\varphi}} .
\end{aligned}
$$

$A_{t}$ is the technology of intermediate good producers, $G_{t}$ is government expenditure in goods, $H_{t}$ is the total amount of central bank reserves, $\xi_{t}$ is capital efficiency and $\varphi_{t}$ is the shock to the discount factor. Additionally $\mu_{t}^{l}=\mu^{l}$ and $\mu_{t}^{d}=\mu^{d}$. I choose $\bar{A}=1$ as a normalization, $\bar{G}$ is pinned down by the equation $\frac{\bar{G}}{\bar{Y}}=0.2$ and $\bar{H}$ is pinned down by the parameter $\bar{H} / \bar{F}$ which as I explain in the calibration section is set to 2 . The steady state value of capital efficiency $\xi$ is 1 , as is the steady state value of $\varphi$, which is just a normalization.

\section{C.2 Steady State}

In steady state with zero inflation the equations simplify a lot. For the retailers, for example, $P^{*}=P, v^{p}=1, Y^{m}=Y$ and $\frac{P^{m}}{P}=\frac{\theta-1}{\theta}$. I can also get rid of the equations for $\Lambda$ and $Q / P$. This way the 6 equations for retailers plus 2 additional equations are eliminated. Then I get rid of superfluous equations, like $i=\bar{\iota}$, the balance sheet of the banks (which just defines $D / P)$, the equation for $X / P$, the equation for $F / P$ and the equation for $L / P$. I obtain the following system: ${ }^{40}$

$$
\begin{aligned}
\chi N^{\frac{1}{\eta}} & =\phi \frac{W}{P} \\
1 & =\beta\left(1+i^{d}\right) \\
\phi & =C^{-\sigma}(1-h)^{-\sigma}(1-\beta h) \\
Y & =A K^{\alpha} N^{1-\alpha} \\
(1-\alpha) \frac{\theta-1 \frac{Y}{N}}{\theta} & =\frac{W}{P} \\
\alpha \frac{\theta-1}{\theta} \frac{Y}{K}+(1-\delta) & =\left(1+i^{l}\right) \\
1+i^{d} & =\frac{\varepsilon^{d}}{\varepsilon^{d}-1}\left(1+i+\mu^{d}\right) \\
1+i^{l} & =\frac{\varepsilon^{l}}{\varepsilon^{l}-1}\left(1+i+\mu^{l}\right) \\
Y & =C+I+G+\mu^{l} \frac{L}{P}-\mu^{d} \frac{D}{P}+\varsigma \frac{F}{P} \\
I & =\delta K .
\end{aligned}
$$

\footnotetext{
${ }^{40}$ Recall that $\frac{L / P}{F / P}=\nu$ and $L / P=K$, hence I know that $F / P=K / \nu$, also from the balance sheet of the banks I know $\frac{L}{F}+\frac{H}{F}=\frac{D}{F}+1$ so $\frac{D / P}{F / P}=\nu+\frac{H}{F}-1$, which implies $D / P=\left(\nu+\frac{H}{F}-1\right) \frac{K}{\nu}$
} 
Then I can get rid of the Euler equation and the bank equations defining interest rates, since $1+i^{d}=\frac{1}{\beta}, 1+i=\frac{\varepsilon^{d}-1}{\varepsilon^{d}} \frac{1}{\beta}-\mu^{d}$ and $1+i^{l}=\frac{\varepsilon^{l}}{\varepsilon^{l}-1}\left(\frac{\varepsilon^{d}-1}{\varepsilon^{d}} \frac{1}{\beta}-\mu^{d}+\mu^{l}\right)$. I can also get rid of investment (it is just $\delta K$ ), $\rho$, the real wage and the definition of output (I assume $G=g Y$ ). I obtain the 3 equation system:

$$
\begin{aligned}
\chi^{\frac{1}{\eta}} & =C^{-\sigma}(1-h)^{-\sigma}(1-\beta h)(1-\alpha) \frac{\theta-1}{\theta} A K^{\alpha} N^{-\alpha} \\
\alpha \frac{\theta-1}{\theta} A K^{\alpha-1} N^{1-\alpha}+(1-\delta) & =\frac{\varepsilon^{l}}{\varepsilon^{l}-1}\left(\frac{\varepsilon^{d}-1}{\varepsilon^{d}} \frac{1}{\beta}-\mu^{d}+\mu^{l}\right) \\
(1-g) A K^{\alpha} N^{1-\alpha} & =C+\left(\delta+\mu^{l}-\mu^{d}\left(1+\frac{H / F-1}{\nu}\right)+\frac{\varsigma}{\nu}\right) K .
\end{aligned}
$$

The capital labor ratio can be obtained from the second equation:

$$
\begin{aligned}
\alpha \frac{\theta-1}{\theta} A K^{\alpha-1} N^{1-\alpha}+(1-\delta) & =\frac{\varepsilon^{l}}{\varepsilon^{l}-1}\left(\frac{\varepsilon^{d}-1}{\varepsilon^{d}} \frac{1}{\beta}-\mu^{d}+\mu^{l}\right) \\
Z \equiv \frac{K}{N} & =\left(\frac{\alpha A(\theta-1)}{\theta\left(\frac{\varepsilon^{l}}{\varepsilon^{l}-1}\left(\frac{\varepsilon^{d}-1}{\varepsilon^{d}} \frac{1}{\beta}-\mu^{d}+\mu^{l}\right)+\delta-1\right)}\right)^{\frac{1}{1-\alpha}}
\end{aligned}
$$

I can introduce this into the other two equations and further introduce the first in the third to obtain:

$$
N^{\sigma+\frac{1}{\eta}}=\frac{(\theta-1)(1-\alpha) A Z^{\alpha}(1-\beta h)}{\theta \chi(1-h)^{\sigma}\left((1-g) A Z^{\alpha}-\left(\delta+\mu^{l}-\mu^{d}\left(1+\frac{H / F-1}{\nu}\right)+\frac{\varsigma}{\nu}\right) Z\right)^{\sigma}} .
$$

And from this variable all the other ones can be backed out. In particular consumption is given by:

$$
C=\left(\frac{\chi \theta N^{\frac{1}{\eta}}}{A Z^{\alpha}(1-\alpha)(\theta-1)(1-h)^{-\sigma}(1-\beta h)}\right)^{-\frac{1}{\sigma}}
$$




\section{Additional Figures}

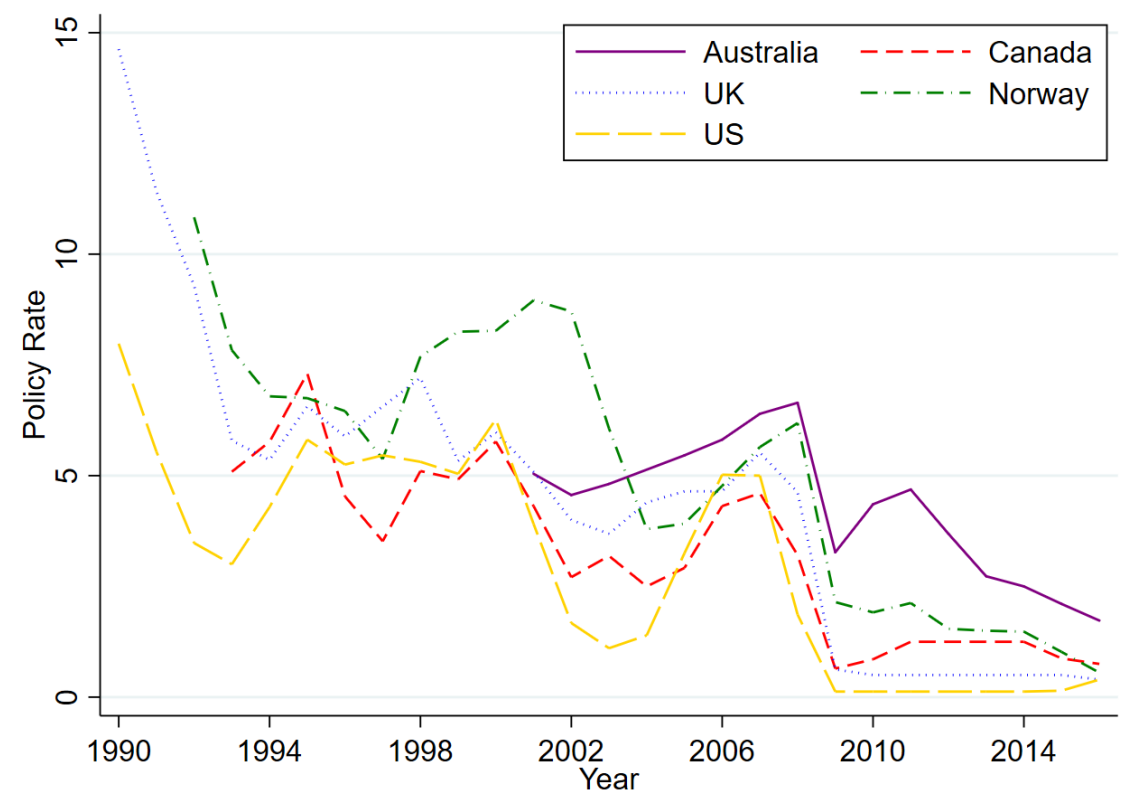

Figure 15: Policy rate across years, positive rates

Notes: This figure contains the policy rate across years for the regions in the sample not setting negative rates.

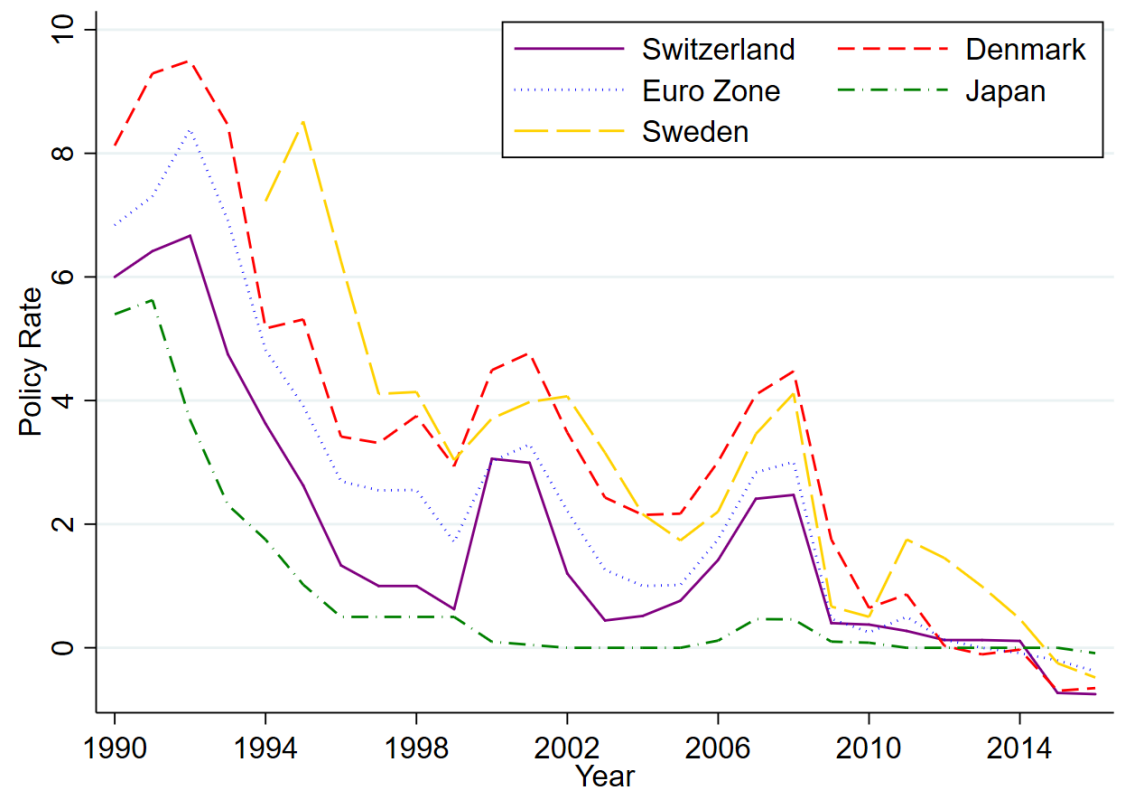

Figure 16: Policy rate across years, negative rates

Notes: This figure contains the policy rate across years for the regions in the sample setting negative rates. 

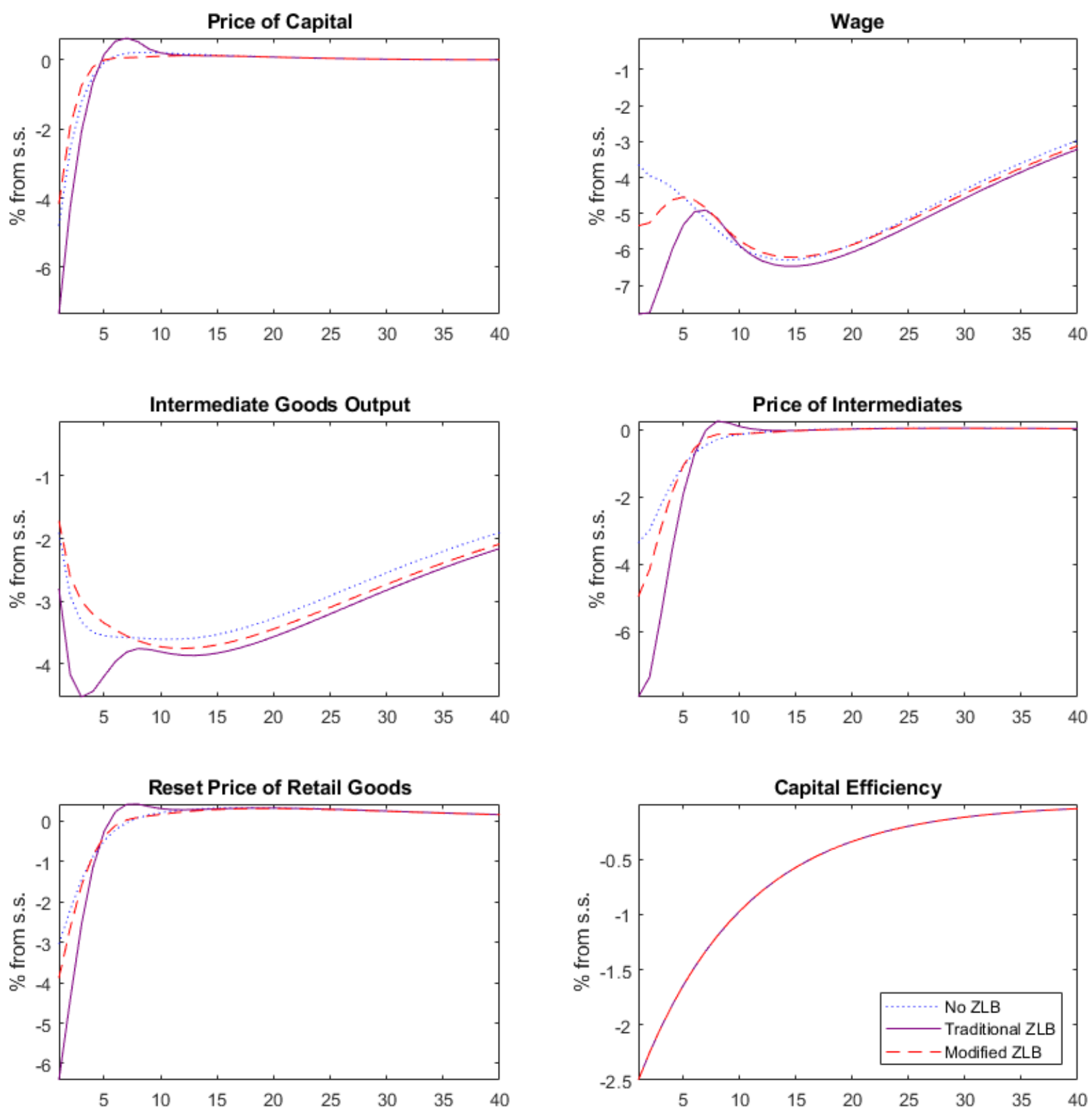

Figure 17: IRF's to capital productivity shock

Notes: IRF's to capital productivity shock under "no ZLB" (blue dotted line), "traditional ZLB" (purple solid line) and "modified ZLB" (red dashed line) when $\kappa=12.5$ basis points. The $x$ axis is given in quarters and the $y$ axis is given in percent deviations from steady state. 